\title{
DWELLING in the Shadows OF ThE NIGHT : DiURnal AND NOCTURnal VEDUTE
}

\author{
by \\ Stephen Wolba, B.A.S. \\ Master of Architecture \\ in \\ Architecture \\ Carleton University, \\ Ottawa, Ontario \\ (C) 2014 \\ Stephen Wolba
}

A thesis submitted to the Faculty of Graduate and Postdoctoral Affairs in partial fulfillment of the requirements for the degree of 


\begin{abstract}
A B S T R A C T
Cities change at night_-places change at night—people change at night. A city as a whole is affected by the circadian rhythms that occur fuelled by the diurnal and nocturnal states that the city takes on. Dwelling in the Shadows of the Night: Nocturnal and Diurnal Vedute, looks at the shifts that take place in the city throughout its daily cycles, and the resulting effect this has on orientation, views, and framing the city. Looking at Confederation Square in Ottawa as the site for a National LRT station stop, the thesis project examines why Confederation Square is the ideal location for a prime downtown station partnered with a photography gallery. Acting as a compass to orient the city, connecting lingering underground circuits, referencing above ground from the darkness of underground, as well creating gateways to important destinations in the city from the station through light are all discussed herein.
\end{abstract}




\section{TABLE OF CONTENTS}

Abstract

Table of Contents

INTRODUCTION

1. Context | City of Ottawa: Downtown + Confederation Square

2. Concept | Examining the City Through the Lens of 3 Urban Devices

3. Content | A national Downtown lRT Station

I $\mid$ Towers: The City as a Network

1. Quartier des Spectacles, Montreal

a. Emerging Nocturnal Networks

2. Systems Pulding You Through the City

a. Nocturnal Beacons

b. The Use of Lighting as a System: Figures, Fabric and Temperatures

3. Moving Through the City

a. The Canal as a System to Get Downtown and Link Neighbourhoods

4. Disconnected, Invisible, Lost, and Missing Networks

a. The "Lost" Downtown Theatre Network

b. Sparks Street Nocturnal Network

II Gates: Framing + Experiencing the City

1. Thresholds Within the City

a. Rideau Canal System

i. Canal Overpasses and Underpasses

ii. Intersections: Neighbourhood Beginnings and Ends

b. $\quad$ Montreal | Nocturnal Streets + Place des Armes

c. Trajectum Lumen Project, Netherlands 
2. VIEWS

b. National Capital Commission Viewsheds for the Capital 28

3. City AXEs

a. Paris (Louvre-Triomphe—Défense)

4. Framing the City from Underground/Below

a. $\quad$ Paris (Lowvre Metro Stop + La Défense)

b. Toronto (PATH Network)

c. Ottawa (The Mysterious Underground Connections)

III | Plazas: Orientation + Activating the City

1. Confederation Square as "War Memorial Triangular Plaza"

a. The Site as a Neutral Zone in the City

b. The Site as a Compass to Provide Physical Orientation

c. Confederation Square as a Canadian "Arc de Triomphe" Roundabout

2. Journeys to Confederation Square Station and Below: Imagining an Architectural Proposition for a National LRT STATION

a. Journey Underground Along the LRT Confederation Line to Confederation Square Station

b. Approaching the Station at Dusk from Ground Level

c. Entering the Subterranean Photography Gallery: Exposing Light in the Darkness

a. Gateway Towards Parliament Hill: Ephemeral Firelight

b. Gateway Towards the Byward Market and Rideau: Borrowed Reflected Light from the Canal 53

c. Gateway Towards Sparks and Elgin Street: Ordered and Structured Light 54

4. Varying Qualities of Light in the Station 55

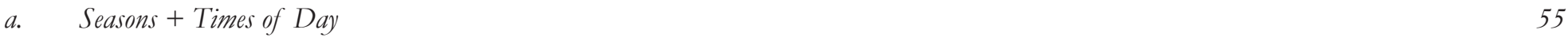

IV | The Reversal and Duality of the City: Day and Night

1. The Changing Nature of the City from Day to Night: Reversal of the City and Buildings 57

2. Emerging Connections and Landmarks at Night: Order and Clarity 58

3. Invisible Spaces: The Ephemerality and Magic of Light, Night and Buildings 59

BIBLIOGRAPHY 


\section{LIST OF FIGURES}

**UNLESS NOTED, ALL PHOTOGRAPHS, GR APHICS AND DRAWINGS ARE PRODUCED BY THE AUTHOR**

Figure 01: Diurnal city view, Ottawa

Figure 02: Nocturnal city view, Ottawa

Figure 03: Aerial view of Confederation Square (site of thesis project) and Downtown Ottawa (Photo: Google Maps)

Figure 04: Quartier des Spectacles, Montreal. View of "foretelling" red dots as night falls.

Figure 05: Quartier des Spectacles, Montreal. Views of red dot branding at night in front of institutions

Figure 06: Light networks existing at various "global" scales: the World, North America, and Southern Ontario (Photos: NASA)

Figure 07: View looking North on Bank. Street towards Downtown from the neighbourbood of the Glebe, Ottawa. Beacon shown in bottom image in dotted circle

Figure 08: View looking South on Bank Street towards Old Ottawa South from the neighbourhood of the Glebe, Ottawa.

Figure 09: View from Parliament Hill looking South down Metcalfe Street to Museum of Nature "Lantern"| Diurnal and Nocturnal views

Figure 10: Altered historical 5-globe fixture, showing use of "S" as top globe for branding, as well as traditional globe fixtures with transparent glass and four different bulb types

Figure 11: Altered historical fixtures in context with non-altered bistorical fixtures

Figure 12: Ottawa's "lost" downtown theatre network (Map + data sources: "Downtown Moves" + "A Theatre Near You" | Graphic assembled by Author)

Figure 13: Sparks Street nocturnal view looking West towards Bank Street from Metcalfe Street

Figure 14: Sparks Street nocturnal view looking West from Bank Street towards Kent Street

Figure 15: Diurnal and Nocturnal gateways and thresholds along the Rideau Canal through the City of Ottawa

Figure 16: Bridge underpass lit as a "gateway" | Rome, Italy

Figure 17: Current marking denoting an "intersection" along the Rideau Canal Parkways. In context (left) and detail (right)

Figure 18: Sreetscape sequence approaching Place des Armes and Notre-Dame Cathedral | Montreal

Figure 19: Trajectum Lumen Project | Netherlands (Photos: Trajectum Lumen Website + Fine Art America)

Figure 20: Trevi Fountain Vedute | Piranesi (Source: Wikipedia)

Figure 21: View towards Parliament Hill from MacDonald Gardens Park in Lower Town, Ottawa. Distant (left) and close-up (right) views.

Figure 22: Diurnal and Nocturnal views along the Grande Axe de Paris showing changing states, and views through "bistorical gateways"

Figure 23: Framing, viewing and referencing the city and its underground | Palais du Louvre, Paris + Confederation Square, Ottawa (Some photos: Flickr + Google Maps)

Figure 24: Confederation Square (project site) showing existing conditions looking North (Source: Google)

Figure 25: Confederation Square looking South-West showing inhabitation during celebrations with street closure. Note: lack of people in green areas of the Plaza

Figure 26: Confederation Square (site of project) showing the site as a compass and gateways stemming from it into the city

Figure 27: Diurnal view of project site showing proposed project in context

Figure 28: Nocturnal view of project site showing proposed project in context

Figure 29: Arc de Triomphe and its plaza | Paris

Figure 30: Section through site looking North with proposed project; diurnal view

Figure 31: Section through site looking North with proposed project; nocturnal view

Figure 32: Diurnal view from Gallery Level showing relationship between city, daylight, and display screens

Figure 33: Nocturnal view from Gallery Level showing relationship between city, lighting, and display screens

Figure 34: Existing conditions with proposed improvements as per Long Term Vision and Plan (LTVP) for Parliament Hill (Map source: LTVP)

Figure 35: Preliminary "nocturnal" concept for Confederation Square showing nocturnal gateways from surrounding areas in yellow (Map source: LTVP) 
Figure 36: Site view of project showing points of entry into gallery and station below

Figure 37: Entry options 1 and 2: curved ramps or glass elevators

Figure 38: Entry option 3: East stairs through tunnel

Figure 39: Entry option 3: suspended glass tunnel link from existing bridge connecting to East-end Downtown

Figure 40: Section looking West showing entry option 3 (East side) into gallery level via tunnel under bridge

Figure 41: Entry option 3: West stairs through tunnel (Parliament Side)

Figure 42: Entry option 4: ramp from Sparks Street

Figure 43: View from Concourse Level showing penetration of daylight and relationship to city

Figure 44: Conceptual section showing nocturnal relationships and proposed gateways of light

Figure 45: Canal/Ridean gateway lighting concept vedute

Figure 46: Sparks/Elgin Streets gateway lighting concept vedute

Figure 47: View into Gallery Level of station showing summer shadows (June 10th, 10:30 am)

Figure 48: View into Gallery Level of station showing winter shadows (February 10th, 10:30 am)

Figure 49: Diurnal layering of Confederation Square and surrounding landmarks

Figure 50: Nocturnal layering of Confederation Square and surrounding landmarks

Figure 51: Diurnal view looking towards Confederation Square

Figure 52: Nocturnal View looking towards Confederation Square 


\section{INTRODUCTION}

\section{Context | City OF OtTAWA: DOWNTOWN + CONFEDeration Square}

A veduta (plural: vedute) is defined as a "detailed, largely factual painting, drawing, or etching depicting a city, town, or other place." 1 Though starting out as largely factual representations of cities, "in the later 19th century, more personal "impressions" of cityscapes replaced the desire for topographical accuracy, which was satisfied instead by painted, and later photographed, panoramas. Veduta morphed into partly or completely imaginary scenes, known as capricci and vedute ideate or veduta di fantasia." ${ }^{2}$ Rather than remaining a representation that was always true to the cityscape, vedute were enhanced with impression, effect, and hierarchy to create a representation that was true to what it depicted, but with personal touches or impressions added by the author.

Depicted in many vedute, landmarks play an important role in a capital city. Knowing where you are within the city is intrinsically tied with being able to reference your given location in relation to what is around you. Of particular importance to Ottawa is the preservation of views towards major landmarks including the Peace Tower and the Parliament Buildings in the downtown core. One could argue that beyond preserving views towards important heritage buildings, a sense of physical orientation is also being preserved. This act of preservation comes in the forms of unobstructed viewsheds, as well as at one time limiting the height of buildings to shorter than that of the Peace Tower.

Sense of place is felt when one can place themselves within the city in relation to landmarks and places around them. The loss of the ability to orient oneself brings on an uncomfortable feeling, causing panic, confusion and physical disorientation. One may argue

1 The Editors of Encyclopædia Britannica. "Veduta (visual arts)." Encyclopedia Britannica Online. Encyclopedia Britannica. 24 Mar. 2014.

$2 \quad$ "Vedute." Wikipedia. 22 Feb. 2013. Wikimedia Foundation. 25 Mar. 2014. 
that being on a train while underground or in a dark tunnel—even during daylight hours—is often essentially no different in feeling from that of being on a train in a vast outdoor space at night. In both cases you are in the same vehicle, but in different contexts. Despite one of the contextual spaces being confining and the other open, darkness and a lack of physical orientation causes a sense of spatial and contextual confinement, causing confusion if one cannot reference themselves to their surroundings.

Ottawa's founding development, based on military infrastructure, as well as the preservation of views, has played an important part in how the city has been planned, has grown, and is set for future development. The National Capital Commission in particular, plays a pivotal role in this choreography, by ensuring that views are preserved towards and around important buildings, monuments, and landscapes. The established choreography may work very well during the day when hierarchy relies on buildings being shown in a uniform and neutral way based on their locations and positioning, however, what happens when the lights of the city get turned out? All of the networks, frames, and views that have been set to target an audience that observes during the day somehow change, fade, or dissolve. Perhaps things change for the better, becoming clearer and more hierarchical in meaning-but has this been considered and planned for, or is it all by accident? Addressing this circadian rhythm of the city to look at both diurnal and nocturnal conditions is of significance in how the city maintains clarity and is perceived from day to night.

Although views are not the only way to frame the city or to help pull you through space, in some cases they can prove to be extremely powerful. In Paris, for example, the axis that stretches from the Palais du Louvre in central Paris towards La Défense-Paris' central business district—stretches so far that it extends past the periphery of the city into an entirely new city. This

"Between the idea And the reality Between the motion and the act Falls the shadow"

-T.S. Elliot 
is an extremely powerful statement, in that this axis, as well as what is stationed along its length, tells a story about the city and how it has developed both in a historical context, as well as more modernly through François Mitterands' Grands Projets. One can look along this axis and see the city through many frames from different time periods, beginning in the centre of the city and reaching all the way out towards the suburbs. Moving from the historically old frame of the Arc de Triomphe du Carrousel in the centre of the city, to the Arc de Triomphe on the North-West tip, and eventually to the modernist and abstracted Grande Arche on the periphery at La Défense, all elements along the length of the axis tell a story of the city through the axial relationship. This axis is further reinforced, altered, and changed both daily and seasonally by permanent elements such as trees, lampposts, and benches, as well as temporal elements such as foliage, Christmas lights, and vehicular and pedestrian traffic.

\section{Concept Examining the City through the Lens of 3 Urban devices}

Cities change at night_-places change at night—people change at night. A city as a whole is affected by the circadian rhythms that occur fuelled by the diurnal and nocturnal presences and states that the city takes on. This change of character that occurs within the city occurs not only at the scale of the city, but also at the scale of neighbourhoods, buildings, and plazas, as well as in how people respond, react and interact with different parts of the city. These complex networks of interweaving changes call for an investigation into how these play a role in framing, addressing, and transforming the city.

Different aspects of a city can be described as different players or parts in the theatre of the city, some composing the fabric of the city, others standing alone as figures. As time changes from day to night, some buildings sleep along with the darkness of night, while others come alive. Many buildings are left in a vulnerable state, transforming from their reflective and fortress-like composure during daylight, to having their insides revealed and turned inside out at night. Seasons, too, act as transformative context in the theatre of 


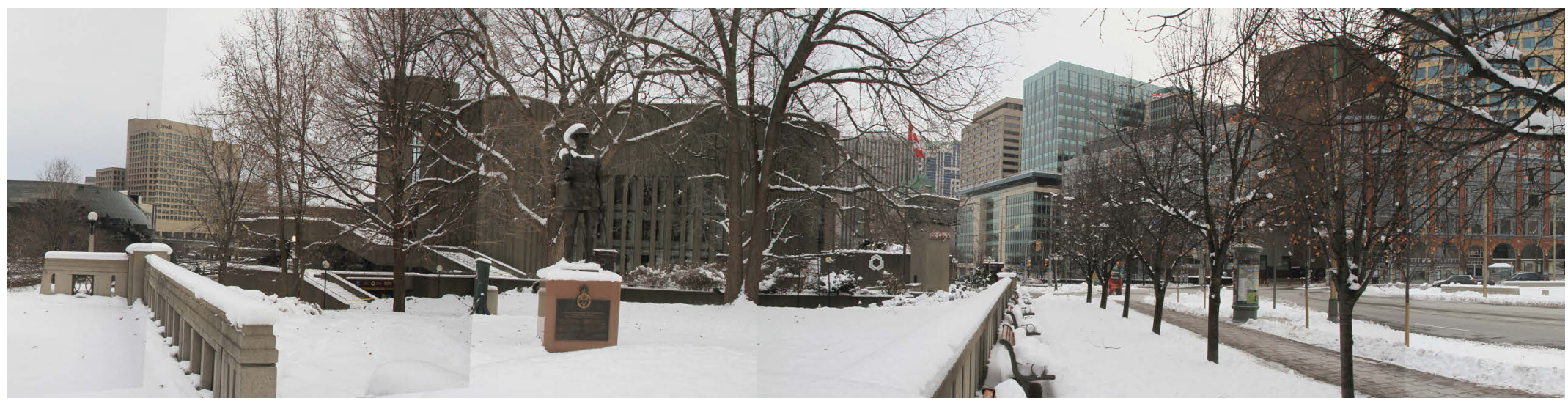

Figure 01: Diurnal city view, Ottawa

the city, affecting the foliage of trees, flowers, and vegetation throughout the year, while concealing and revealing different buildings, places, and spaces. Cyclical changes and reversals, combined with light and darkness, create a complex framework within which the buildings, people, and backdrops of the city continuously evolve, change, and transform in a temporal and ephemeral manner.

What is it about the nocturnal quality and darkness of night that causes a sense of emptiness; a sense of fear; but also a sense of peacefulness and excitement? Often darkness can be associated with throwing off one's physical and spatial orientation, however, it

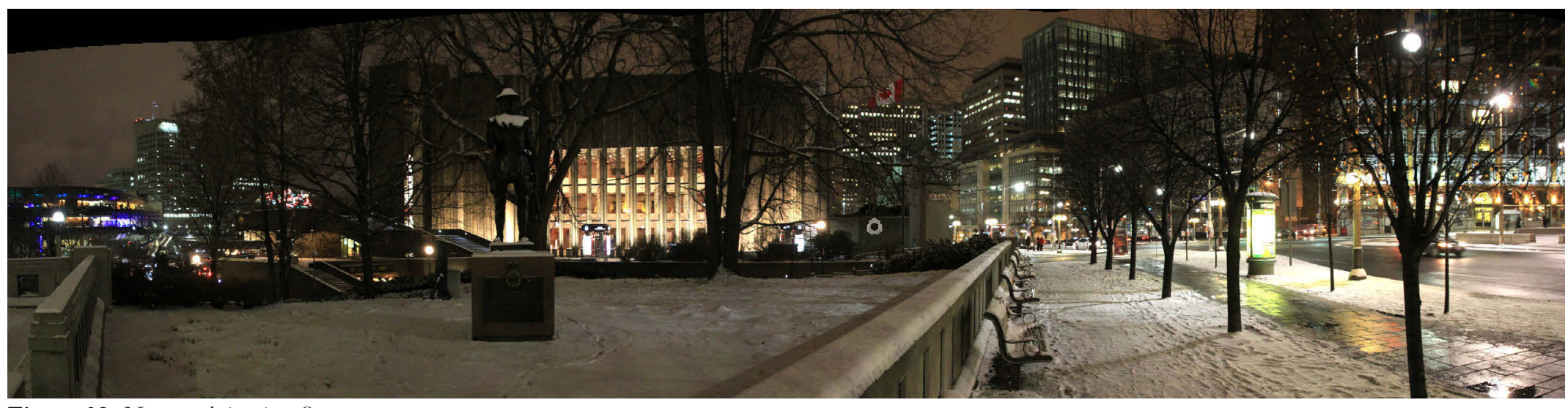

Figure 02: Nocturnal city view, Ottawa 
could be argued that in darkness the important parts of the city should come to light, causing a sense of clarity and order that would facilitate orientation. One wonders if comfort through orientation and a sense of visibility extends beyond the visual sense into the physical: in an ever-changing city, knowing where you are is important, but, of equal importance is knowing who you are, and what role you play in a civic context. Night and darkness mask the city and the visibility of its diurnal state, but it also creates a masqued condition of the individual, concealing and altering identities, comfort levels, and perceptions. Richard Sennett describes the public realm as "a place where strangers meet." He goes on to say that "the difference between public and private lies in the amount of knowledge one person or group has about others; in the private realm, as in a family, one knows others well and close up, whereas in a public realm one does not; incomplete knowledge joins to anonymity in the public realm.”3 People too take part in the masquerade of the darkness of the city, transforming from their un-masqued personality during the day into a free-self at night, especially in a public setting.

Relationships change at all scales and levels, both between individuals, and between individuals and the buildings of the city. In contrast to the less-hierarchical layering of the city during daylight hours, at night, landmarks, networks, and systems often emerge through the presence of light, irrespective of their arguably actual importance and hierarchical significance. A shift in hierarchy and importance also occurs at a smaller and personal scale, changing and reversing personal comfort levels and relationships between individuals, groups, and places within the city throughout the day and night. Though there is a contrast between the uncomfortableness in a dark area caused by a lack of diurnal sunlight or warmth, and that of a darkness during a nocturnal period, both equally change the choreography of the city and interaction with its spaces.

3 Sennett, Richard. “The Public Realm.” The Blackwell City Reader. By Sophie Watson and Gary Bridge. Malden, MA; Chichester, West Sussex, U.K: Wiley-Blackwell, 2010. 261. Print. 
In order to analyse the various scales within the city, and their effect on diurnal and nocturnal conditions, the city can be broken down into three primary metaphorical elements. These urban devices take the form of tower, gate, and plaza, and reference the city from macro to micro elements, each playing a separate but integrated part in the theatre of the city. A tower, a gate, and a plaza can further be translated into networking, framing, and orienting, analyzing how the city is referenced, framed, tied together, and experienced.

\section{CONTENT A National DOWNTOWN LRT STATION}

Operating within the core of the city of Ottawa, several areas can be identified as areas where the Theatre of the City can be discovered and experienced. Bridges, underpasses, underground spaces, topographical changes, and various landscape elements such as trees, greenery, and water, combine to create areas where all elements interact and can create dramatic spaces through their horizontal and vertical intersections. Built over the trench of the Rideau Canal, as well as in the location of the convergence of two historical bridges, Confederation Square is a place of history, excitement, and intersection within the city, where places and neighbourhoods of various character and of different topographical elevations meet.

With plans having gone ahead for the implementation of a new Light Rail Transit (LRT) network in Ottawa, there has been much discussion about the location of stops at the various points along the line. Of particular importance and interest is the controversial discussion about the proposed location of the downtown LRT stops that will replace the existing bus stops on Albert and Slater Streets serving the existing downtown Transitway. The question of referencing the city through connecting networks, framing, and sense of place, raises questions relevant to an architectural project tied to the LRT. In what ways can the city be referenced, framed, and connected to in a subterranean LRT station? Additionally, how do these impact the role of infrastructure in the future development of the city? Of particular importance to this case, is: how does a subterranean LRT stop play an active role in relating 
to and referencing the city while providing a sense of physical, historical, and social orientation from the underground as well as upon emerging out of the station at grade?

When above ground, knowing where you are is typically more easily defined and visually evident than when underground. Thinking of what it is like to be in subterranean transportation system, such as a subway, underground LRT, or underground train, what elements are removed from your senses that can be returned when above ground? How does one orient themselves when below grade in transit, while in a station, and upon emerging from the underground out into the city?

As a network, the city connects the various parts that make up its fabric. Confederation Square as a proposed location for a National LRT Station acts as a portion of this network, not only placing it at an important part of this large overarching structure or network, but also connecting crucial parts of the downtown network. The next sections look at the city as a network composed of nodes, intersections, and fabric, as well as the diurnal and nocturnal states these elements take on and the resulting effects.

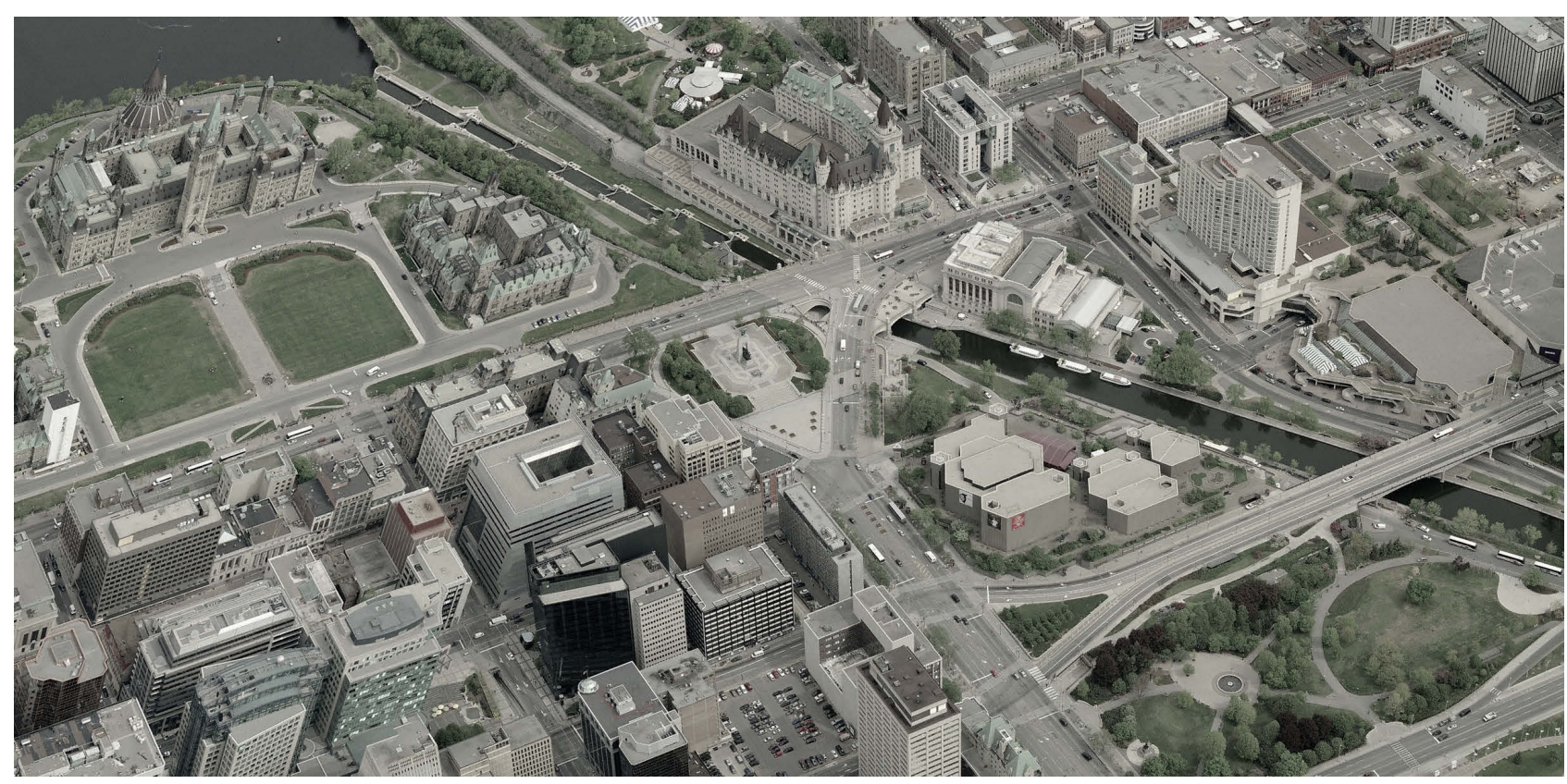

Figure 03: Aerial view of Confederation Square (site of thesis project) and Downtown Ottawa (Photo: Google Maps) 


\section{TOWERs: The City as a Network}

Towers as tall elements stand out within cities and help to draw attention. Throughout this section, the notion of towers as beacons within a larger context will be examined for their ability to orient and move people through cities both during the day and at night. Beacons, systems, and networks, among other things, will be discussed and examined in order to reveal their importance, clarity and success in producing physical orientation during diurnal and nocturnal cycles and changing conditions.

\section{Quartier des Spectacles, Montreal}

\section{A. Emerging nocturnal networks}

Quartier des Spectacles as a whole-Montreal's Theatre District—is a prime example of a network within the city that can be read and experienced on several levels. It is a unique network in that it is both visually present and contains infrastructural components evident

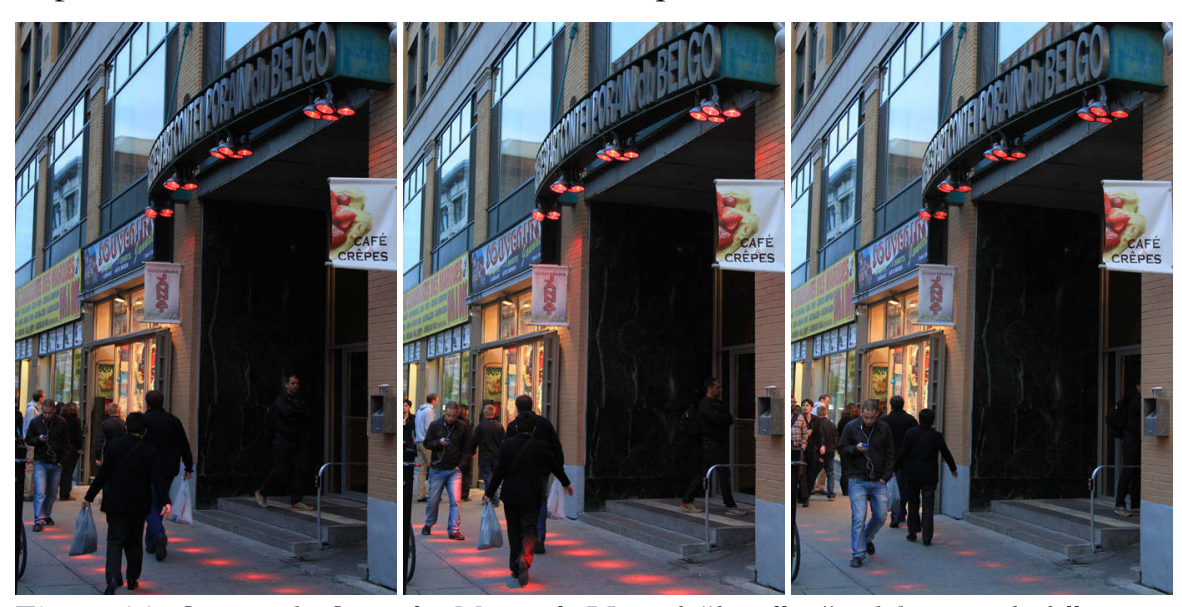

Figure 04: Quartier des Spectacles, Montreal. View of "foretelling" red dots as night falls. during both day and night (namely buildings and public spaces), as well as, hidden elements that only emerge during periods of darkness. The network of various cultural spaces both in the form of buildings and public spaces, is contained within 1 square kilometre of the city core, and contains over 80 cultural venues with 28,000 seats across 30 performance halls. ${ }^{4}$ The multi-layered network has permanence in terms of its infrastructure 
and the buildings proper, however, is heightened, clarified, and reinforced at night with the use of a system of light-based branding and identification. The use of a consistent red lighting motif-in the form of a series of red dots-identifies the "participating" institutions. Rather than being a statically lit element, the dots have a foretelling nature, suggestive of an emerging nocturnal network. As dusks falls upon the city, the series of red dots of light begin to pulsate at the exterior of institutions, alluding not only to a hidden network that will reveal itself at night, but also to hint at unseen internal activities that occur within these institutions' spaces primarily in the evening hours.

In the case of the Quartier des Spectacles, this network is one that is evident both during the day as well as at night, albeit at different levels of clarity. At night, the networking effort and connections between the cultural institutions emerges and is strengthened by the use of lighting and branding elements to unite the neighbourhood and the community of buildings. Although existent both diurnally and nocturnally, an arguably different and hidden network emerges at night not only at the scale of a neighbourhood, but also at the scale of individual buildings and public gathering spaces.
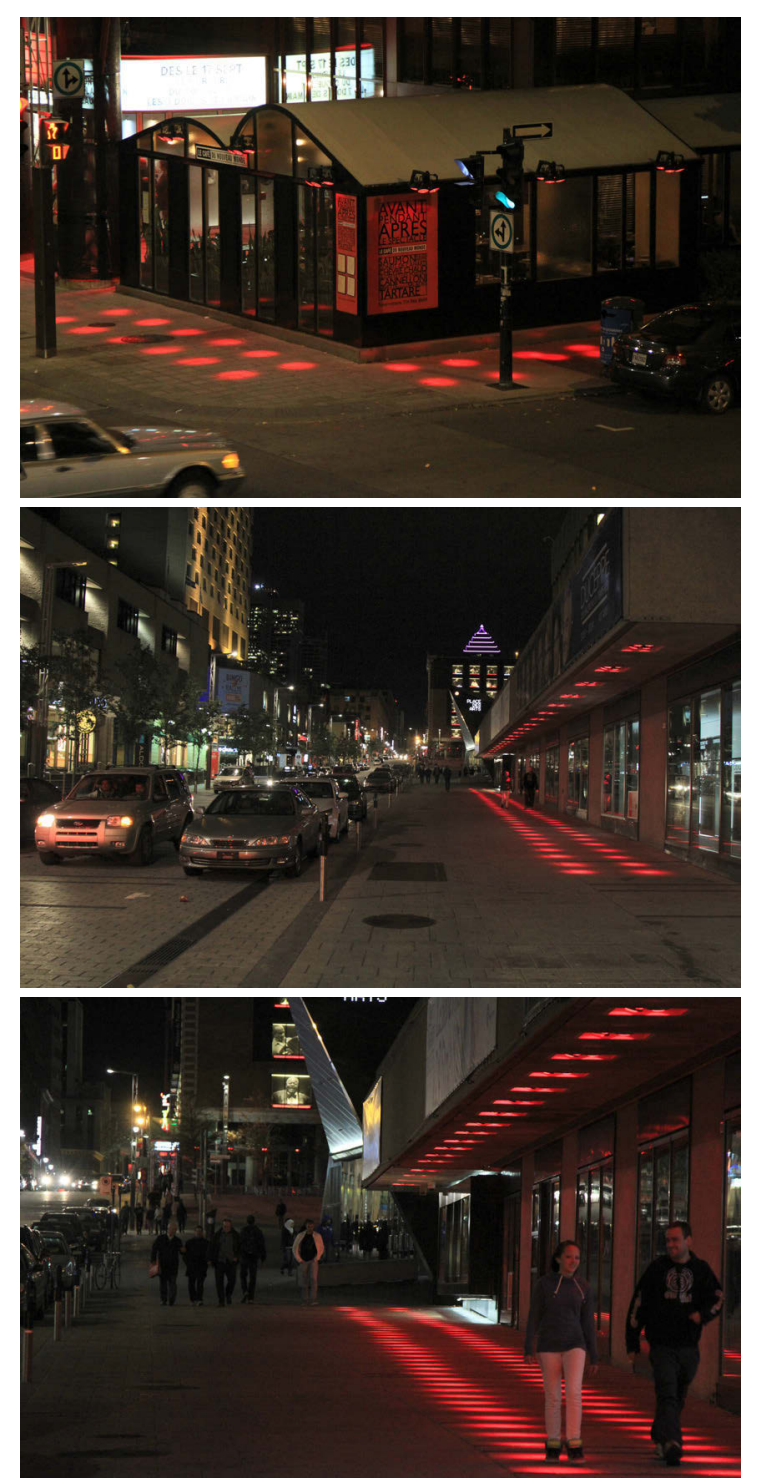

Figure 05: Quartier des Spectacles, Montreal. Views of red dot branding at night in front of institutions 

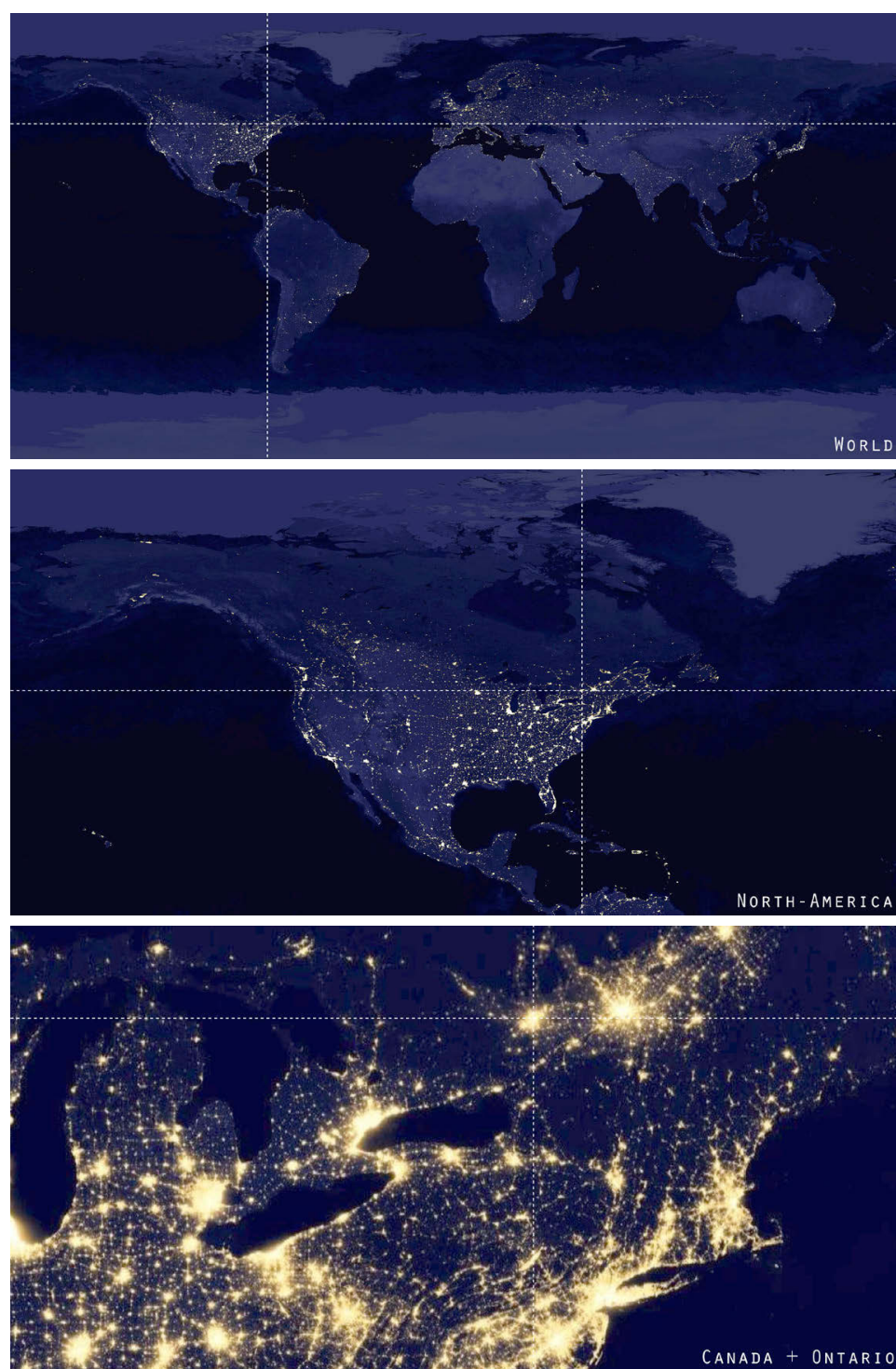

Figure 06: Light networks existing at various "global" scales: the World, North America, and Southern Ontario (Photos: NASA)

\section{Systems Pulling You through the C I TY}

\section{A. NOCTURNAL BEACONS}

A beacon is defined as being "a fire or light set up in a high or prominent position as a warning, signal, or celebration" as well as "a light or other visible object serving as a signal, warning, or guide." ${ }^{5}$ By definition, both instances of a beacon reference the involvement of light in some form, whether through firelight or other means. Light in the form of a nocturnal beacon, and as a visible nocturnal network, exists at various scales, ranging from the scale of the world as a whole, to that of continents, and to that of cities. Acknowledging that at the scale of the city the use of light exists primarily in an outdoor context, and that in terms of visibility it is predominantly noticeable at night, this raises the question: "is there such thing as a diurnal beacon, or do only nocturnal beacons exist?" Additionally, "what role do buildings and other landmarks in the city play in terms of physical orientation within the city, both in diurnal and nocturnal contexts?"

"Definition of beacon in English:." Beacon: Definition of beacon in Oxford dictionary (British \& World English). 20 Mar. 2014 
Nocturnal beacons can be primarily divided into two categories: permanent and ephemeral. These can further be subdivided into the categories of: intentional or wanted beacons and unintentional or accidental beacons. In some cases beacons intended or planned do not achieve the desired result, while others that are not intended or ought to recede into the surrounding darkness are unintentionally prominent. It is important to note that perhaps a diurnal beacon translates into what one would identify as a landmark. The evenly lit, general illumination presence of daylight, in conjunction with large or prominent objects, places, or buildings, is seen as an identifier of beacons, drawing people towards them. In daylight, however, despite a landmark having significance and being visible in terms of enough luminance, buildings with similar materiality that overlap with the landmark can cause it to vanish or to be camouflaged within the context of the city. When daylight is removed from the equation, an object visible during the day can unintentionally become invisible, changing its role in the orientation, hierarchy and clarity of the city. This is true of both objects that blend into their contexts as fabric during the day as well as objects that stand out as figures. Careful choreography of nocturnal and diurnal states must be considered when thinking about orientation, presence and visibility of buildings, monuments, and public spaces at night. Conversely, carefully considered disappearance of prominent buildings or landmarks might be considered as an opportunity to tell a hidden story that lies within the darkness of the shadows of the night.

Anecdotally, a recent personal experience noted the appearance of a beacon of flashing light of unknown origin visible on Bank Street in Ottawa as you moved North towards downtown from the neighbourhood of the Glebe. This seemingly accidental beacon, though not extremely distracting, had piqued enough interest in me to incite a search for the location of its origin. Though a small light in the distance, the journey through the city that this light triggered was substantial. Having travelled North on Bank Street, the bend that occurred after the underpass of the Queensway (417) had made this beacon suddenly disappear, making the pursuit very difficult. Though continued travel in the apparent direction of its origin had been maintained, the beacon simply vanished. Upon 

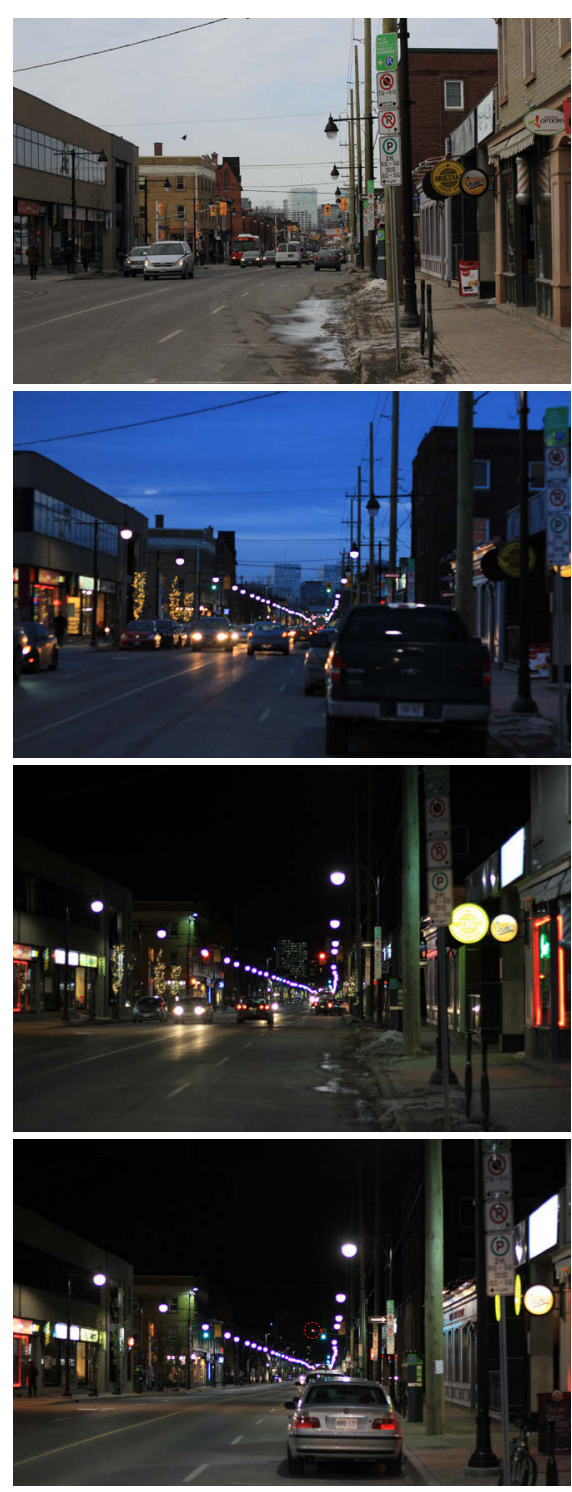

Figure 07: View looking North on Bank Street towards Downtown from the neighbourbood of the Glebe, Ottawa. Beacon shown in bottom image in dotted circle revisiting the documented location of the light the next day and referencing it with daytime conditions, the geographical location became clear, if not its origin or purpose. It seems likely that a flashing and colour-changing domestic light fixture had been left on by a resident of the upper floor of a new condo development-perhaps within a communal space or private unit. It was interesting to see the effect that a small, assumedly unintentional light, had on creating a momentary civic beacon and a beckoning force, with the ability to attract inquisitive people through the city streets.

In the context of downtown Ottawa, and particularly around Confederation Boulevard, many nocturnal beacons exist that become particularly evident at
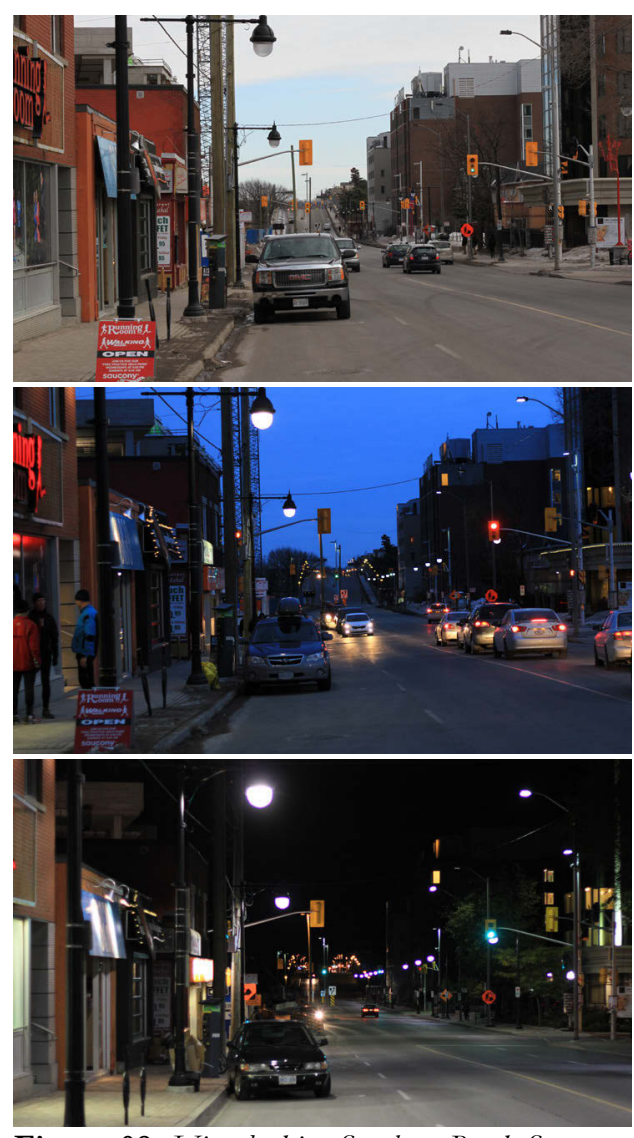

Figure 08: View looking South on Bank Street towards Old Ottawa South from the neighbourbood of the Glebe, Ottawa.

night. The list is rather long and includes but is not limited to: the Peace Tower, the War Memorial, the Chateau Laurier, the Museum of Civilization, the National Gallery of Canada, Notre Dame Cathedral, the Government Conference Centre, the National Arts Centre, Postal Office B, etc. In the context of Confederation Square, several buildings play into the equation 
of the composition of the surrounding area, with many overlapping and layering effects occurring as you move around and experience prominent nocturnal views.

Though many of the significant buildings and landmarks in Ottawa are illuminated at night, several miss this opportunity or miss an opportunity to fit into a larger system. Some examples within this group include: the Rideau Locks, the Rideau Canal's water, and the newly added Museum of Nature Lantern (especially as a beacon from Parliament Hill at the intersection of Metcalfe and Wellington Streets). Though this may not be a problem of poor illumination in all cases, a fine balance of establishing and linking networks and illumination would benefit from their incorporation. In the case of the Museum of Nature lantern, despite the fact or the admission that it was designed as a "lantern as beacon," the choice of whether or not to light it, as well as the enhanced narrative
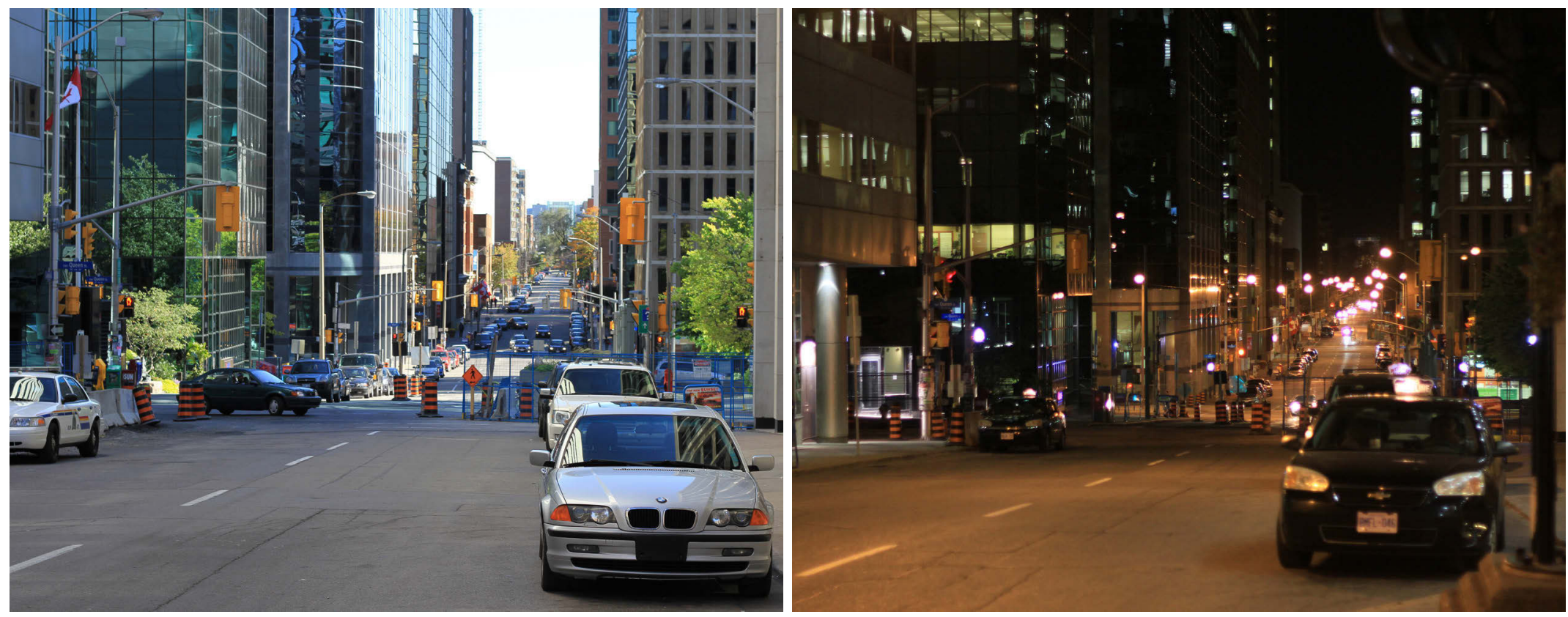

Figure 09: View from Parliament Hill looking South down Metcalfe Street to Museum of Nature "Lantern"| Diurnal and Nocturnal views 
opportunity would allow it to appear and disappear at night, signifying the building's history and the reinstatement of the tower, long ago dismantled. It is important to note that views and connections can, and must, be made not only during daylight hours, but also at night when views and networks can be clarified, enhanced, reinforced, and, when appropriate, reversed.

\section{B. The Use of Lighting as a System: Figures, Fabric and temperatures}

The use of lighting as a system, particularly in Ottawa, is one that can generate much discussion based on the role of the light fixture as a figure alone. As the capital of Canada, and possessing significant heritage values in many places, this preservation effort trickles down into the lighting of the city and some of the limitations that come with it. In some cases, this results in the use of conservative fixtures for their historical semblance while neglecting the desired and necessary illumination. Although it is not evident that the fixtures are constraining, in some cases the lighting fixtures as objects act too much as figures, preventing a cohesive network of lighting and light fixtures. In some cases the act of using light fixtures as figures is desirable, however, in other cases lighting becoming a figure rather than fabric causes an interruption of figure and ground, while simultaneously negating the desired effect: this effectively solves neither of the intended goals. Incorporating current technology, achieving necessary illumination, and preserving historical fixtures is a delicate balancing act that must be carefully considered.

Light acts not only as a method of reinforcing a system or network of vistas and paths, but also as a means to heighten the coloured textures of materials. Additionally, light can add an ephemeral materiality to neutral surfaces through the use of patterns, textures, or colour. Colour, especially, is of utmost importance in order to create a cohesive and consistent system throughout a project, a site, or a civic space. Even when using non-coloured light on neutral-coloured materials, there is much variation within colour temperatures of light, with intended and unintended effects. Having a system or façade washed in the temperature of incandescent 
lamps interrupted or juxtaposed with a fluorescent lamp is enough to completely change the effect and intention of the initially proposed concept. Though care is often taken to ensure that this is not the case at the outset of a lighting concept or design for a project, often this mixture of temperatures can result from improper maintenance. Not only can a variety of temperatures disrupt and look out of place within a consistent system, in the case of heritage fixtures it can look completely nonsensical. In a fixture that is meant to allude to a historical fixture, one would associate the light temperature coming from the fixture to be that of candlelight or other means of warm-coloured incandescent light. Placing a cool-coloured temperature compact-fluorescent bulb in a historical fixture raises concerns that could be compared to the lighting-equivalent of façadism for buildings. Conversely, a lighting design that carefully mixes colour temperatures can result in dramatic effects and compositional emphases, such as with the Notre-Dame Cathedral Basilica on Sussex Drive in Ottawa.

\section{Moving through the City}

\section{A. The Canal as a System to get downtown and Link neighbourhoods}

A case example of lighting as a system is the lighting along the Rideau Canal from Hog's Back Falls through Dow's Lake to its terminus downtown at the Rideau locks. In this case, lighting has been used in order to light both the pedestrian paths that flank the Rideau Canal, as well as along both Colonel By Drive and Queen Elizabeth Drive as parkways. Traditional lamppost fixtures have been used in order to preserve heritage values, however, one questions what role they play in the effectiveness, efficiency, and clarity of lighting of these pathways and thoroughfares, as well as how clearly intersections are visible within the system.

Examining the effectiveness of lighting along both the roads and pedestrian paths, the resulting effect is largely one of punctuated darkness that result in an inappropriate level of ambient light for comfortable use during evening hours. Returning to the problem 
of non-critical use of heritage-style fixtures and lampposts, the use of lamppost fixtures with globe toppers along the pedestrian section of the canal is of historical beauty, however is a very poor fixture in terms of lighting the path. Much light is wasted by being directed upward - towards tree branches in some cases — and little is directed downward towards the path where it is most needed. Although reflected light from the tree canopies could be an interesting solution to the problem, the result being achieved through the current configuration of fixtures is problematic and is not necessarily a solution that would work well during the winter months with deciduous foliage.

Looking at how the car realm fares, similar problems exist in terms of levels of lighting and spacing of fixtures. Several points at which combined pedestrian and automobile lighting configurations begin to overlap appear to be most successful, however these

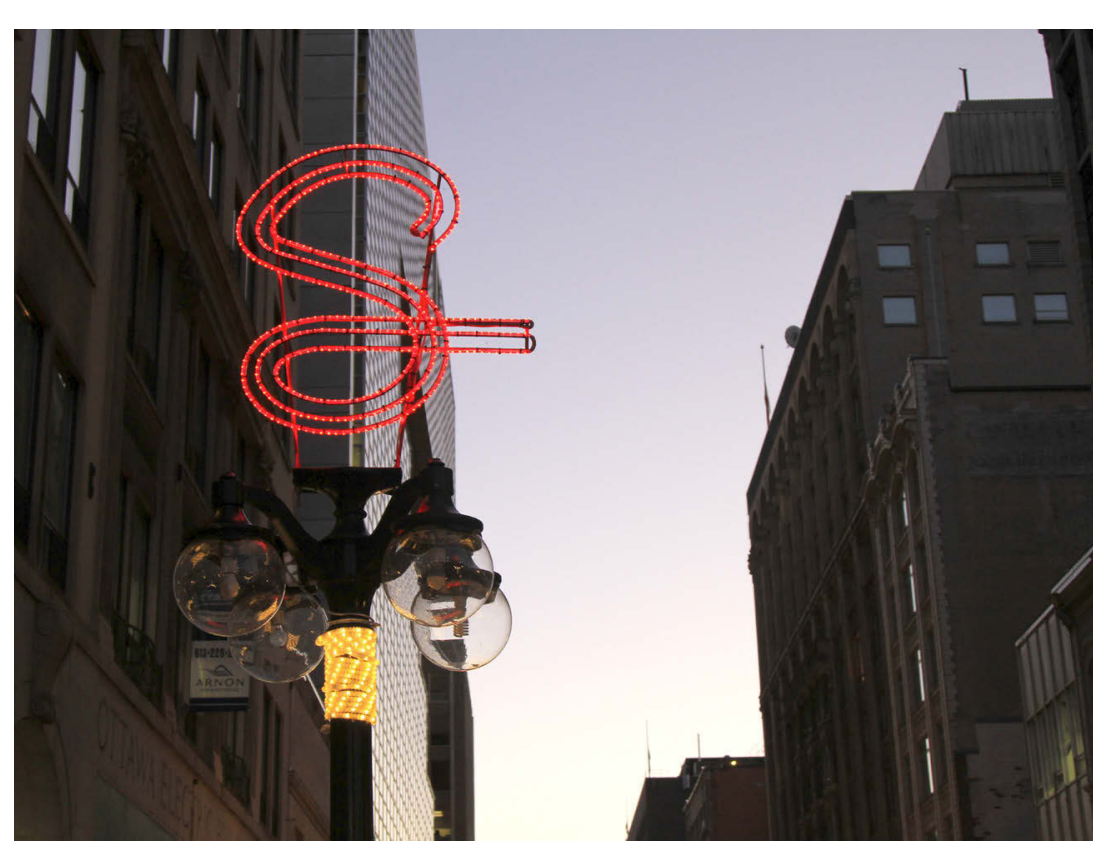

Figure 10: Altered historical 5-globe fixture, showing use of "S" as top globe for branding, as well as traditional globe fixtures with transparent glass and four different bulb types primarily exist only along the network when moving closer to the downtown core, or when passing under bridges. These gateways, and the experience of moving towards and through them, raise other issues and point to potential improvementsthis is discussed and addressed in a following chapter.

Finally, it is important to note that there are instances downtown, where the use of traditional lamps and fixtures have been used, but have been altered appropriately in order to help address more practical concerns. On Confederation Boulevard, for example, typical streetlights have been combined with historical 
fixtures in order to create a hybrid lamp post that addresses both the need to have properly lit roads, in combination with the beauty of historical fixtures in the pedestrian realm. Similarly, the recent addition of the fluorescent red "S" on top of fixtures on Sparks Street combines a modern branding icon with a historical lighting fixture. By systematically removing the traditional top globe from typical 5-globe fixtures,

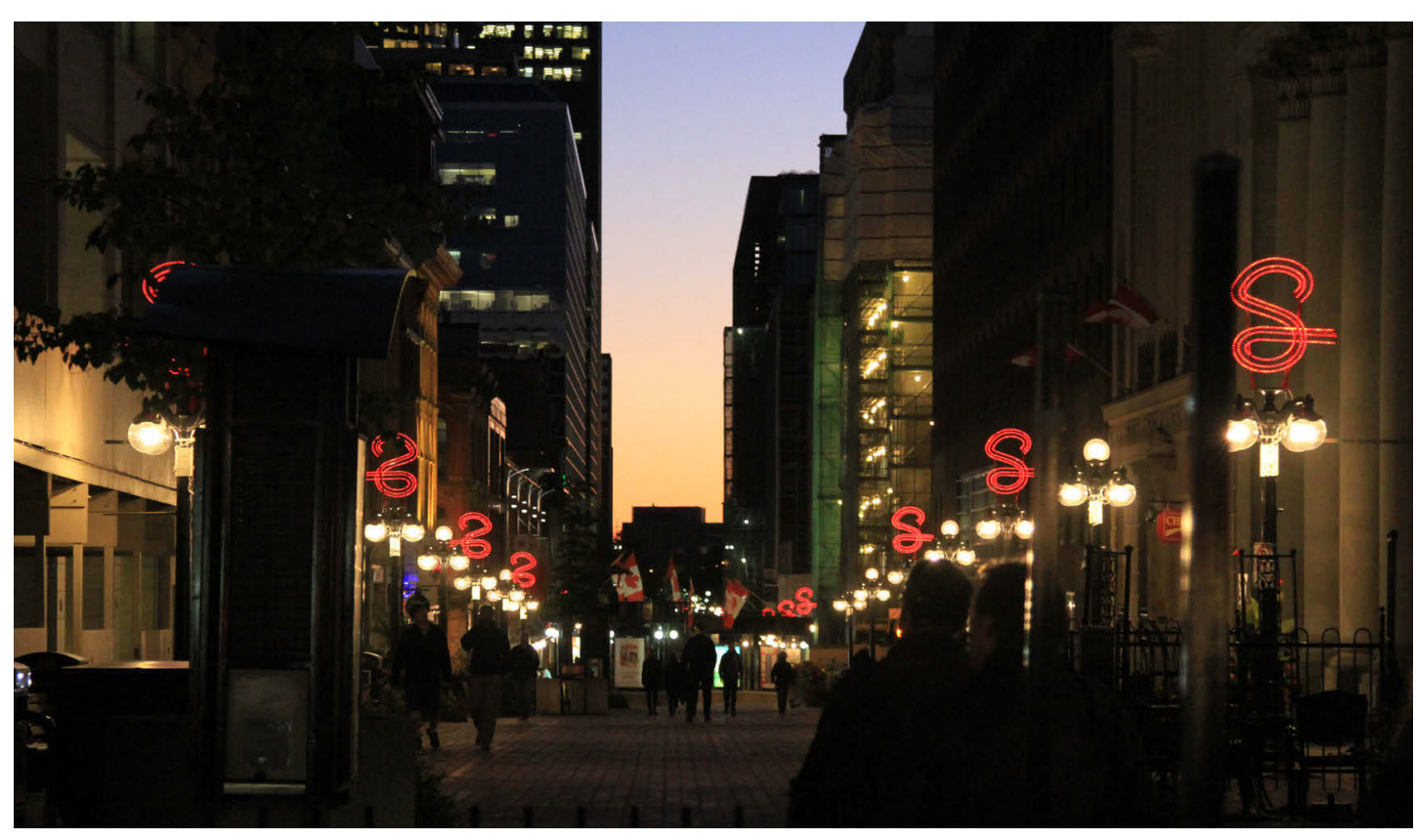

Figure 11: Altered historical fixtures in context with non-altered historical fixtures

it allows for a unique branding on the street, while still keeping the altered fixtures in their historical context. This allows the altered lamppost to be compared to the traditional ones, setting up a compassion on the street. This notion of branding through lightsimilar to Quartier des Spectacles in Montreal—allows for the creation of a diurnal and nocturnal network, albeit more outwardly literal and blatant.

\section{Disconnected, invisible, Lost, and Missing networks}

\section{A. The “lost" Downtown theatre network}

In contrast to the diurnal and nocturnal network of Quartier des Spectacles, and the nodal and neighbourhood-linking network of the Rideau Canal, there are networks that are invisible, that are lost, that have yet to be discovered, or which have gone missing. 
A "lost" theatre network, originally comprised of movie theatres, existed in downtown Ottawa (some of which were ironically replaced by Confederation Square and the National Arts Centre), and slowly deteriorated and was dismantled over recent times. Today, it has mostly

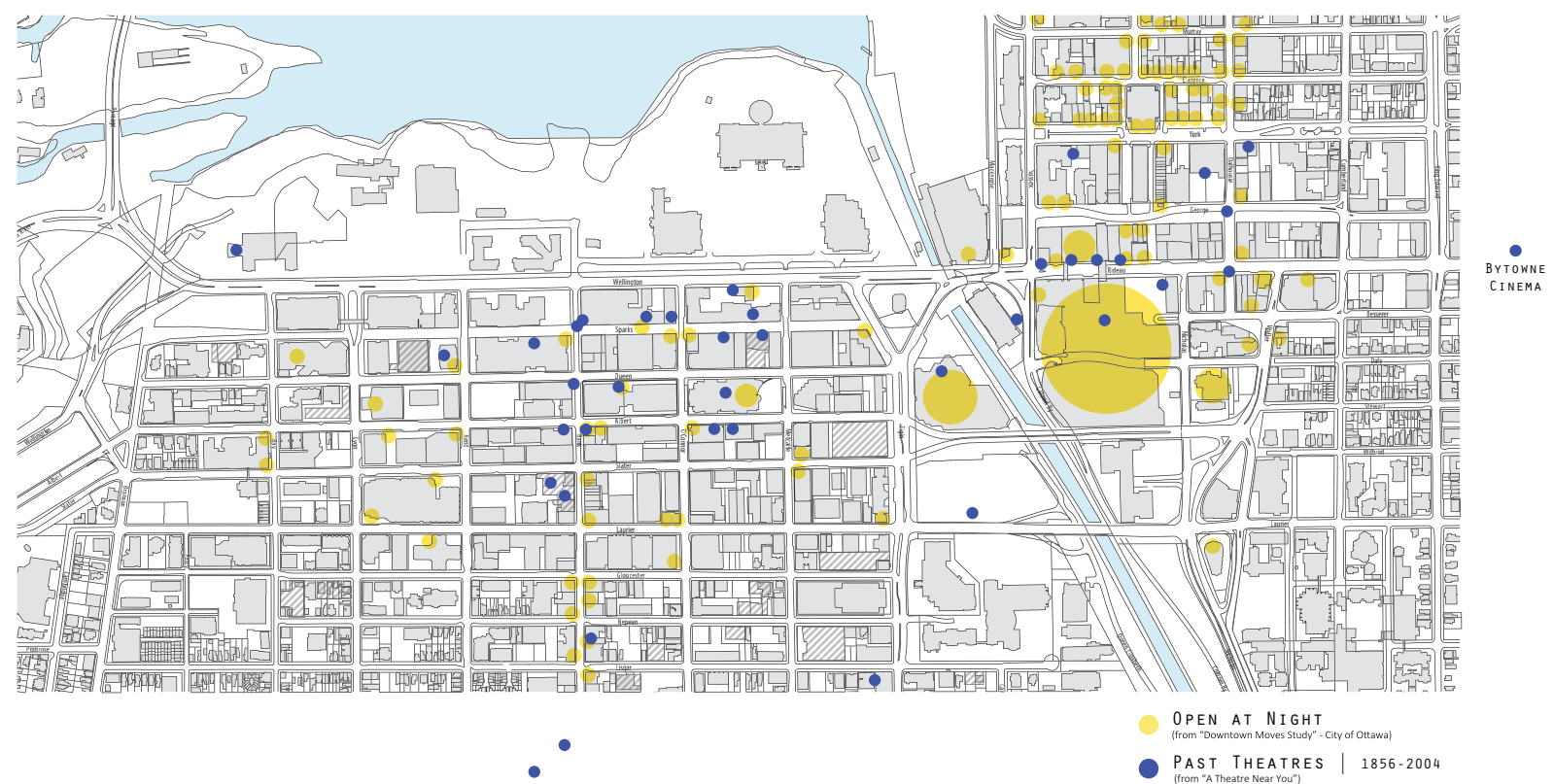
disappeared, with the only

Figure 12: Ottawa's "lost" downtown theatre network. (Map + data sources: "Downtown Moves" + "A Theatre Near You" Grapbic assembled by Author)

remaining public movie theatres in and around Ottawa's downtown being the Bytowne Cinema in the South-end of the Byward Market, and the Mayfair Theatre between the Old Ottawa South and Glebe neighbourhoods.

\section{B. Sparks Street nocturnal network}

Sparks Street itself once contained a large number of theatres that helped to make up Ottawa's "lost" theatre network. The disappearance of theatres on Sparks Street, and the related disappearance of nocturnal theatre-going, are substantial contributors to the sharp contrast and duality of the Street in terms of nocturnal vs. diurnal activity. ${ }^{6}$ A lack of activity on the street at night raises an important question in terms of the use of lighting and how this could help to enhance or have an effect on this darkness of activity at 
night. Though the aforementioned use of historical fixtures, with the occasional use of an "S" logo seems to be providing a sufficient amount of light to the space, one wonders what lighting could do to add additional layers of detail and information to this street as a network. While the levels provided by the street fixtures are adequate, perhaps fewer fixtures would be more efficient, with light distributed or used in others configurations. From a personal analysis of night time lighting conditions on Sparks Street, conclusions suggest that the use of lighting to light the façades of buildings—-specifically heritage elements and buildings_yielded a more effective and pleasant result than that of only streetlights, and added additional layers of information to enrich and strengthen the mix of architectural fabric on the street. Through lighting the buildings that make up the street rather than the street itself, the stories of the

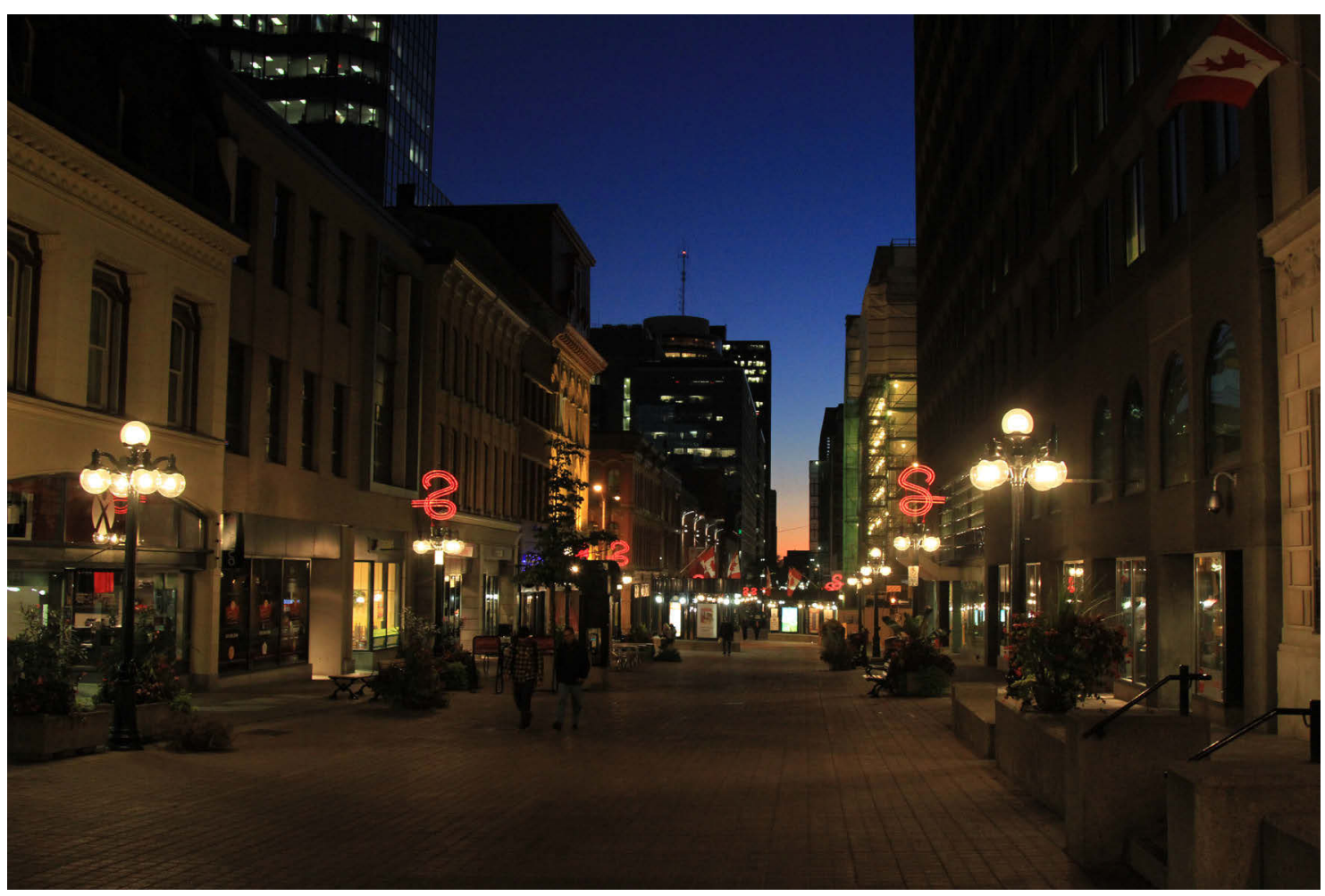

Figure 13: Sparks Street nocturnal view looking West towards Bank Street from Metcalfe Street buildings start to inform, address, and define the street. As a result, the street is not solely defined through its role as a thoroughfare.

Walking the length of the pedestrian mall to the more deserted portion (West of Bank Street), it is interesting to note that much of the infrastructural light provided on the street was not in use or was poorly maintained. This circumstance, however, allowed for a comparison $-19$ 


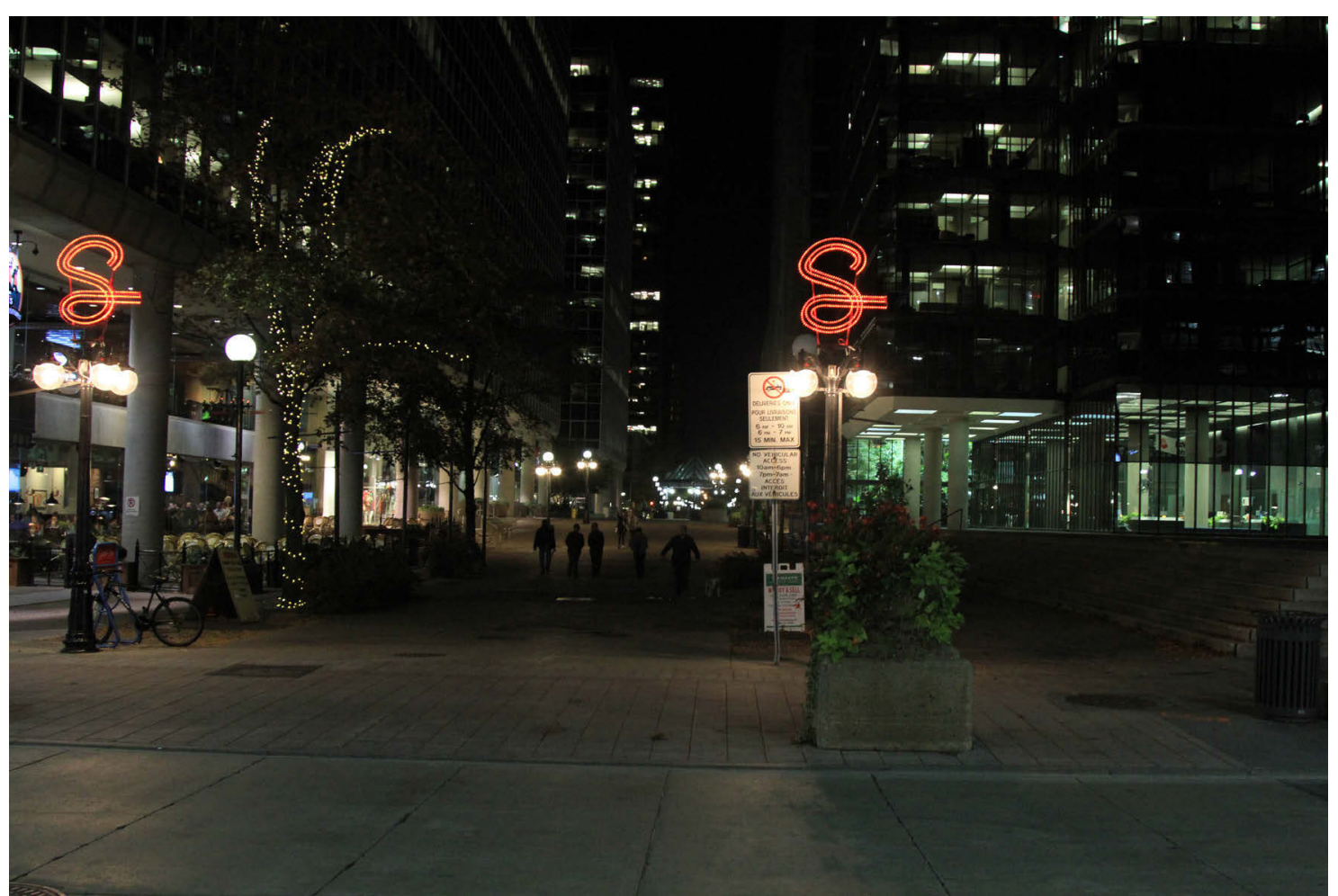

Figure 14: Sparks Street nocturnal view looking West from Bank. Street towards Kent Street and analysis of what effect could be achieved not only through lighting the façade of buildings, but also, in the case of a glass curtain wall, the contents behind. Allowing the insides of the building to be lit, resulting in a spillage of light onto the street, provides a nice ambient light that engages the street in a welcoming and appropriate manner. Although this method of engaging and activating the street or surrounding site is not possible with all types of heritage architecture due to limitations of structural and material makeup, the idea of allowing the building to radiate onto and activate its environs is a point of consideration. Different approaches and techniques are required for glazed façades that become lanterns, as compared to solid masonry façades that only allow punctured openings. More innovative, effective, and refined strategies for lighting heritage building façades however, can begin to enliven the street at night through the activation and participation of the building in conjunction with the street. Rather than relying on the street to do all of the work, buildings' interiors and façades can play a role in activating the street at night. 


\section{I GAtES: FRAMING + Experiencing the City}

Stepping down in scale from the over-arching "network" view of the city, the next urban devices used to examine the city are nodes or intersections within the urban network. Differing from points or terminations along a path, the urban device of gate seeks to look at thresholds and experiences of the in-between when moving from network to place. These intersections come in various forms including: the intersection of a network and infrastructure (e.g. road and bridge or building), the intersection of two networks, or the intersection of a network with a public space. Additionally, these nodes within the network take on the form of thresholds, frames, and gates, helping to focus on views or destinations at specific locations within the network of the city.

\section{Thresholds Within the City}

\section{A. RideAu CANal System}

As a system that runs throughout a large part of the city, the Rideau Canal plays an important role in linking important parts of the city. Although the Canal as a waterway is not necessarily used as a main means of transportation in a traditional sense, it does get used frequently in the summer for boats, and in the winter for skating. Though these seasonal methods of transportation and use are significant, of equal or greater importance is the role the canal plays as a reference for physical and visual orientation within the city. Although it does not consistently follow clearly defined cardinal points, the Canal remains a physical orientation mechanism that largely defines neighbourhoods by means of which side of the canal they are on. Similar to the River Seine in Paris, the Rideau Canal is more effective at defining a personal "mental map" than it is as acting as an axis for the city. The pedestrian and bike paths as well as parkways that run parallel to the Canal, weave through the fabric of the city and rely on the Canal as a frame of reference for those travelling 


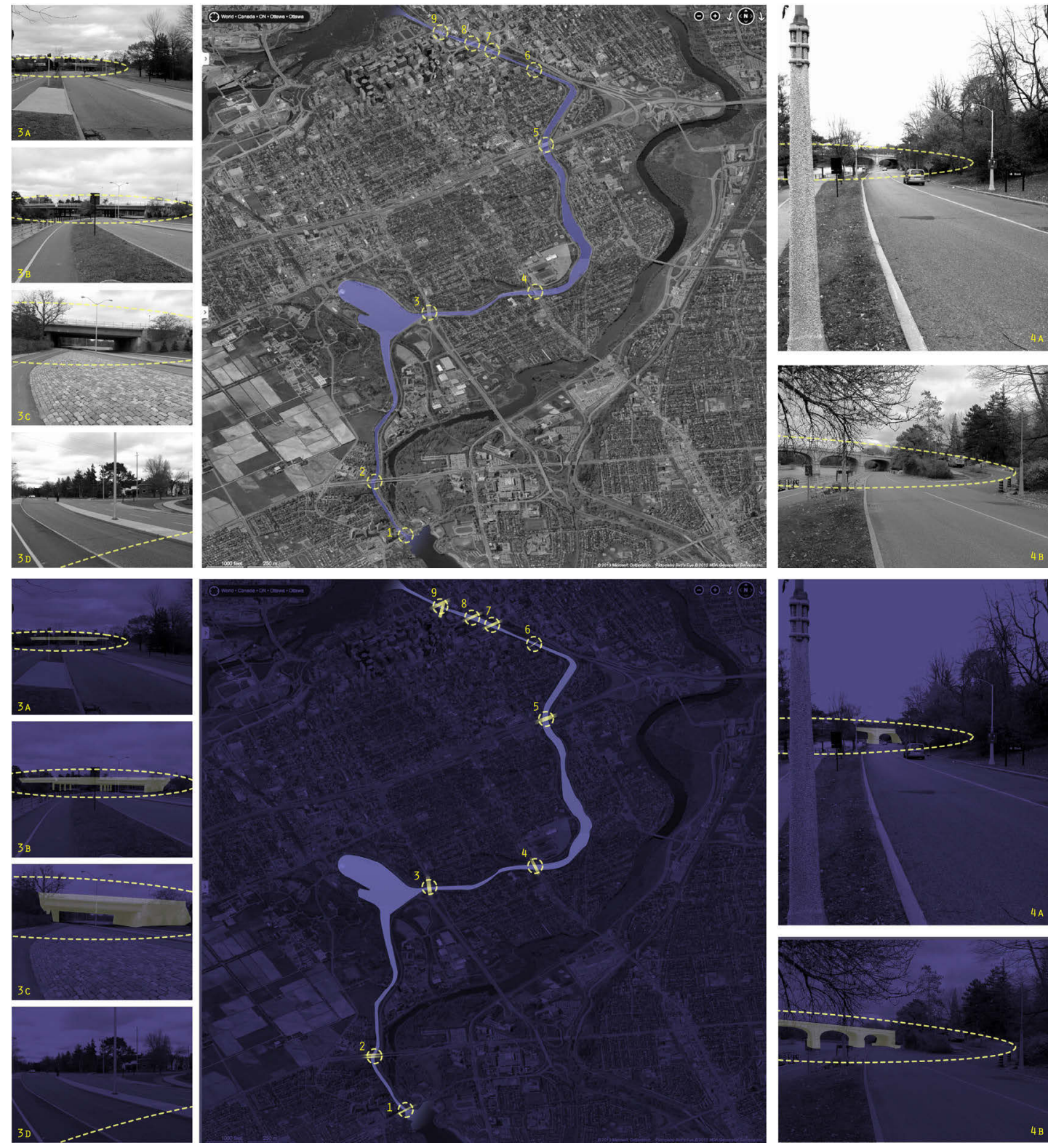

Figure 15: Diurnal and Nocturnal gateways and thresholds along the Ridean Canal through the City of Ottawa along it. Additionally, not only does the

Rideau Canal serve to frame and define neighbourhoods, it frames significant buildings along the way, as well as aspects of the Canadian landscape and indigenous vegetation.

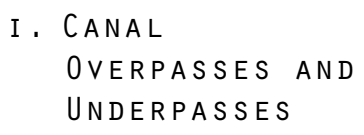

The points at which Colonel $\mathrm{By}$ and Queen Elizabeth Drives intersect main arteries within the city create nodes where bridge overpasses and underpasses occur. These intersections, in the form of bridges, create important gateways through which one passes while moving along the parkways to and from Downtown. Similar to gates that skiers pass as they quickly weave down a mountain, these gateways serve 
as thresholds along express roads where drivers are able to reflect on the beauty of the city as they drive freely and at a good pace along a parkway unhindered by traffic lights or stop signs. As identifiable thresholds along a journey that many take downtown, these overpasses and underpasses have the ability to take on a distinct character that reflects the history of their construction, or the history of the surrounding site or neighbourhood. At night, this character can be enhanced and reinforced through the use of light, to create a type of beacon that not only beckons people towards the gates, but which also emphasize the significance of passing through them on the

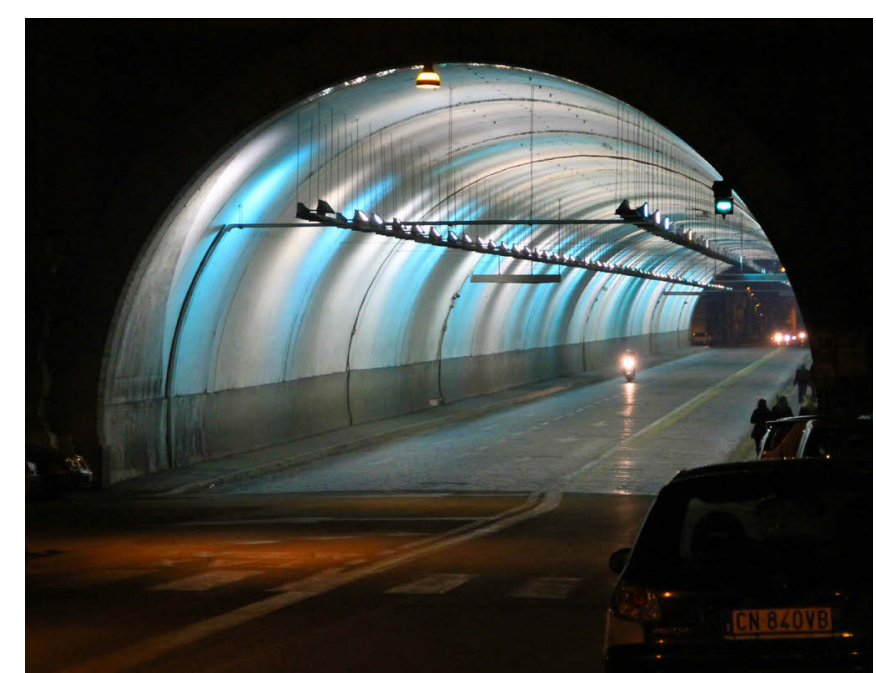

Figure 16: Bridge underpass lit as a "gateway" | Rome, Italy way to a destination.

\section{I i. Intersections: NeighbOURHOOD Beginnings and Ends}

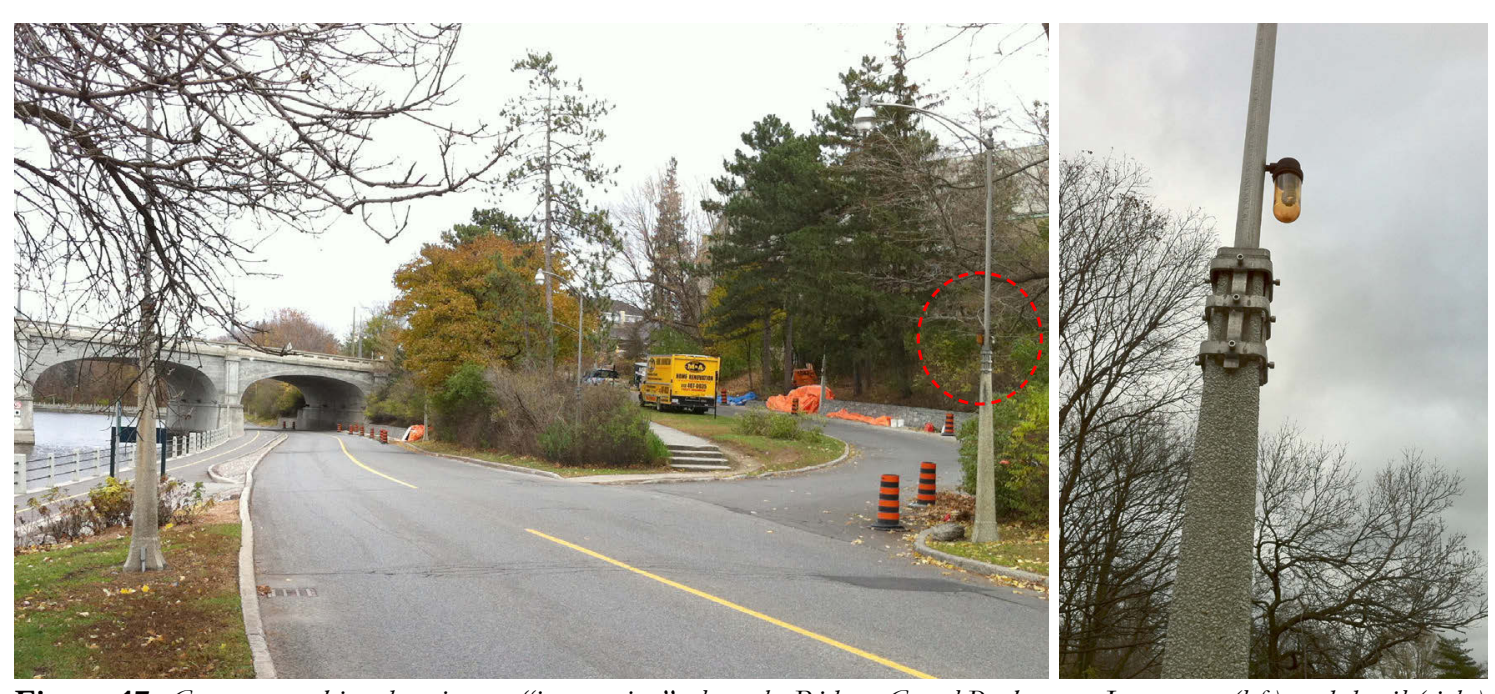

Figure 17: Current marking denoting an "intersection" along the Rideau Canal Parkways. In context (left) and detail (right)
In addition to the gateways created by large arterial intersections, many intersections occur along the Canal parkways, specifically at particular neighbourhoods within the city. Because the Canal weaves through the city on its way downtown, the beginnings, middles and ends of 
neighbourhoods appear, are experienced, and then disappear while moving along this route. Finding a way to emphasize this passingthrough of neighbourhoods by creating gateways when entering into the neighbourhoods or communities would be desirable. The question of a light network along the length of the canal is challenged by very poor lighting conditions that currently exist in many places where intersections occur. The intersection of side streets with the parkways is of particular importance, and it should be noted that during night or darker hours of the day, it is currently very difficult to identify these. This is especially true when travelling quickly along the winding road where the present little orange lights that denote a side street, are not substantial enough to provide an effective notice of intersection. Providing proper indications of side streets and gateways in and out of the communities and neighbourhoods would help to showcase the rich variety of neighbourhoods along the parkway, but also help to strengthen the network as a whole.

Another consideration when analysing the neighbourhoods that intersect the parkways is the duration of the transition that exists between the parkway and the side street. Ideally a hint of the neighbourhoods could be given at the location of this node, providing a slower and more meaningful transition as you experience them. Materials, greenery, and other character-defining elements specific to the neighbourhoods should be introduced at nodes along the parkway, and while transitioning into the neighbourhoods.

\section{B. Montreal nocturnal Streets + Place des armes}

Walking the streets of Montreal at night, especially those within the Quartier des Spectacles, it is interesting to compare streets purposely lit at night with those which remain dark. Additionally, lit building façades can help not only to accentuate specific characteristics about the building itself, but can also create a more pleasant environment around the building and in its outdoor space. A series of façades lit on either of the street, helps to frame a view and enhance the perspectival nature of a space. Whether for identification for 

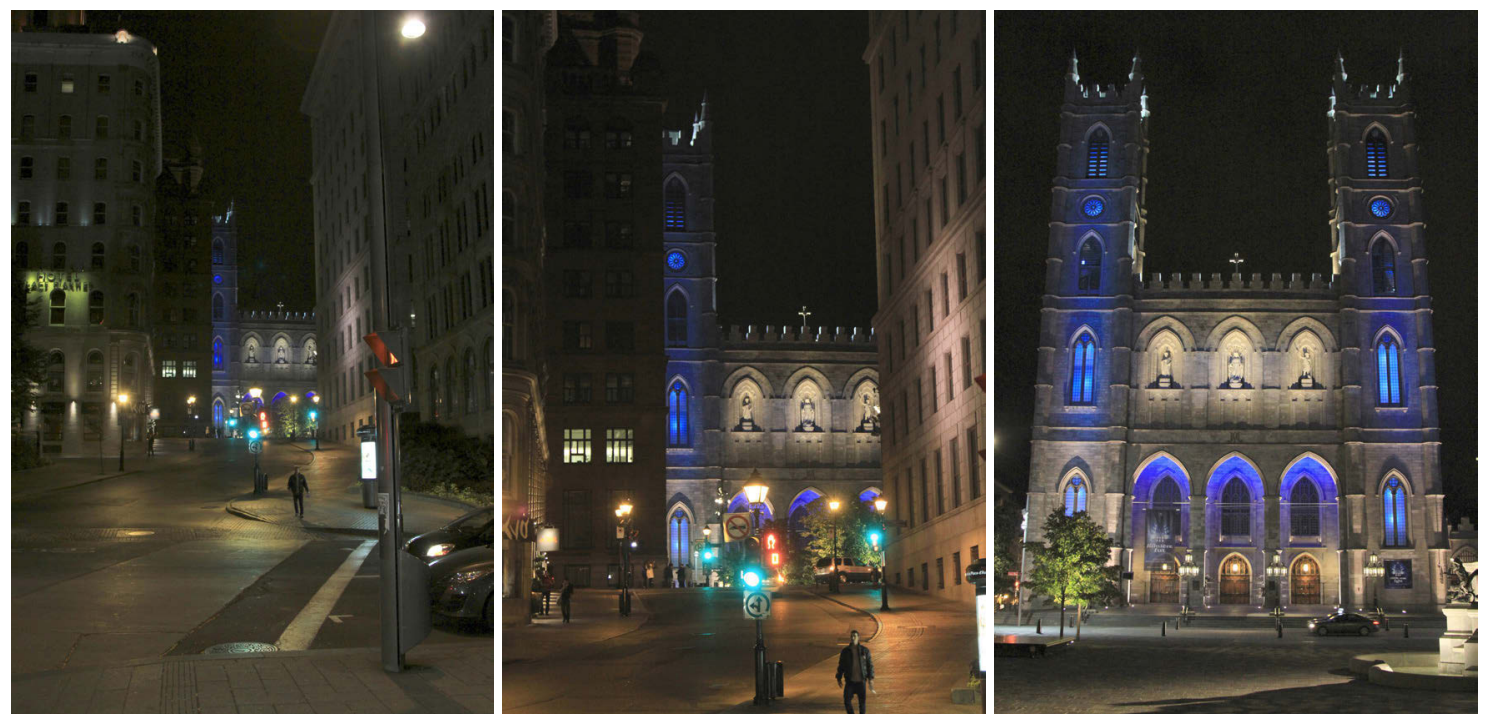

drivers or pedestrians, the view down a street helps to characterize streets, reducing the need for signage. Streets can start to become identifiable within the city, each different, unique, and recognizable.

The use of a lit building at the end of a darker street helps to create a choreography that moves dwellers through the space, drawing them from the darkness towards the light. A case example of this is the approach towards the urban space of Place des Armes in Montreal, and, more specifically, towards Notre-Dame Cathedral. The partially-concealed view of the Cathedral as you move southeast along the bending street of Saint-Urbain towards Place des Armes, piques a sense of interest. One longs for a complete view of the beautifully building in the distance. The desire for the full reveal of the building prompts one to move along the street until the terminus is reached, pulling one through the space of the streets in pursuit of the destination.

\section{Trajectum lumen Project, netherlands}

Similar to the hidden and nocturnal networks of Quartier des Spectacles, and to the discussed potential of gateways along the Rideau Canal, The Netherlands has developed a project entitled “Trajectum Lumen: A Utrecht Tale of Light”. This project, coming alive at night, engages various parts of the city including bridges, tunnels, buildings, and the canal, highlighting them and raising awareness of their nocturnal presence in the city. Trajectum Lumen is described as " an exploration after dark, which follows artistically lit locations 


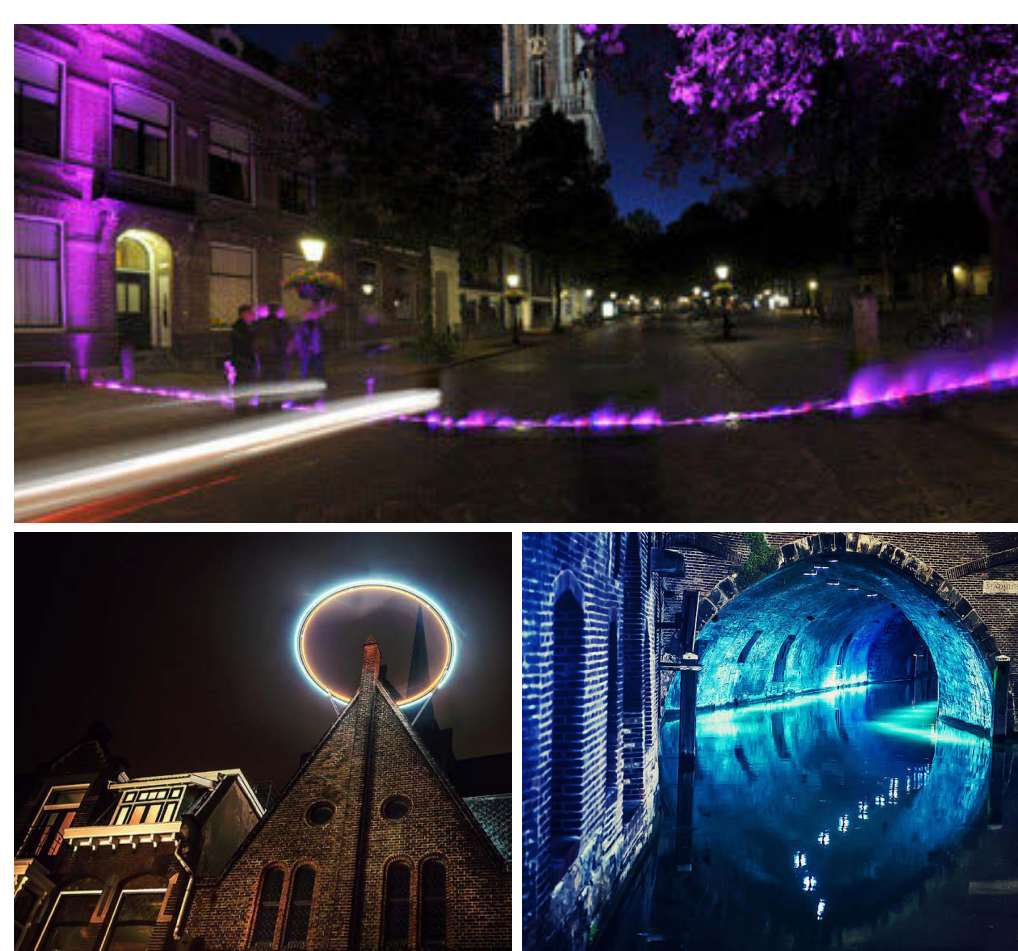

Figure 19: Trajectum Lumen Project | Netherlands (Photos: Trajectum Lumen Website + Fine Art America) throughout Utrecht's historical city centre. When night falls, Trajectum Lumen leads from centrally located Vredenburg past a growing number of installations by (inter)nationally renowned light artists...together, they illuminate this city's past and present in spectacular fashion." ${ }^{\prime 7}$ The intent of this project to raise awareness of both historic (past) and modern (present) parts of the city in their nocturnal states, is a project that could benefit and celebrate Ottawa's combination of historic and modern fabric. Especially for places such as Sparks Street and the Rideau Canal Lockshistorically charged places that may drastically change from day to night-illumination gives an opportunity to tell stories of these places that are specific to their nocturnal vedute, or which would be hard to tell with obstacles present during the daytime (e.g. crowds

of people). Additionally, the changing states and seasons of the city, allow for opportunities for these stories to vary and change with time of year, telling a different story when the canal is in a liquid state, compared to when it is solid, for example.

\section{VIEWS}

In a city, views become elements that tie the macro to micro elements that form the choreography of the city together. The use of a tower as an a mechanism to stimulate physical or visual orientation, the use of a gate to frame a view, and the importance of a

7 “About Trajectum Lumen.” Trajectum Lumen. 2014. 20 Mar. 2014. 
plaza as a termination point, all work together in order to form what makes up a view. Views help to provide a sense of both physical and historical orientation, helping to facilitate moving through the city and to identify landmarks that act as cardinal points for mental maps. Though not all views are crucial to providing physical orientation, sometimes views can take on other roles such as helping to emphasize various buildings, public spaces, or symbolic elements of the city.

\section{A. Piranesi's vedute}

Piranesi's series of vedute (views) of Rome raise

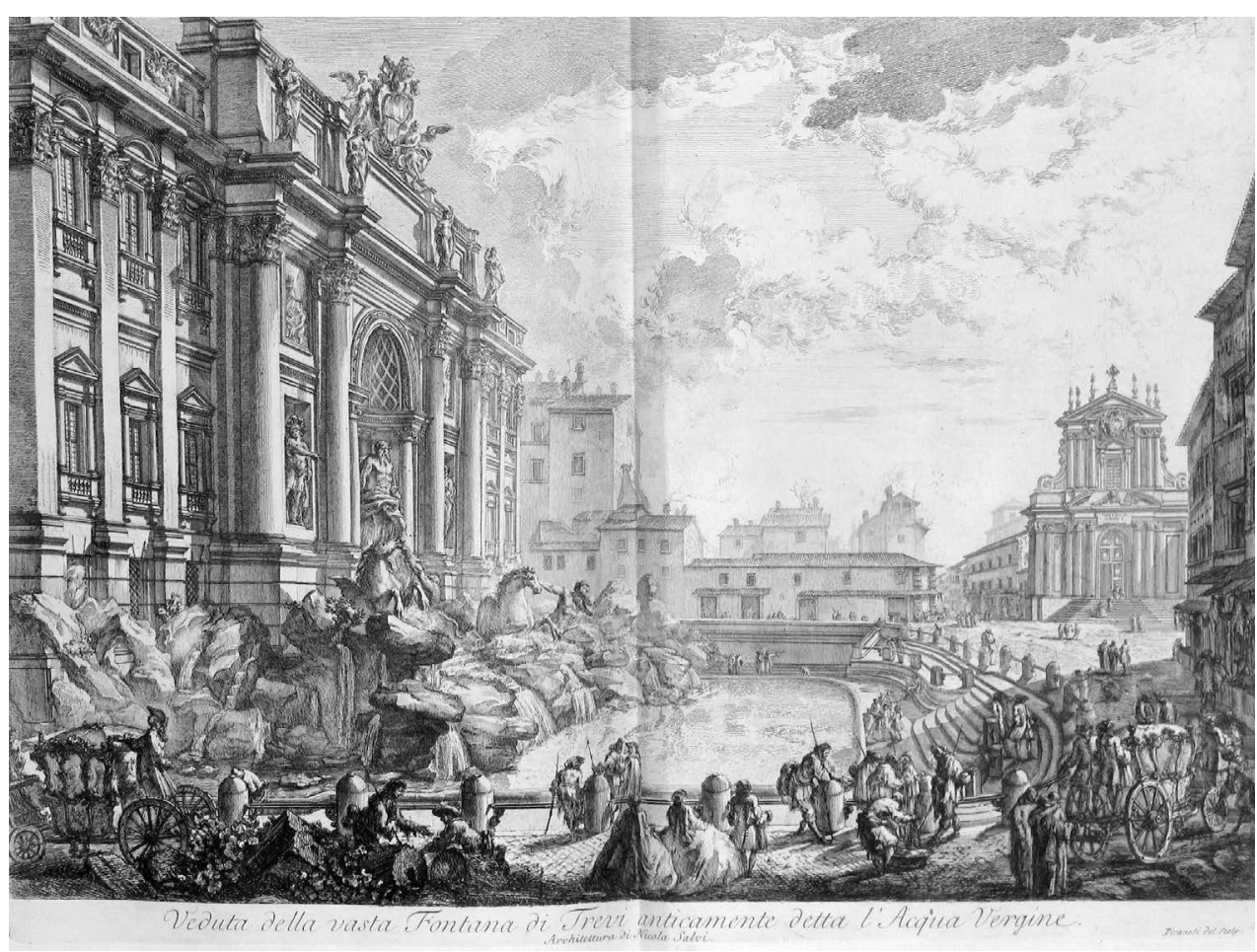

Figure 20: Trevi Fountain Vedute | Piranesi (Source: Wikipedia)

some interesting points that relate to the city and its various scales. Though vedute initially began as factual representations, in "parts of 18th-century Italy, idiosyncratic varieties of the genre evolved. Giovanni Paolo Pannini was the first veduta artist to concentrate on painting ruins. Later, Pannini’s veduta morphed into the scenes partly or completely imaginary, known as capricci and vedute ideate or veduta di fantasia. Giambattista Piranesi was the foremost master of vedute ideate etchings. His topographical series, Vedute di Roma, went through many printings." Not only do vedute show the layering of various scales of the city in terms of foreground, middle ground, and background, they also allude to other layers of the city including the people of the city, and what one could consider different 
times of day of the city. Although many of the views he has represented appear to take place during the daytime, the shadows that often lie in the foreground add layers to the representation that allow for readings of the views on several levels. The darkness of the foreground often depicts the not so well-to-do people of the city, also suggesting a type of underground to the city that lingers or lurks in its shadows. Though not in fact underground, the presence of the shadows in the lower foreground of the etchings gives the effect that the going-ons being depicted could have a clandestine nature to them; whether the events taking place are ones that others pretend not to know about, or whether the events taking place are of a secret nature, there is a clear distinction between the events that are shown in the shadows compared to events depicted in the light. The ambiguity of the events in the darkness of the shadows leaves the composition as a whole open to interpretation, leaving the viewer lingering somewhere between darkness and light.

\section{B. National Capital Commission Viensheds for the Capital}

The National Capital Commission plays a large role in how views have been determined and preserved in the City of Ottawa. Being the Capital of Canada, views towards many historical buildings, monuments, and public places are of importance to understand the
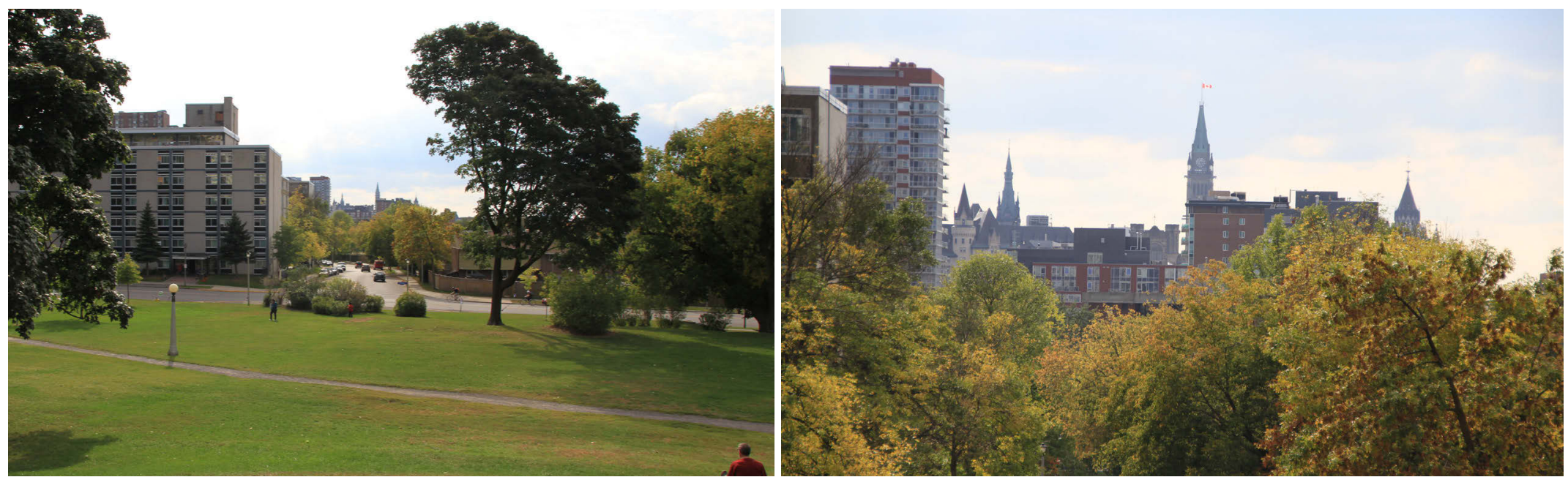

Figure 21: View towards Parliament Hill from MacDonald Gardens Park in Lower Town, Ottawa. Distant (left) and close-up (right) views. 
history of the city as well as to understand how its development has occurred. The primacy of Parliament Hill is evident throughout the downtown core, with the Peace Tower being noticeable from many places downtown and across the city, even from afar. Despite the many viewsheds that have been set out, and that are preserved by the National Capital Commission, it is interesting to think about how, and if, these views are preserved at night. Especially in a city that does not rely on axial relationships for physical and visual orientation and hierarchy of views, layering of buildings becomes especially crucial to be reinforced at night in order to preserve the same presence and composition buildings have during the day.

\section{CITY AXES}

Comparable to views, city axes speak to how a city is organized and is laid out, influencing how one moves through a city and finds their physical orientation. Although axes and resulting views are not one and the same, views can often be seen best along city axes. Whether ordered in the form of a grid, or more organic, growing from various connecting nodes, city plans are legible through their distinct axes and axial relationships. Not only do these axial relationships affect future development in cities, they also allude to historical significance based on the history of the city's growth.

\section{A. PARIS ( LOUVRE-TRIOMPHE-DÉFENSE)}

Trajectum Lumen's ability to describe the history of the city nocturnally through light is interesting to note in terms of how the history and story of a city can be brought alive. A nocturnal setting allows for a blank canvas from the more permanent one of the day, allowing important_and sometimes unimportant—buildings to appear on the night's dark backdrop. The history of a city, however, can also be told through its various layers of history. Paris is unique in that the story of the city can be read through its Grande Axe that stretches from the historical centre of the city to its outer modern layers. Almost becoming rings of a tree that tell the 


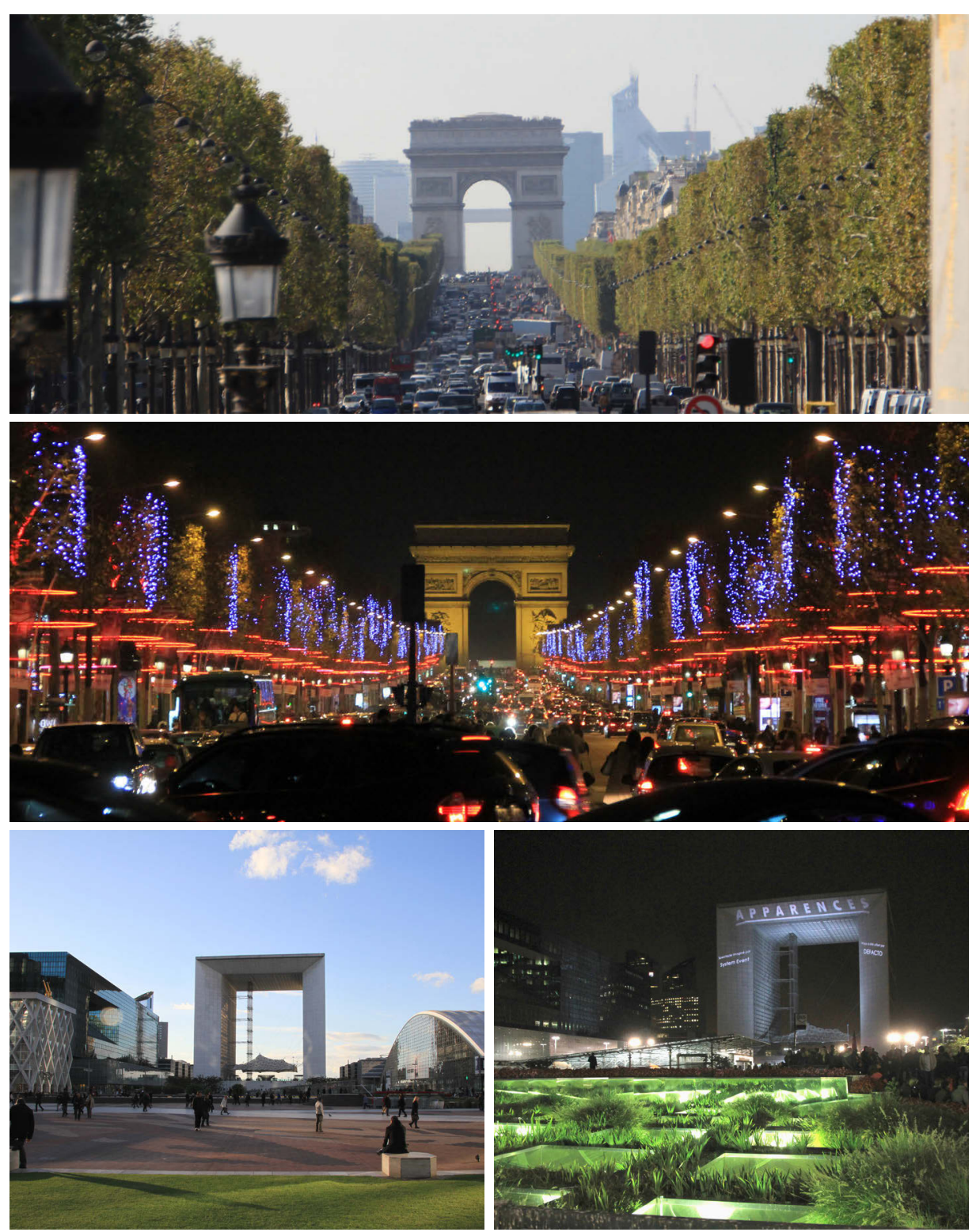

Figure 22: Diurnal and Nocturnal views along the Grande Axe de Paris showing changing states, and views through "bistorical gateways" history of its growth, the Grande Axe of Paris pierces through the rings and spiralling arrondissements of the city, getting a historical cross-sectional sample of the city from its inner historical core to its outer modern outskirts. Starting at the historical Palais du Louvre in the centre, and moving outwards to the Grande Arche de la Defense, the large axis of the city acts as a timeline and gauge, depicting the history of the city along the way. At various key points along the Grande Axe, it intersects with several nodes of the city that stem other axes, including the massive roundabout at the $A r c d u$ Triomphe which seems to be the point of convergence of endless roads.

\section{B. OTTAWA}

Differing from axially planned capital cities such as Paris, or Washington D.C., Ottawa as a city can be looked at as a city that celebrates the beauty of asymmetry. Ottawa's urban asymmetries are evident 
not only in how the city is laid out in important parts of downtown, but also in how its buildings are layered, overlapped, and intersected from different viewpoints around the city. Ottawa's non-symmetrical plan is especially apparent on Parliament Hill, where buildings are viewed obliquely from all different sides as pavilions in the round. ${ }^{9}$ Rather than having a primary façade that borders and addresses an axis, all façades of the buildings become their own unique façades, meant to be viewed from various points along Confederation Boulevard_-views towards Parliament Hill from Wellington Street, the Rideau Canal, the Ottawa River, and the Portage Bridge all have their own composition, and are all important in their own respects.

Confederation Square as an important anchor, node, and roundabout in the city and within the route of Confederation Boulevard, bears an importance in how it relates to the city. As a triangular plaza, Confederation Square fits into the asymmetrical nature of the planning of its surroundings, and defies the notion of axial relationships through its triangular form—rather than a rectilinear form such as a square or rectangle which allows parallel lines to be drawn through its points, a triangle does not allow for this, and forces the perception of hierarchy and layering through its triangulation.

\section{Framing the City from Underground/Below}

Experiencing the city from above ground is the route best known by most people. Convenience and speed achieved by moving through the city underground, however, allows for an efficient flow of traffic. Conversely, physical orientation and framing the city often become a problem in the eternally-nocturnal realm of the underground. At the subterranean level of the city, framing the city and its important landmarks above becomes difficult, causing a sense of confusion and visual and physical disorientation. Cities such as Paris and Toronto deal with translating and relating the aboveground to the underground in different ways, with interesting results.

9 Government of Canada. Building on a Solid Foundation: A New Approach to Implementing the Long Term Vision \& Plan. Ottawa: Government of Canada - Parliamentary Precinct, 2007. 24. Print. 
A. Paris (louvre Metro Stop + La défense)

Due to an elaborate and highly developed subway system, a vast array of underground spaces developed beneath Paris, in the form of subway (Metro) stop stations. Several places within the city demonstrate how the city above ground can be translated to the underground through referencing neighbourhoods, landmarks, or through having a distinct sense of place.

The metro station Palais Royal-Musée du Louvre, and the underground Carousel du Louvre shopping centre that is connected to the station, demonstrate how referencing elements of the building or site help to give a sense of visual and physical orientation to people underground. In this case, it is not necessarily important to clearly indicate what direction one is pointing, but simply to acknowledge and reference what exists above ground in order to understand one's location in the city. In the case of the Musée du Louvre, the glass Pyramide du Louvre acts as the entry portal to the museum, and is the part of the building that is referenced and recognized by the public rather than the historical palace itself. Through arches and gateways above ground, the glass pyramid is viewed and referenced, helping to orient one on the site and direct them towards the building without needing a full glimpse of the pyramid to achieve this result. In some cases, only a small portion of the pyramid is enough to orient a visitor. Similarly, but inversely, the form of the pyramid acts as an object that references the site at the location of an underground node within the underground plaza of the Carousel du Louvre shopping centre. The Pyramide Inverséés inversion and reference to the site doesn't directly orient one while underground in terms of a specific direction, but rather reminds them of where they are while acknowledging that they are not in the same place as above ground. A reminder of where one is in an underground space, while not necessarily providing a specific direction, can sometimes be enough to orient a person.

It is not always a case of being underground that causes a feeling of lack of visual or physical orientation. At La Défense, Paris' central 


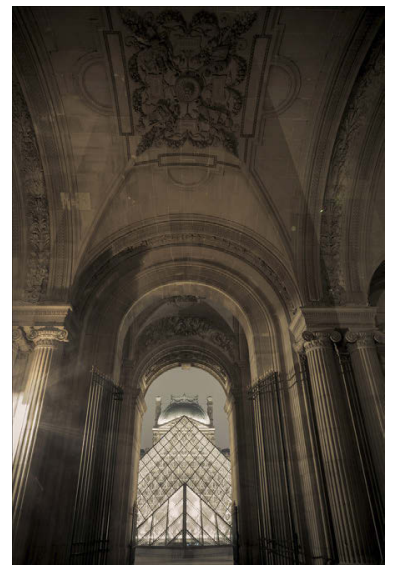

FRAMED
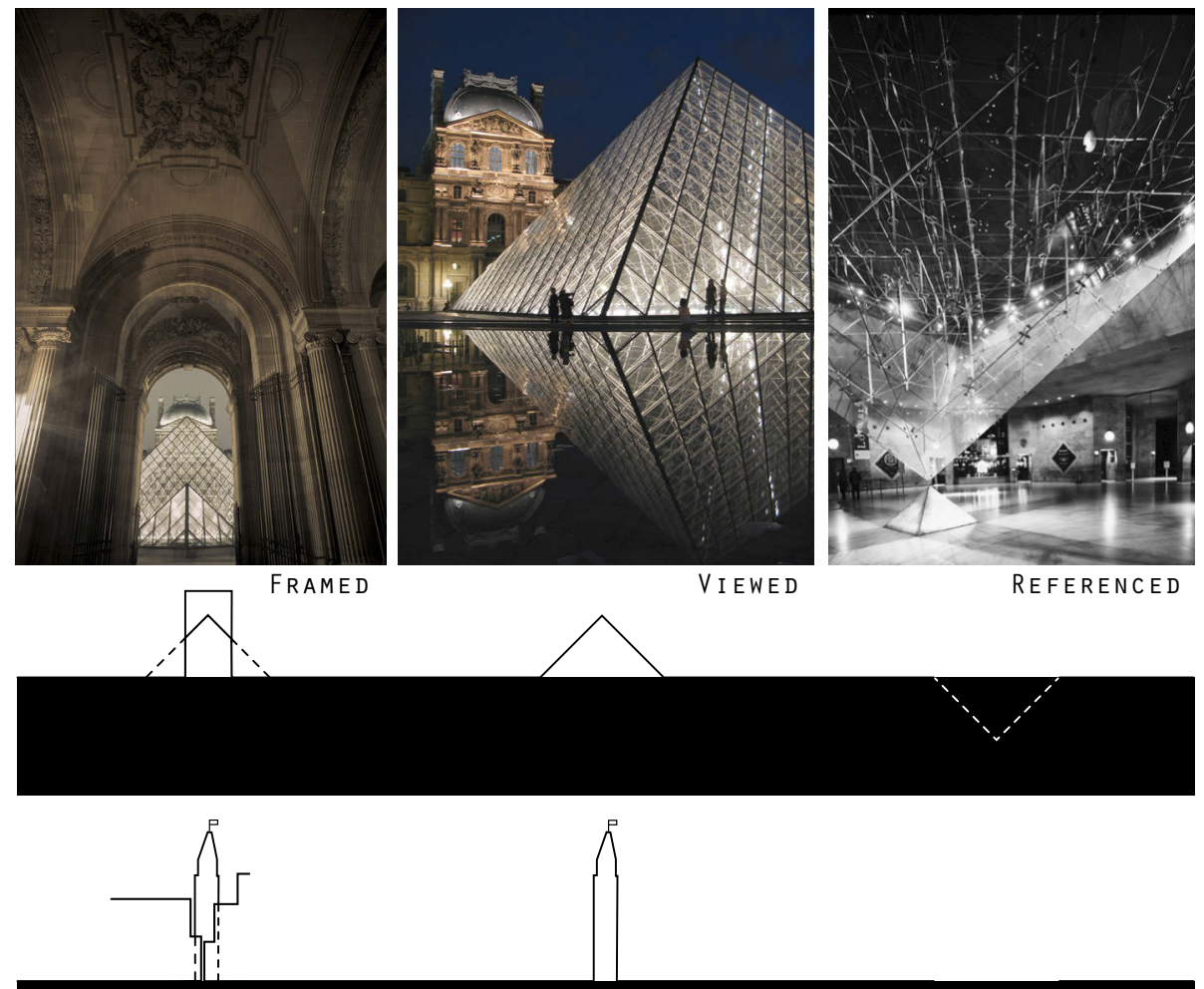

VIEWED

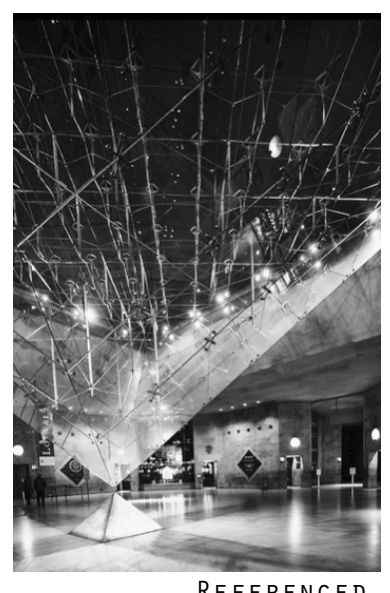

REFERENCED
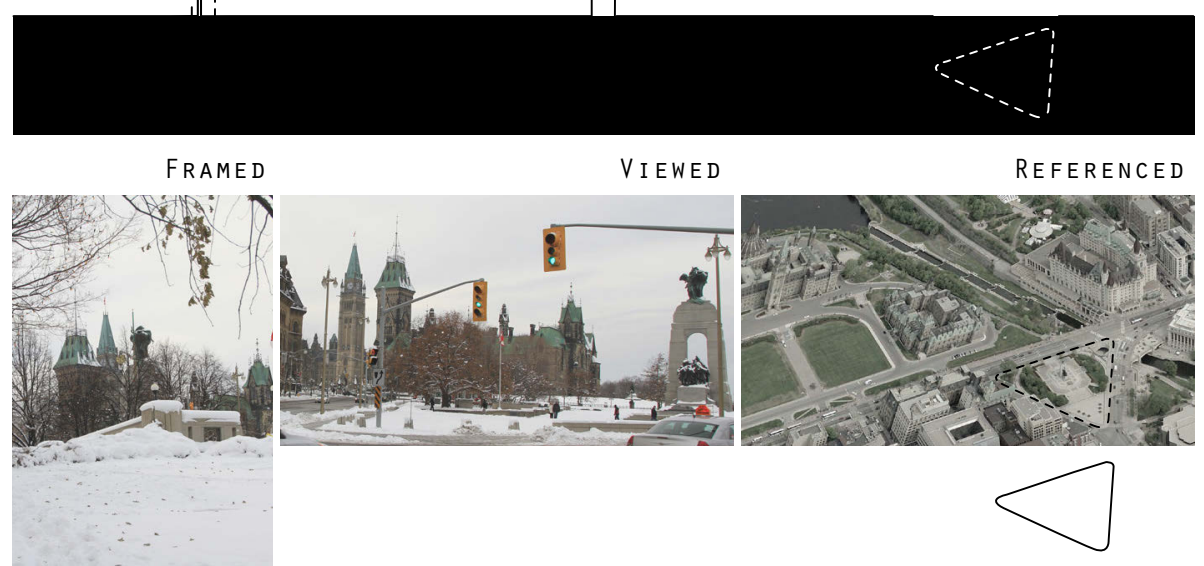

Figure 23: Framing, viewing and referencing the city and its underground | Palais du Louvre, Paris + Confederation Square, Ottawa (Some photos: Flickr + Google Maps) business district, the enormous slab that the site sits on covers the majority of what is actual ground level in relation to the rest of the city. This over-ground under the slab that appears to be underground, is a dark space that lacks elements that would normally help to identify sense of place at an above ground level. A simple, but noticeable element that is present along a large part of the Grande Axe is the presence of trees on the boulevard. Though this notion has been carried from the centre of the city out past its periphery to the slab of La Défense, the topographical location of the trees in terms of their elevation gives a false reading of what is underground, what is over-ground, and what is the actual ground. Though it seems appropriate to have the trees at what appears to be ground level— the level which is in fact the slab-the simple notion of lowering them to true street level would help to give a true reading of the site, and a sectional sense of physical orientation on and within the slab. 
B. TORONTO (PATH NETWORK)

Although Toronto's arguably undersized subway system cannot compare to that of Paris, its underground network, particularly in downtown, has developed in a surprising way. Similar to emerging networks discussed earlier in the thesis, the PATH Network is one that has emerged over time in the underground of the downtown core. Although there is no overseeing body that manages the subterranean PATH network, most buildings seem to be aware of their underground presence, and have allowed for a connection, albeit sometimes confusing, to be made between buildings and into the PATH network. In fact, it is possible to move from Toronto's main transit hub, Union Station, all the way North to a major commercial centre, the Toronto Eaton Centre, through the underground network. Although it is about a twenty-minute journey underground, which can be a little confusing if unfamiliar with the city, the convenience the PATH offers for use during inclement weather is of great value. Although one may argue that the most efficient way of getting from point A to point B underground would be through a subterranean "as the crow flies" path, a reflection of the city that is rooted and translated down to its foundations could perhaps be the most efficient way to orient people who are used to travelling above ground. Similar to the design of the complex Paris sewer system, the simplicity of translating the street system from above-ground to below brings the volumes of the city to the subterranean level. Bringing not only the volumes of buildings to the underground, but also characteristics of the buildings such as material palettes and structure, help to facilitate familiarity and physical orientation below grade within the PATH system in the form of referencing.

\section{Ottawa (The Mysterious Underground Connections)}

Similar to what has happened in the core of downtown Toronto, downtown Ottawa begs for an underground network to be developed in its core areas. Ottawa would benefit from an underground plan in order to allow existing underground circuits that linger, waiting to be connected, to be joined together. The existing underground areas that surround Confederation Square, whether exterior 

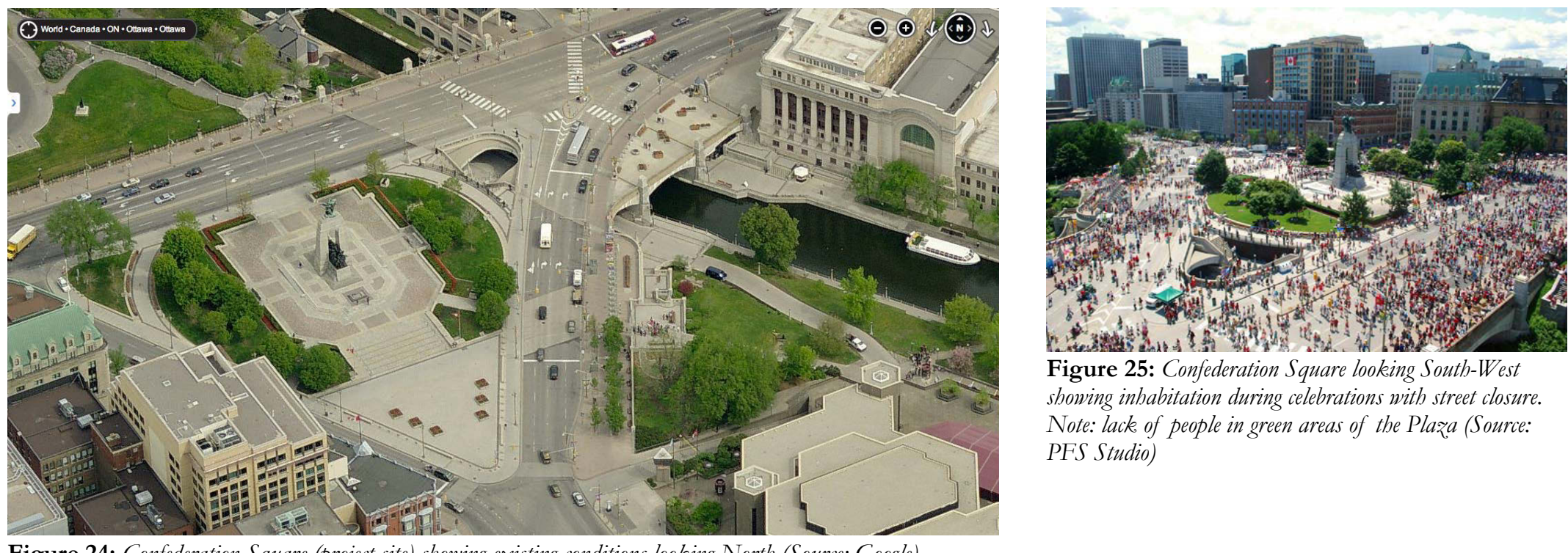

Figure 25: Confederation Square looking South-West showing inhabitation during celebrations with street closure. Note: lack of people in green areas of the Plaza (Source: PFS Studio)

Figure 24: Confederation Square (project site) showing existing conditions looking North (Source: Google)

public spaces such as the tunnel which the Rideau Canal passes through, or the underground levels of buildings, are in need of being connected - the underground of Confederation Square is the ideal node to receive and join them. Existing underground circuits such as the underground parking garage of the National Arts Centre, the promenade along the West side of Chateau Laurier from the former Museum of Contemporary Photography, the underground spaces of Chateau Laurier, and the once existing transit spaces of the Government Conference Centre (former Union Station) all lie dormant awaiting to be utilized and connected. Additionally, future underground spaces such as potential underground connections from Parliament Hill and Sparks Street, would plug nicely into the circuit of Confederation Square. The many instances of underground and over-ground around Confederation Square, in conjunction with the change in elevation and dramatic shifts in landscape around the escarpment of Parliament Hill and the Rideau Locks, allow for an intermingling landscape and urban setting to tie together existing underground spaces which frame and reference the city. 


\section{I PlazAS: ORIENTATION + ACTIVATING THE CITY}

\section{Confederation Square as “War Memorial triangular Plaza"}

\section{A. The Site as a neutral Zone in the City}

This section of the thesis seeks to look at the last urban device used to analyze the city: the plaza. Confederation Square is a zone that is unique in its neutrality in comparison to the rest of the city: as a site, the triangular plaza is the beginning or termination of many

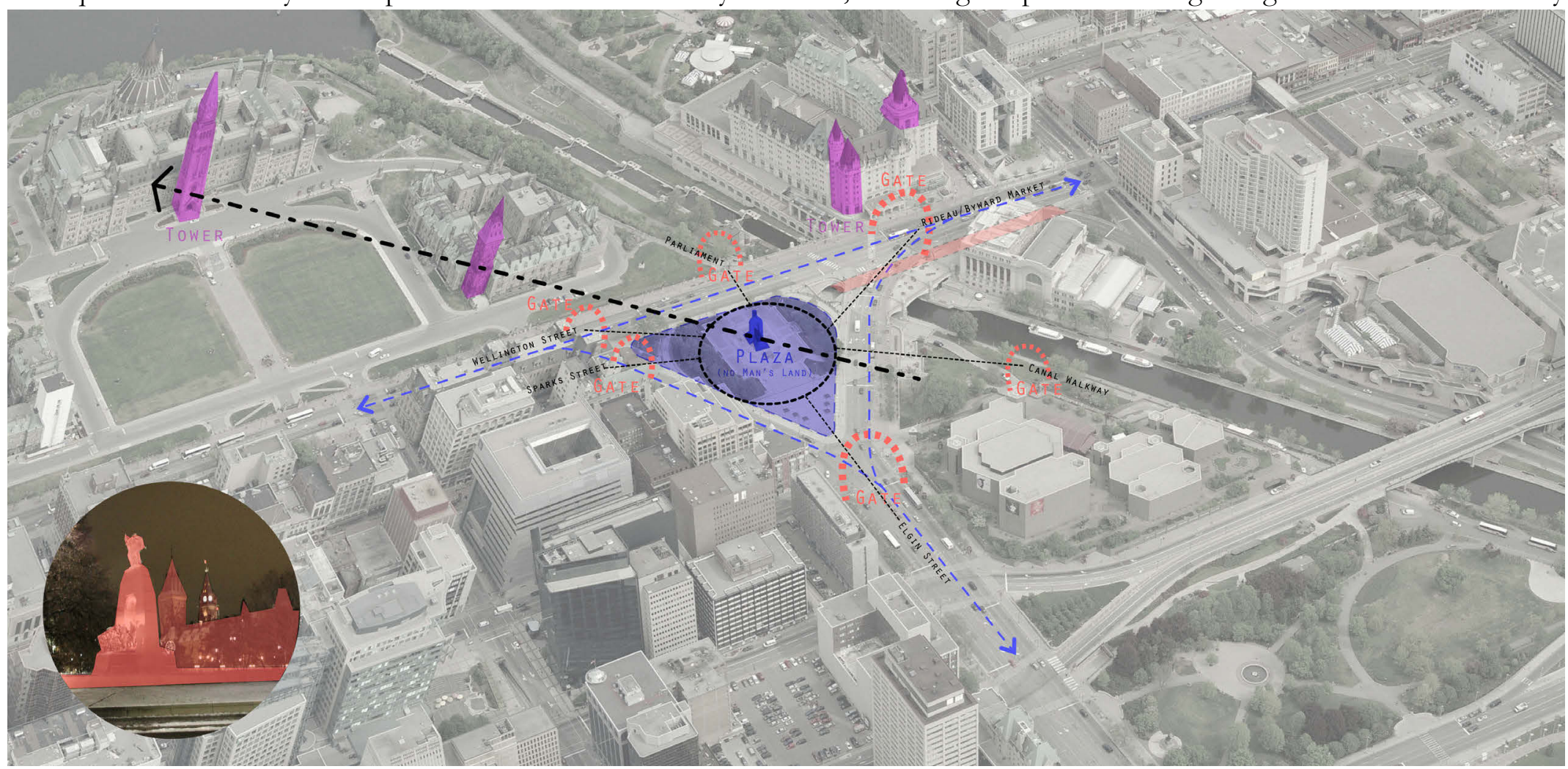

Figure 26: Confederation Square (site of project) showing the site as a compass and gateways stemming from it into the city 


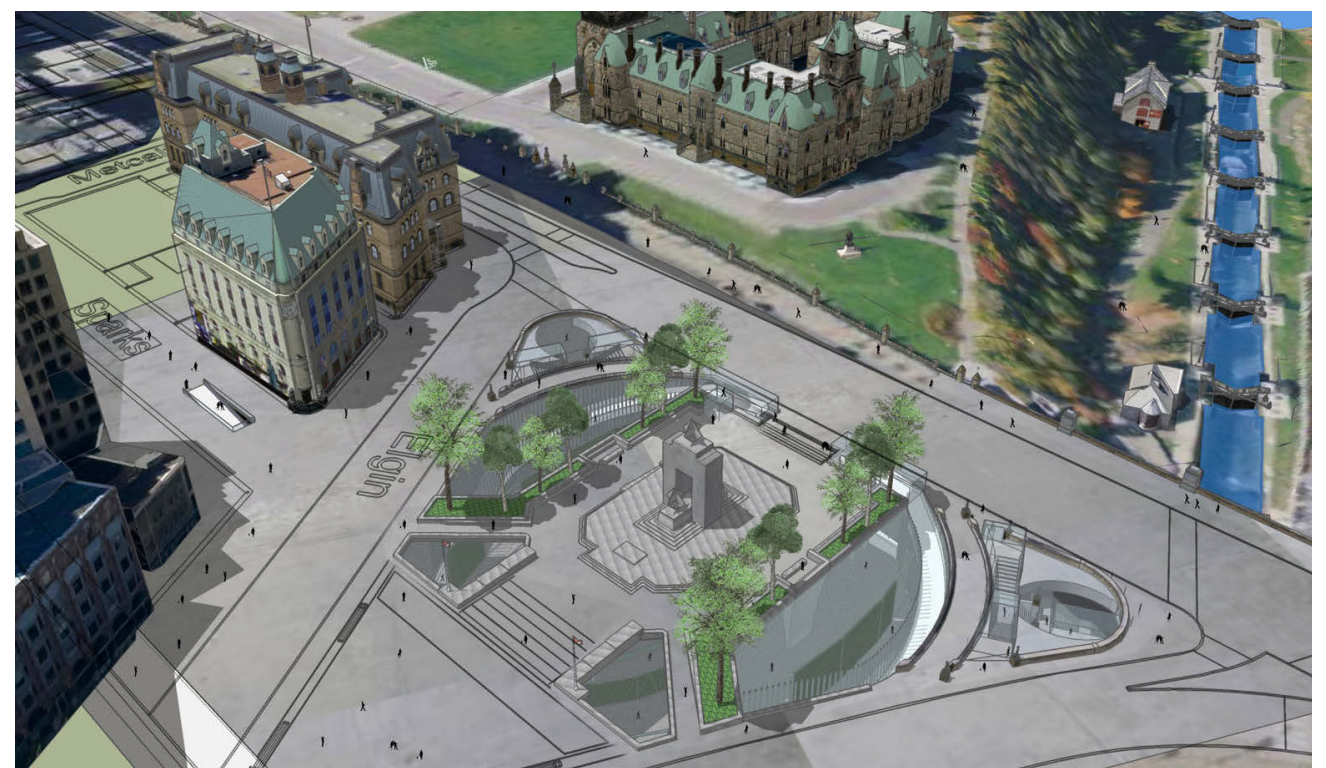

Figure 27: Diurnal view of project site showing proposed project in context

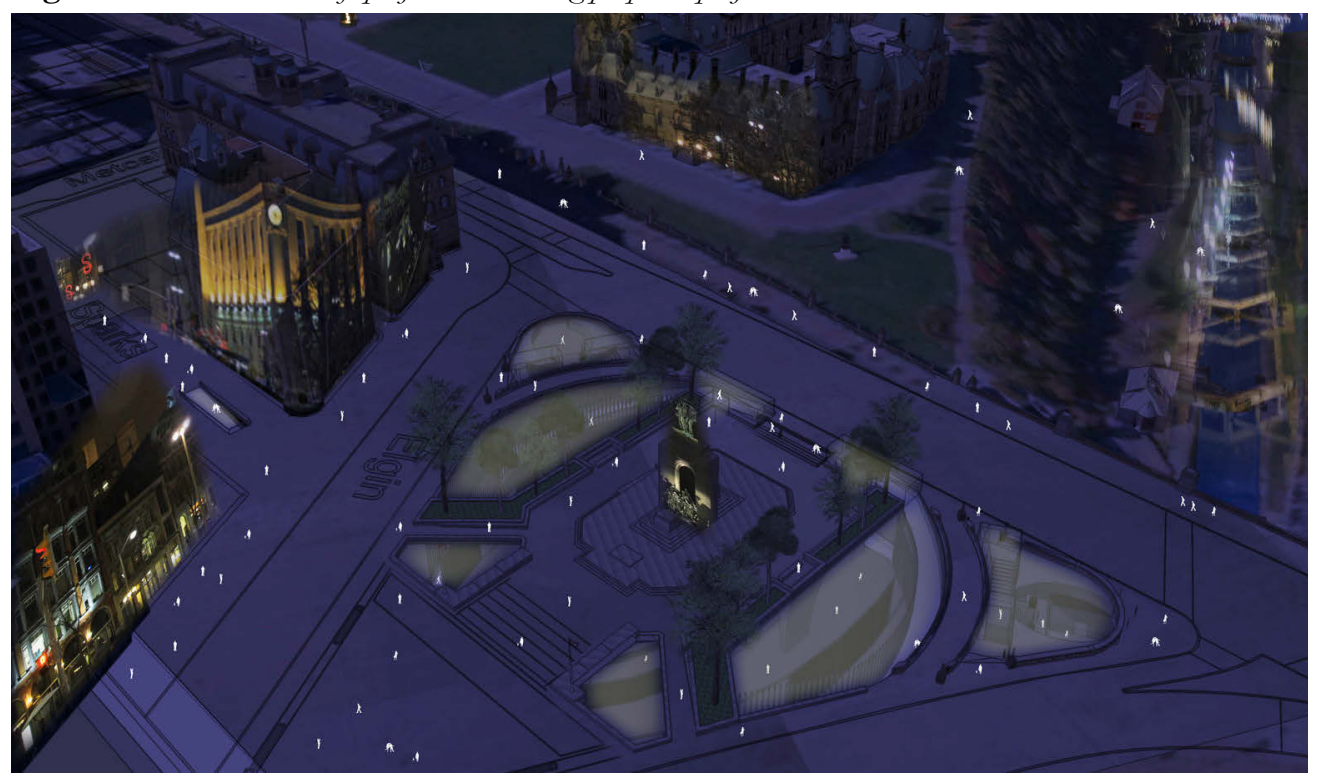

Figure 28: Nocturnal view of project site showing proposed project in context neighbourhoods, and is a zone that addresses its surroundings but that doesn't distinctly belong to any one in particular. Similarly, it is an important node within the city and within the loop of Confederation Boulevard, and does not define itself as being a building, landscape, or public space that borders any one road in particular. Instead, it is an island that bridges the gap between several zones that it reaches out to and connects. It is bordered by Wellington Street to the North, and Elgin Street to the South East and South West edges, as a split street that wraps the plaza. As a more metaphorical space, the plaza is a place of peace and tranquility among busy traffic, symbolically relating to the War Memorial and Tomb of the Unknown Soldier as peacekeeping monuments. 
B. The Site as a Compass to Provide Physical orientation

As an open site with only the War Memorial as a tall object on the plaza itself, the site benefits from being a landmark and from being clearly visible. The War Memorial is the termination of many viewpoints directed towards it, as well as being an ideal location from which to observe the city outwardly. Because of this, the site is an anchor for the city as a capital, and is an ideal location for the compass of the city. From the plaza, one is also able to clearly identify one of several destinations by noting that multiple gateways stem off the plaza, namely: Wellington Street, Parliament Hill, Sparks Street, Elgin Street, The National Arts Centre, The Rideau Canal and Locks, as well as the Rideau Centre and Byward Market. As a location that reaches out towards all of these locations, this site is an ideal place to emerge from darkness, provide physical orientation, and allow one to identify and choose their desired direction, path, and destination.

\section{Confederation Square as a Canadian “arc de Triomphe” Roundabout}

The Arc de Triomphe in Paris is not only a major landmark, but also an area of convergence of many different important streets of the city. Although not quite as busy, Confederation Square can also be described in terms of an important landmark and monument that lies on an island surrounded by busy traffic on all sides. In order to reach the Arc de Triomphe, one must descend a staircase which lies on the outside of the areas of traffic, directing pedestrian traffic under the street in order to easily reach the island that is the centre of the roundabout. Ease of access is an important consideration to take

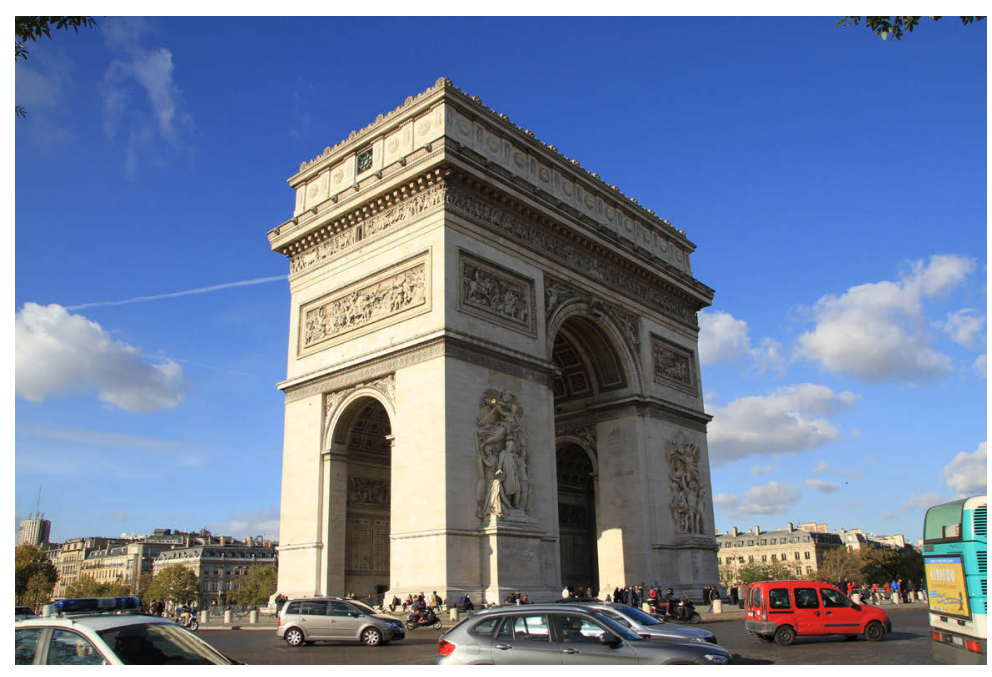

Figure 29: Arc de Triomphe and its plaza | Paris 
into account for accessing the plaza of Confederation Square, and in order to connect all the above and below grade circuits that exist around the site in a cohesive and efficient way. By employing select parts of the plaza—namely areas of greenery-that are not efficiently used or often inhabited, a connection to below can be achieved by cutting voids in the site of Confederation Square. These voids will allow for sunlight to penetrate to the station below, as well as for subtle light to emerge at night creating a soft glow and beacon. By removing select parts of the greenery of the plaza, while equally retaining a sufficient amount, an un-intrusive station can be proposed below the Square, while retaining the historic value of the site.

\section{Journeys to Confederation Square Station and Below: Imagining an ARCHITECTURAL PROPOSITION FOR A NATIONAL LRT STATION}

\section{A. Journey Underground Along the lRt Confederation line to Confederation Square Station}

As the LRT car travels along the underground network, from one stop to the next, people sit in angst wondering where they are on the subterranean transit network. Passing through thresholds from darkness to artificial light, and then back into darkness again, imaginings of the visual and lit outside world lingers in passengers' minds as light flashes occasionally, and quickly fades. How can they orient their mental maps, and get the bearings for their underground compasses in order to be pointed in the right direction after getting off the train that moves in darkness? As the train approaches the stations in the downtown core, passengers anticipate sights of Ottawa's national buildings and scenery, causing them to wish for an experience of these vistas from their subterranean location. Above ground, these places, buildings, and monuments help to physically and historically orient them, and place them in the city. They help to provide grounding, acting as a frame of reference, framework, and compass for movement throughout the city. As the train pulls into Confederation Square Station, something suddenly feels different—and that it should. Confederation Square Station is the prime downtown station along the LRT line, and is the National LRT station both for Ottawa as a city and for the city 


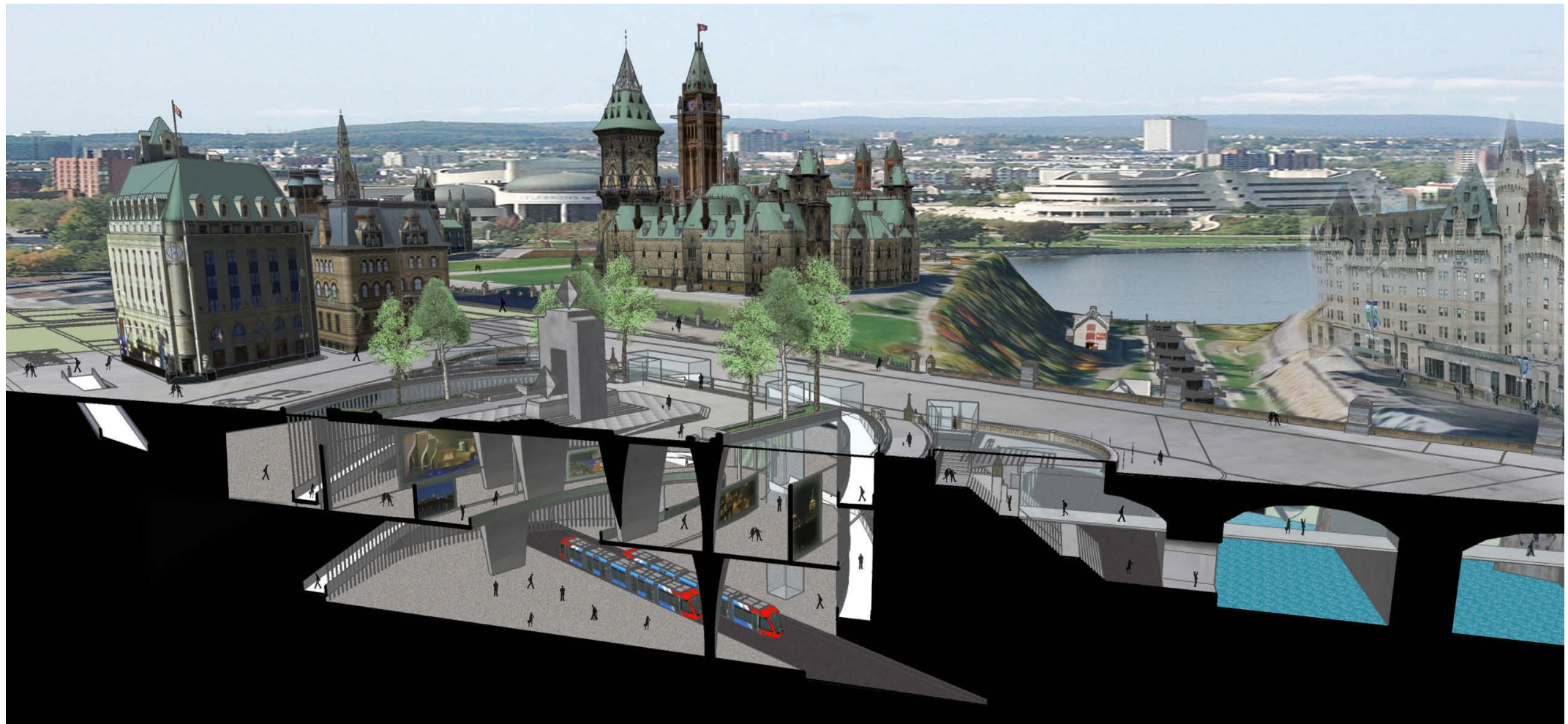

Figure 30: Section through site looking North with proposed project; diurnal view

as the capital of Canada. Situated below Confederation Square, it is the national anchor for the Capital and within the national route

of Confederation Boulevard. The experience of daylight in the subterranean station is a welcome surprise-the naturally-lit space belies its location, far underground.

\section{B. Approaching the Station at dusk from ground level}

As dusk falls, and people start to make their way home from work and downtown, the city starts to transform from its diurnal state, shifting to reveal its nocturnal state. Confederation Boulevard starts to collect traffic from all parts of downtown as people make 
their way towards Confederation Square and approach the triangular island on which the War Memorial sits, carved out amidst the surrounding streets. Around this area several important buildings and monuments are lit up at night, including the Cenotaph and Tomb of the Unknown Soldier (by Martin Conboy Lighting Design - MCLD) both which lie within the plaza of Confederation Square. An additional subtle glow, however, now emerges from trenches that surround the cenotaph, highlighting and strengthening the triangular geometry of Confederation Square. As cars zoom past on all three sides, the centrally located, but neutral, landscape of the island of the Cenotaph reaches out to address all directions, but neither touches, nor belongs to any of them. Something hidden is being revealed-a history; ruins below; a hidden story. Moving closer to the glow that is coming from below, people look down into the void

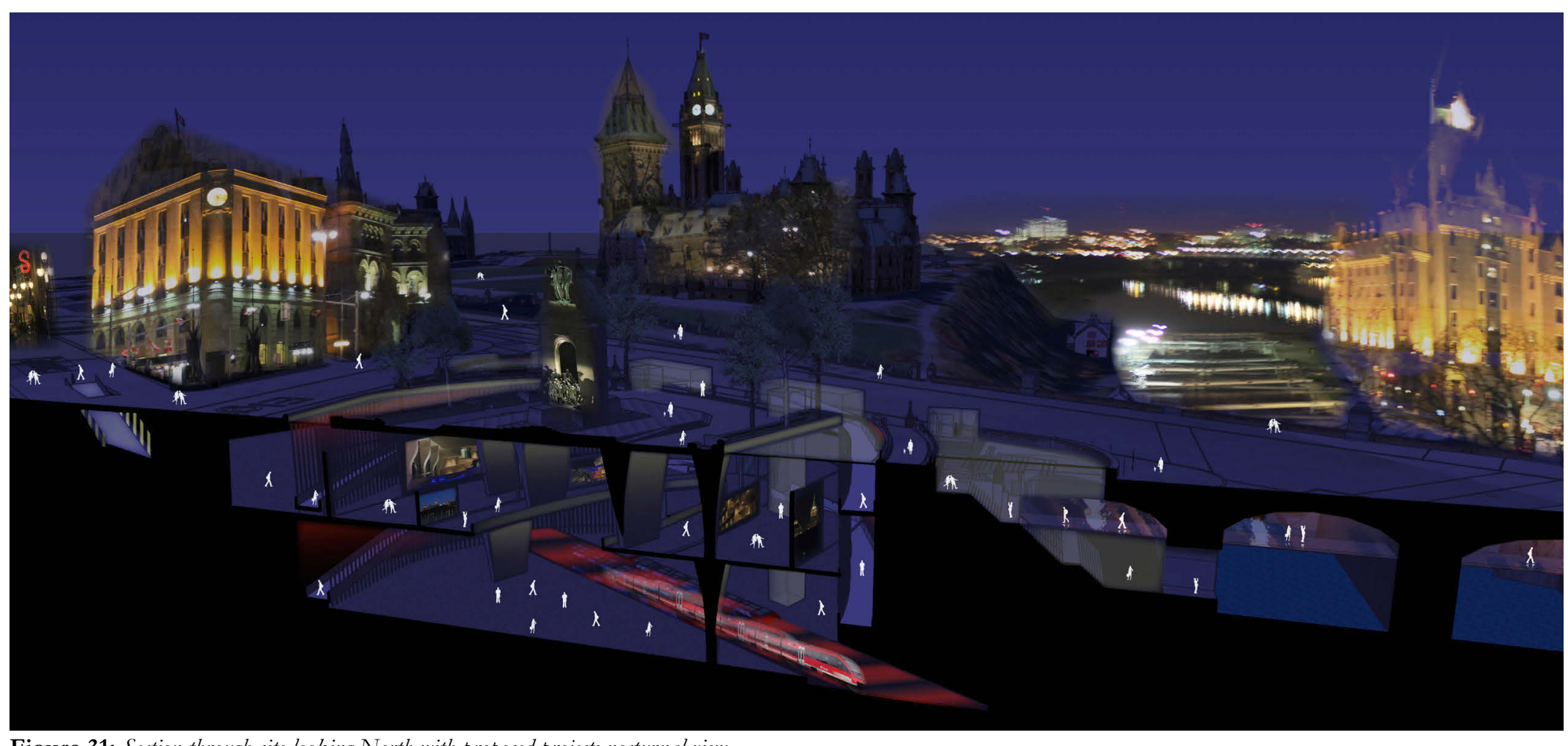

Figure 31: Section through site looking North with proposed project; nocturnal view 
peering down into the trenches from which have emerged the statues that inhabit the War Memorial. People in silhouette can be seen, standing on the bridges that cross the voids, talking to each other, reflecting on the day, or gazing down into the space below. This activity and joyfulness is a stark contrast to the seriousness of the statues that occupy the plaza, both around the stairs and nestled on or around the arch of the War Memorial. Approaching the glass beacons which announce the entries to the station, one can see that they delicately and unobtrusively enclose both new and existing areas of vertical circulation with people being welcomed in French, English and Native languages through frosted panels inset within

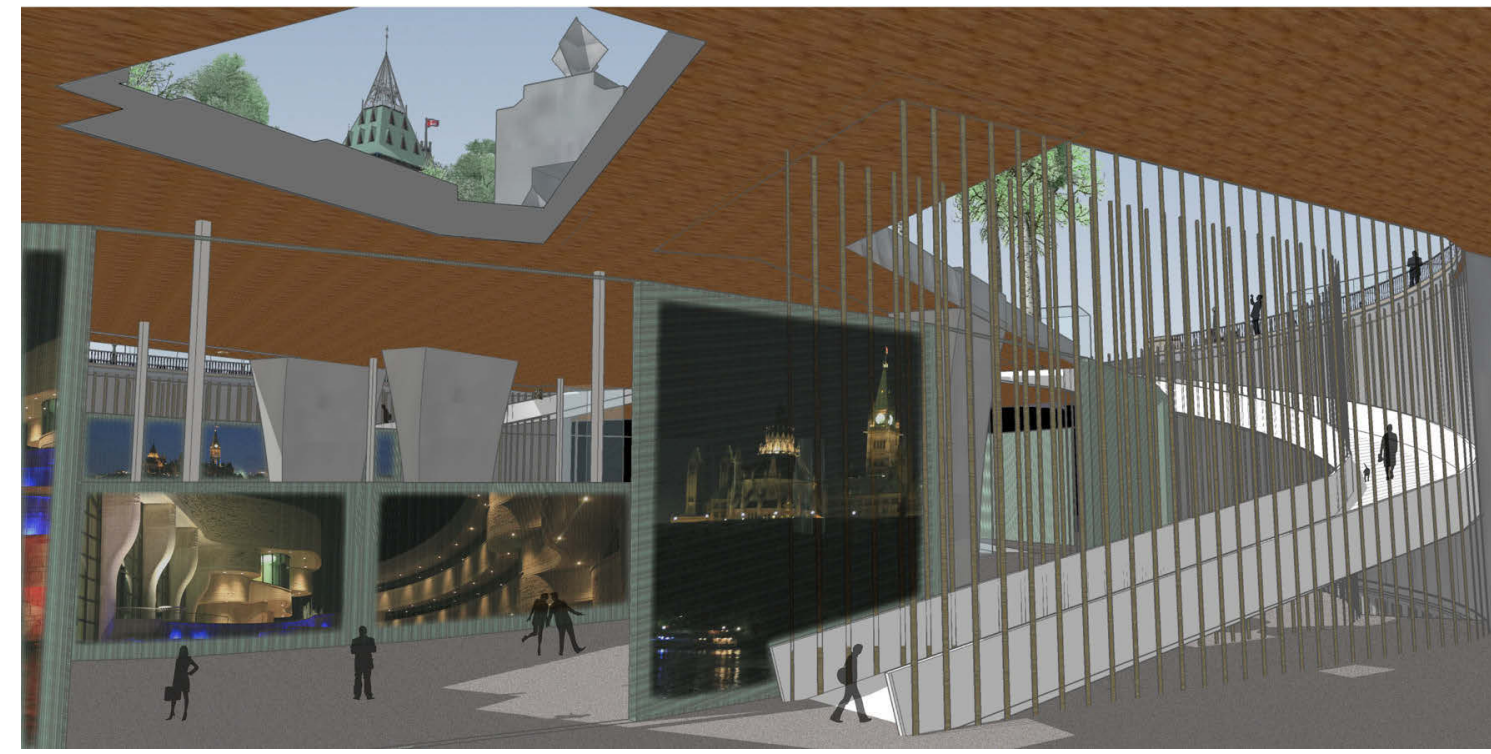

Figure 32: Diurnal view from Gallery Level showing relationship between city, daylight, and display screens

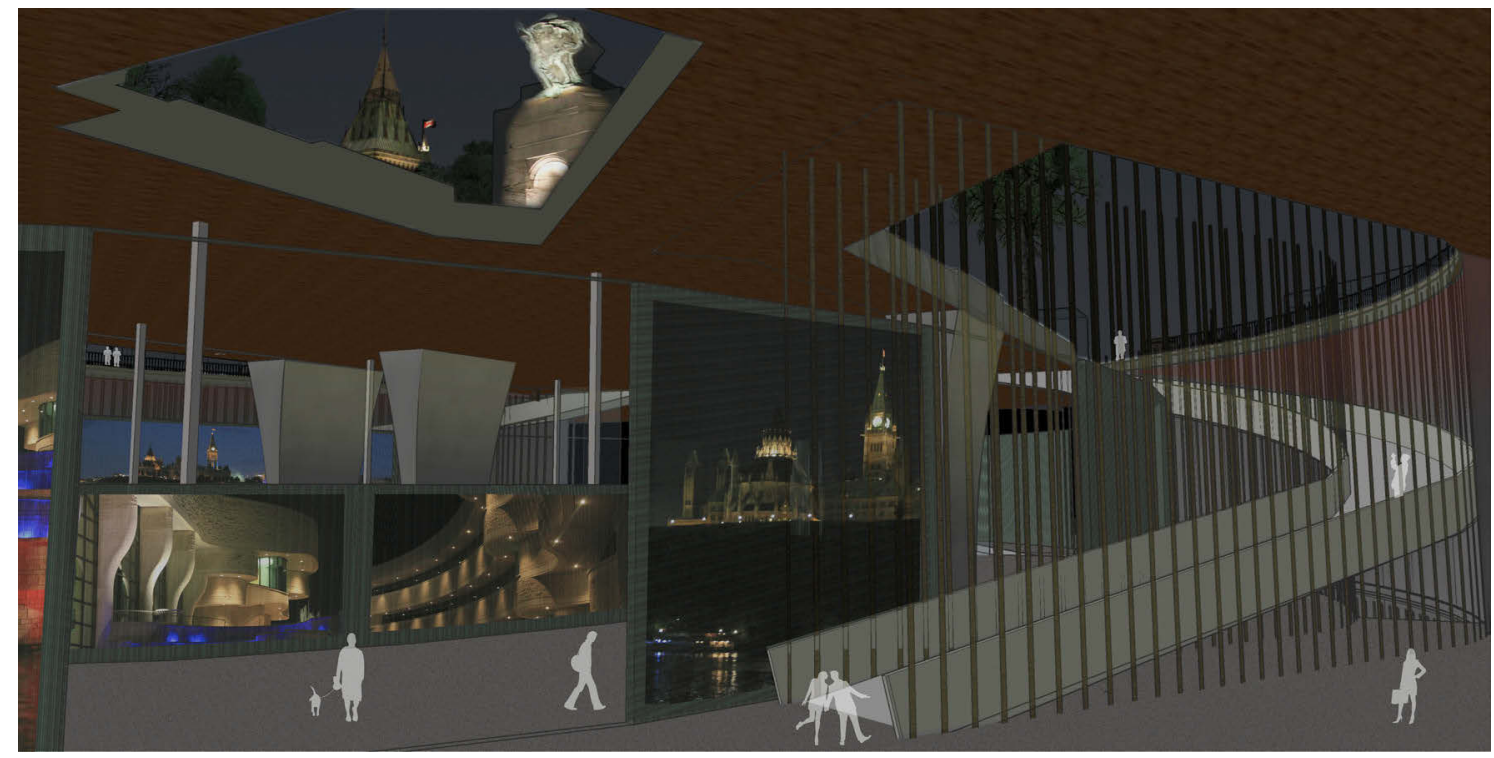

Figure 33: Nocturnal view from Gallery Level showing relationship between city, lighting, and display screens 


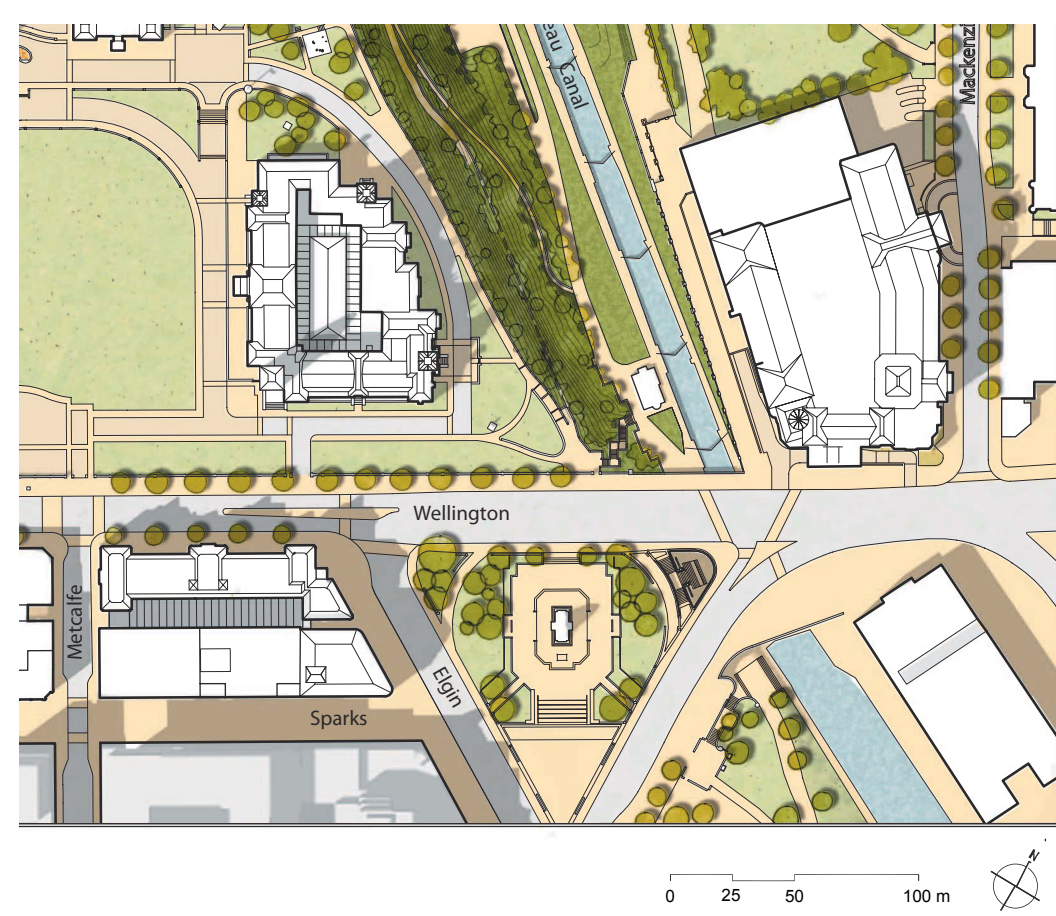

Figure 34: Existing conditions with proposed improvements as per Long Term Vision and Plan (LTVP) for Parliament Hill (Map source: LTVP)

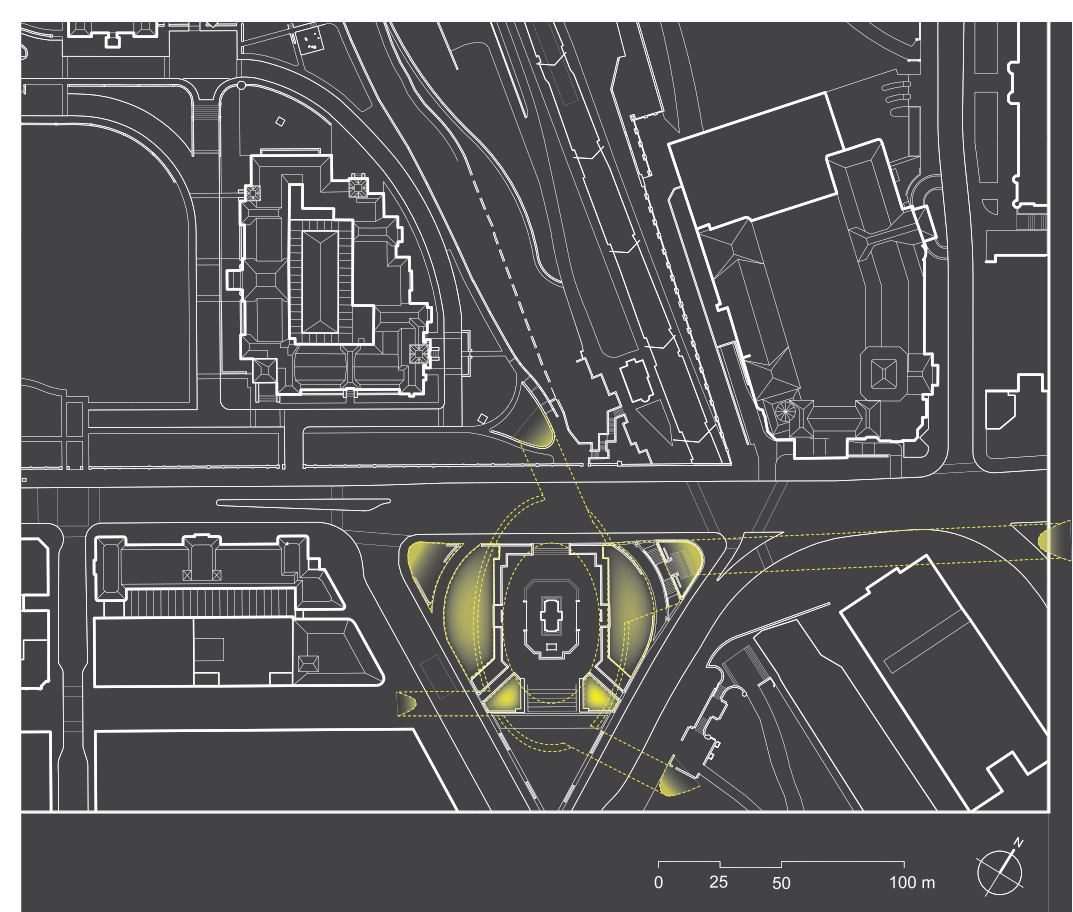

Figure 35: Preliminary "nocturnal" concept for Confederation Square showing nocturnal gateways from surrounding areas in yellow (Map source: LTVP)

the beacons. Below, in the void, a network and gallery is revealed that extends the busyness of the upper streets into the subterranean space below. Despite the bustling nature that can be seen below and that which surrounds the plaza, a sense of peace and calmness remains on the island of Confederation Square.

\section{Entering the Subterranean Photography gallery: Exposing Light in the Darkness}

Voids in the slab, which allow light to emanate from below at night, as well as for sunlight to enter the station during the day, have been cut primarily in areas of the Square's previously existing greenery. Although this reduces some of the grassed areas within the 
plaza, vegetation, including trees, have been retained at the edge of the slab between the paths and the void in order to mediate an edge, and to retain greenery on the site. These cuts in the slab for light penetration and emergence, also serve as points of entry into the gallery and station below.

Entering the station from one of the entry points, visitors cross the glazed threshold, a seemingly minimal transition between outdoor and indoor space. Four options allow entry into the station from street level: mirrored, curving ramps, with access at the centre North tip of the plaza; glass elevators with access from the centre North tip of the plaza; stairs on both the Eastern and Western tips of the plaza; and a ramp from the Eastern end of Sparks Street. The photography gallery itself is an in-between space, acting as a threshold between the Plaza and the transit level. The gallery is, however, a destination in itself, and is a place that is about light and which relies on light.

The following options describe the means of entry into the station.

Option 1: Taking either of the mirrored curved ramps-the scenic entry into the station-visitors gently descend, slipping gracefully

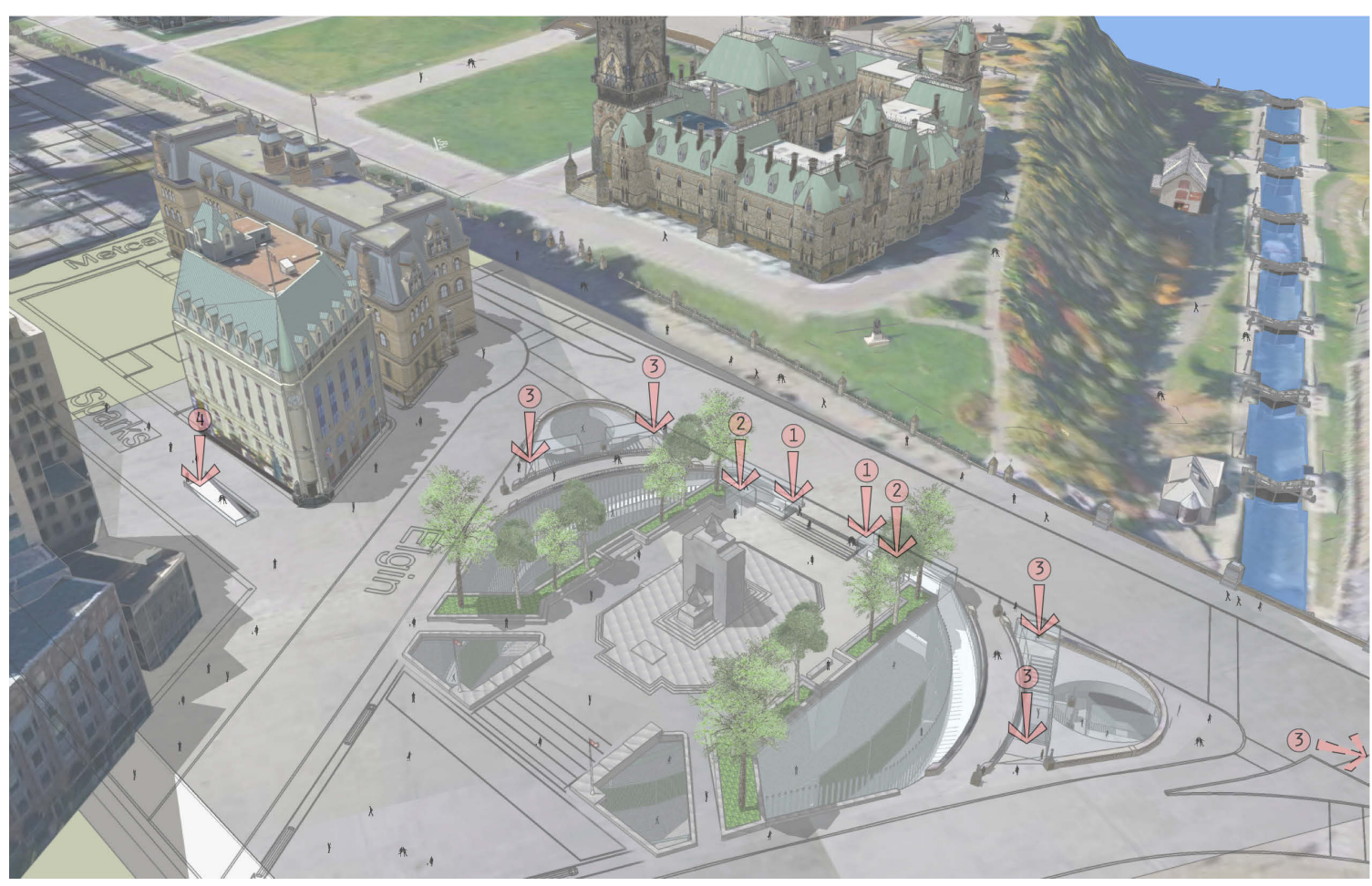

Figure 36: Site view of project showing points of entry into gallery and station below 
down through the trench carved out of the earth. As they slowly descend the ramp to the gallery space, they are able to experience the collection of photographs that lie between the point of entry from above and the second ramp down to the trains. Pausing along the way as they descend the ramps, wooden slats conceal and reveal views towards the gallery and into the central spaces. Grounding the ramps, and

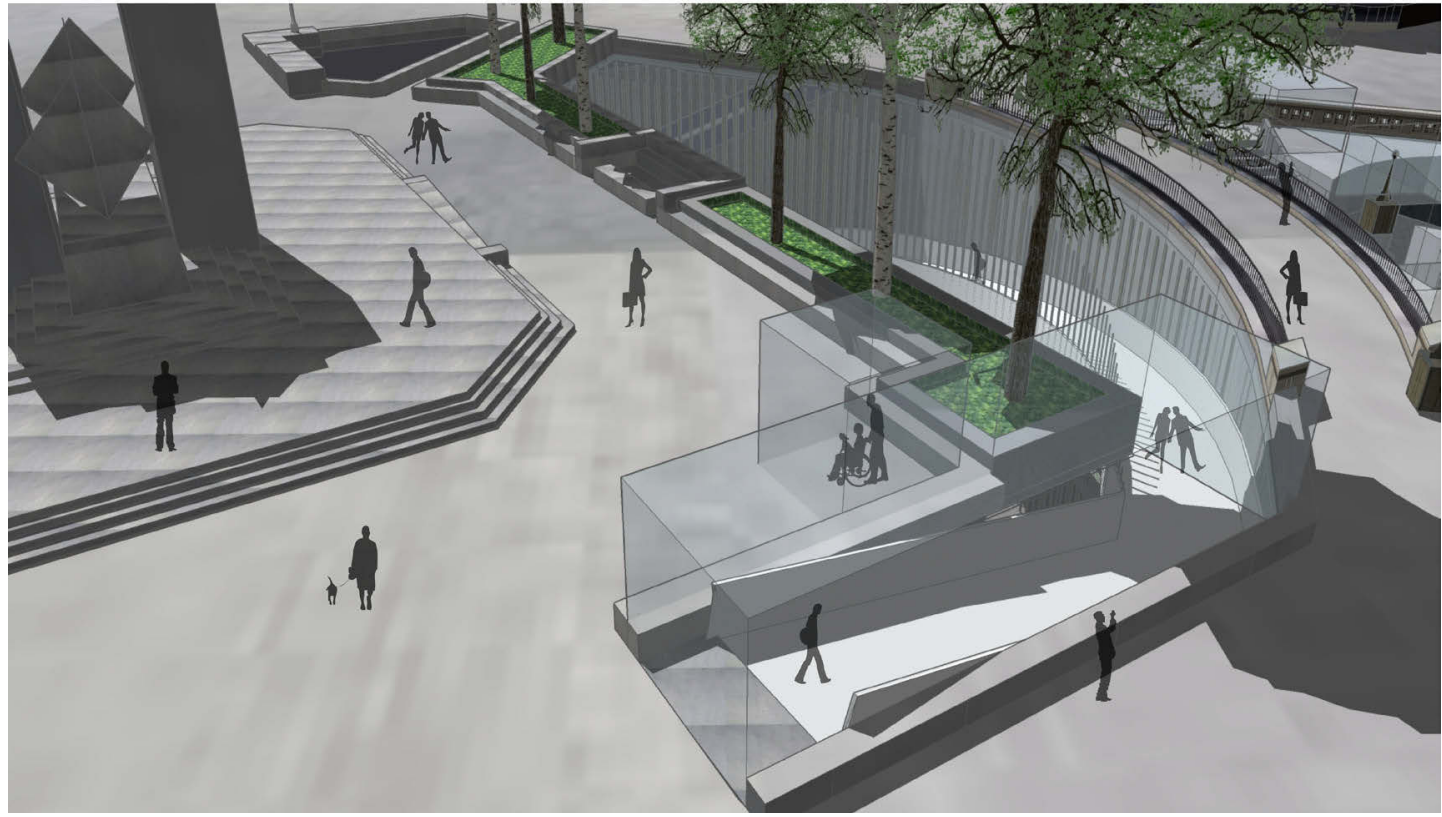

Figure 37: Entry options 1 and 2: curved ramps or glass elevators

rooting them within the subterranean space, the slats allow visitors to understand that they are entering the heart of the city, in both a lateral (centrally located in plan) and sectional (roots of plaza below) manner.

Option 2: Entering the station via either of the two glass elevators, people have a truly sectional and transparent experience. As they descend quickly from the plaza level to the levels below, they are struck by the sharp and quick contrast they experience between the tranquility of the plaza, the "pause-and-go" of the gallery, and finally, the agitated movement of the station below.

Option 3: The stairs on the Eastern and Western tips provide for a more traditional and grand entry into the gallery. Descending stairs which are already familiar to many-used in order to access the tunnel through which the Rideau Canal passes on the Eastern 
side of the plaza - the option now exists to use this type of circulation on both sides of the plaza. The Eastern stair entry first spills into the tunnel where the Rideau Canal and locks meet, before entering the gallery space below the plaza through arched entries similar to those through which one can see the Rideau Canal by looking the opposite way. At the bottom of the Eastern stair entry, a connection at the level of the tunnel links into the newly conceived water taxi service, providing service along the Canal from Dow's lake to the Locks downtown. Additionally, from the Eastern stairway entry, a platform at mid level down the stairs to the gallery connects to a glass bridge that extends to the East. This glass link is nestled into the upper arches of the existing bridge, and provides a connection towards the Byward Market and Rideau Centre via

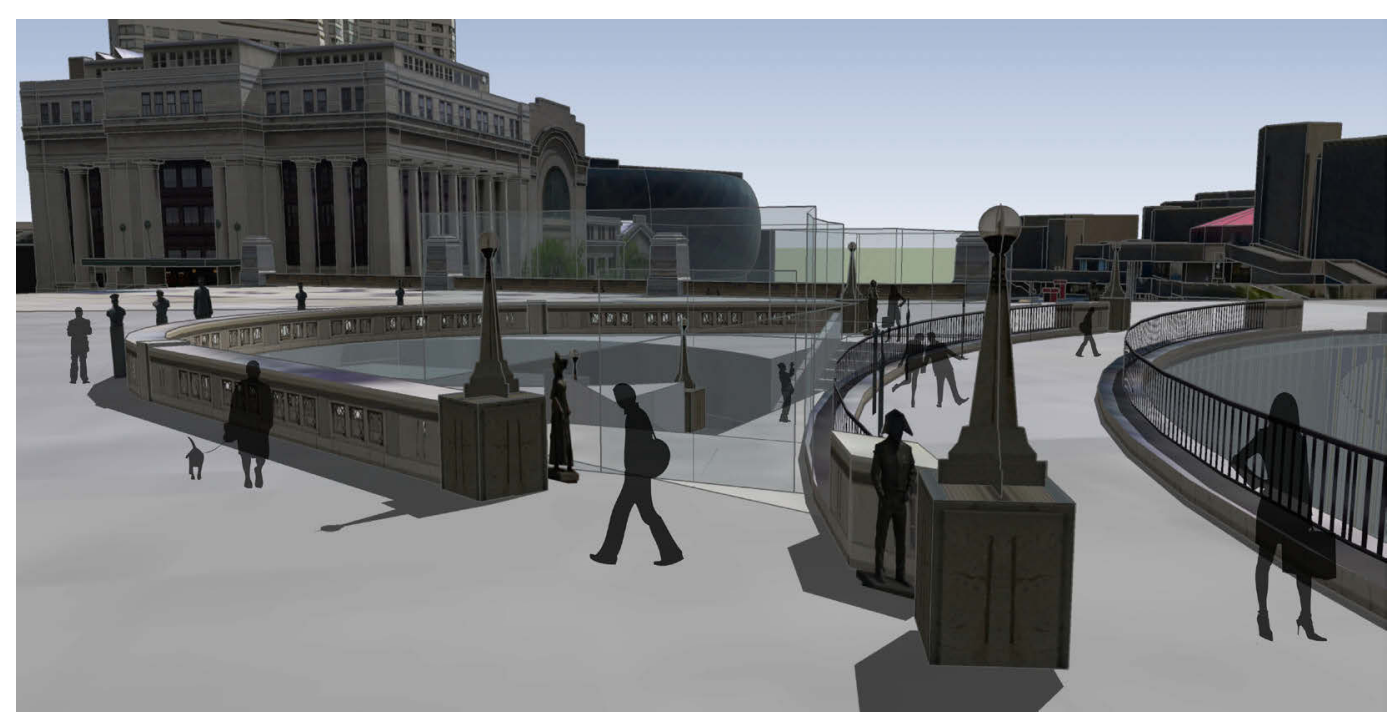

Figure 38: Entry option 3: East stairs through tunnel

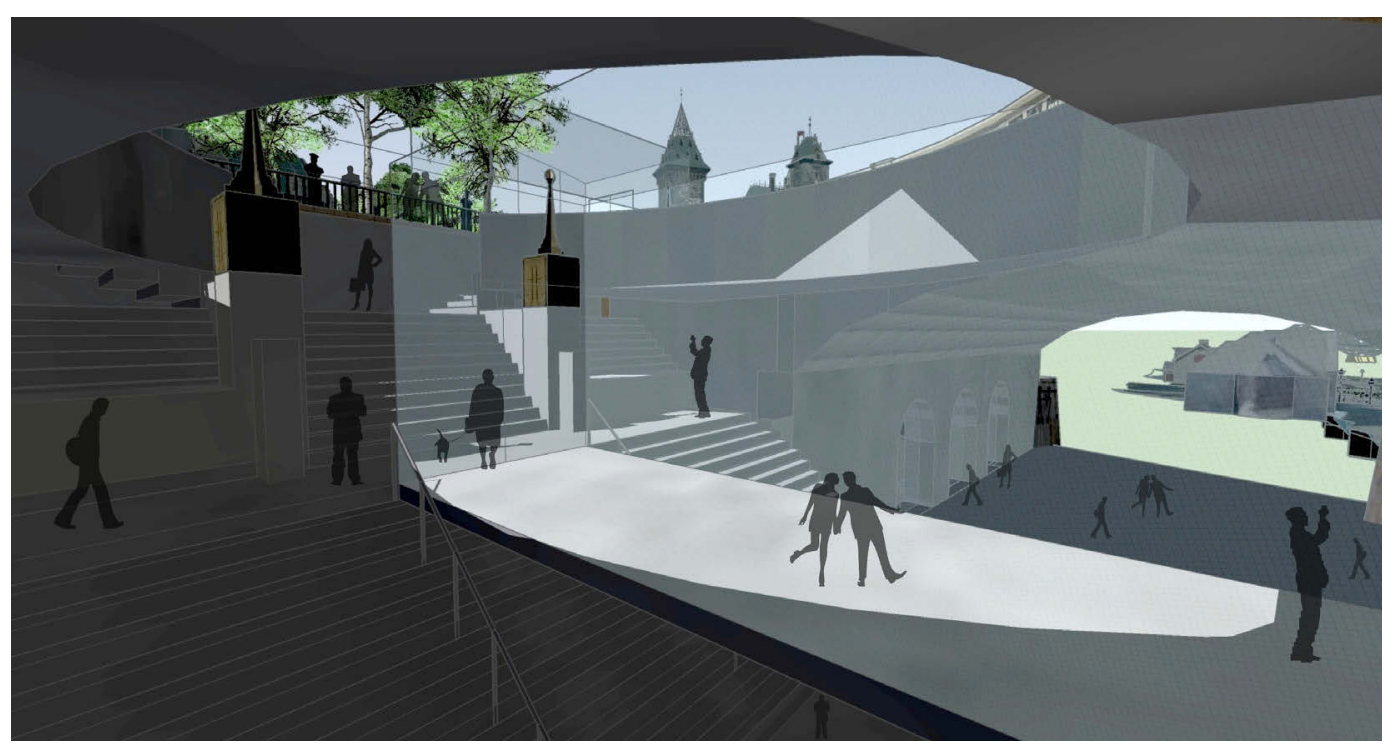

Figure 39: Entry option 3: suspended glass tunnel link from existing bridge connecting to East-end Downtown 


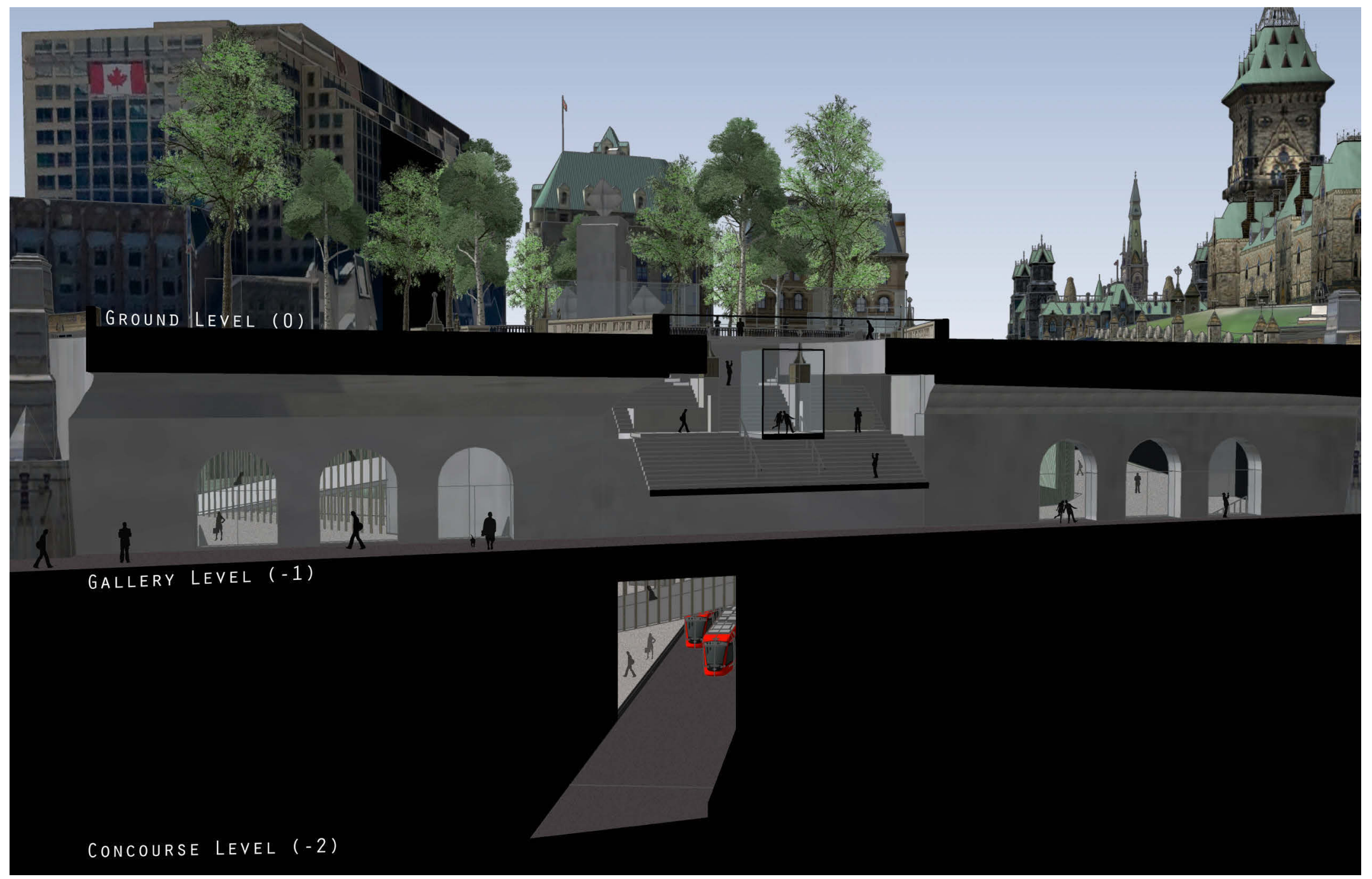

Figure 40: Section looking West showing entry option 3 (East side) into gallery level via tunnel under bridge 
an exit under the bridge at Wellington Street and Sussex Drive. This aids the pedestrian traffic flow between the station and the Eastern end of downtown, while providing a sheltered passage below grade.

Similar to the configuration of the Eastern stair, the Western stair descends to the gallery level, spilling into an arched tunnel space reminiscent of the tunnel on the East side. From here, one can either continue straight through underground arched connections to Parliament Hill, or can switch back to enter the gallery level of the station.

Both of these entry options set up a series of frames within the tunnels, causing sequencing to occur during passage between transit level and ground level.

Option 4: The ramp from the Eastern tip

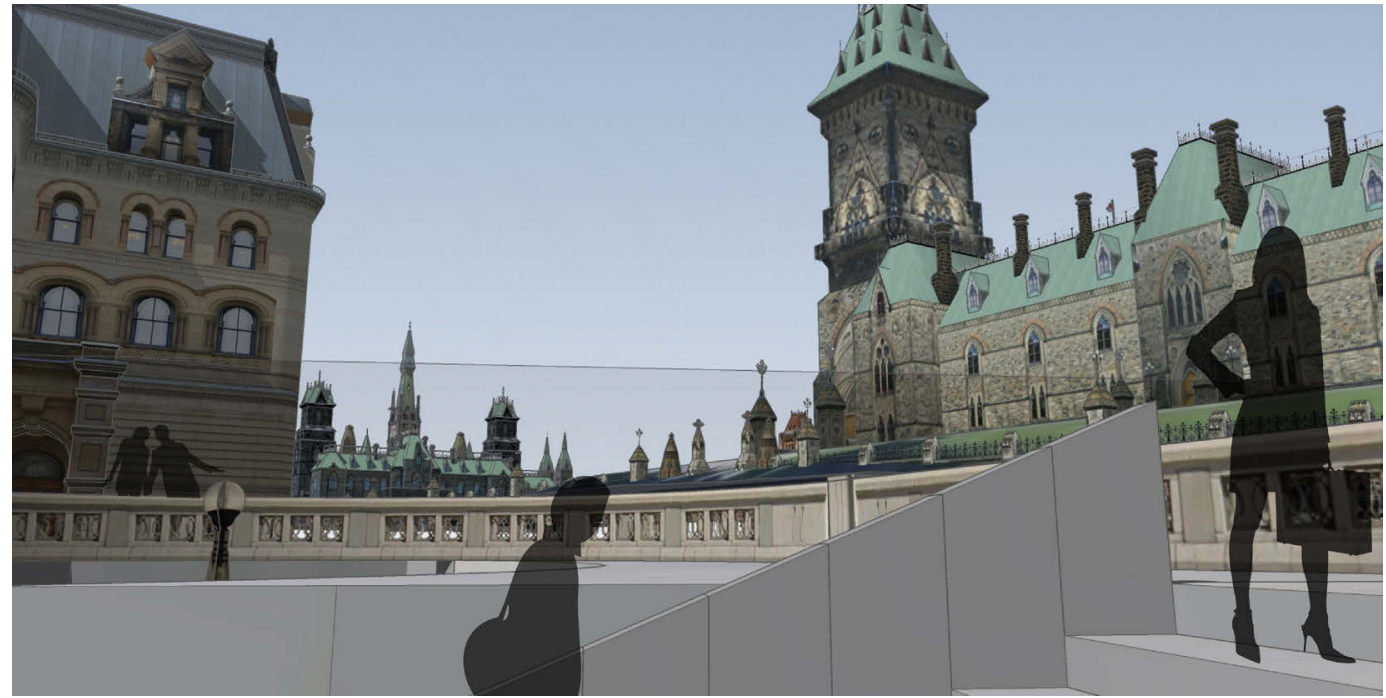

Figure 41: Entry option 3: West stairs through tunnel (Parliament Side)

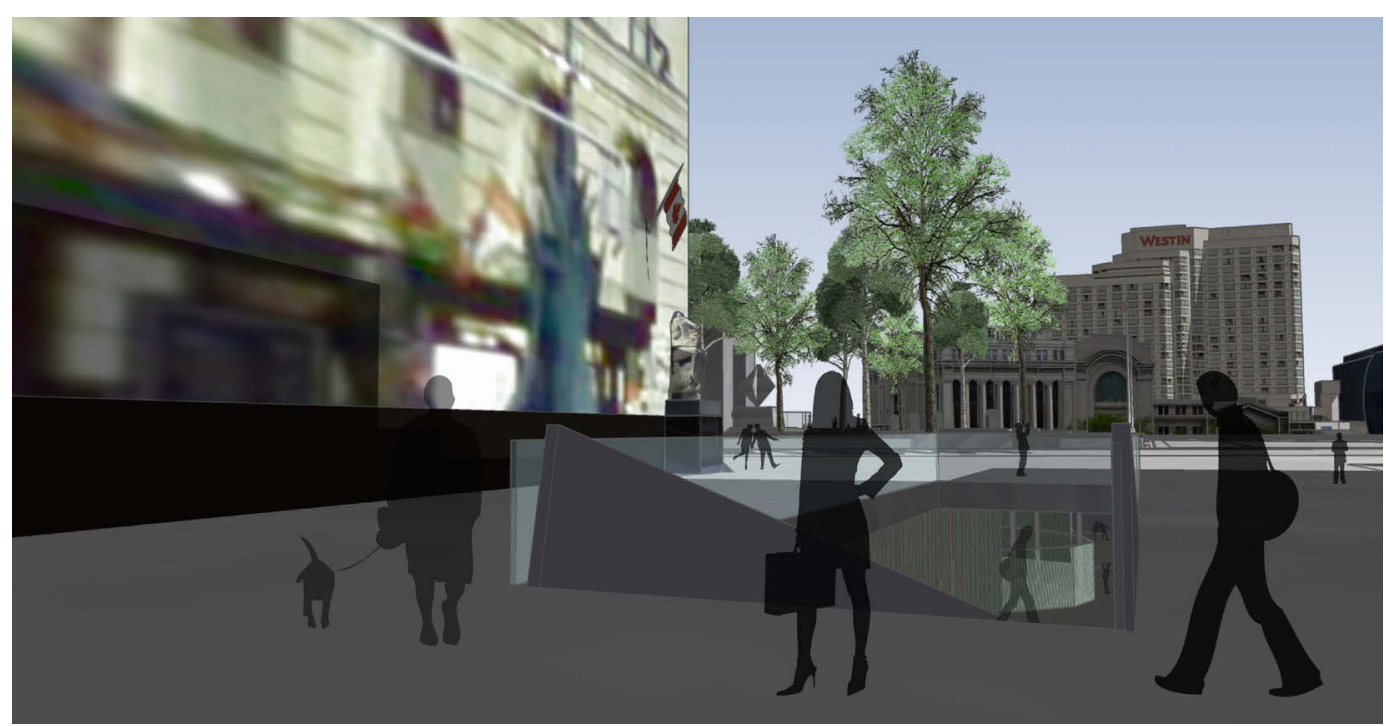

Figure 42: Entry option 4: ramp from Sparks Street 
of Sparks Street provides a practical alternative for access to the gallery and station without having to cross Elgin Street when coming from Western parts of downtown. As one moves along Sparks Street towards Confederation Square, a centre portion of the pedestrian street starts to slowly descend into the ground, allowing for an efficient passage below Elgin Street and directly into the gallery. Similar to the connection provided by the glass tunnel stretching out to the East portion of downtown, this underground connection provides effective entry into the gallery from a pedestrian zone without having to cross a busy street (Elgin Street) that borders Confederation Square plaza.

In the gallery space, elements of the structure start to allude to the roots and foundation of the nation, telling its story. Around the large, centrally located elliptical void, that sits directly below the centre of the plaza, an inner ring made up of thirteen columns form a colonnade, each column representing a province or territory. The heavier structure in the outer rings anchor the four cardinal points of the compass, helping to reinforce and strengthen physical orientation. In conjunction with the large voids cut in the slab, directed outward views help to make a connection to surrounding heritage fabric at street level. At each entry, the lobby space outside of the gallery is populated with artefacts and displays of nearby galleries and monuments, announcing the direction one is headed, or from which one has entered the station.

Upon entering the station's gallery space, a collection of photographs are displayed—photographs recounting a history, telling a story of the city, of the country, of a nation, of historical traces of power and governance, of its people and architecture. The light that has beckoned people to this space at night, or the sunlight that has infiltrated the gallery space during the day, helps to expose and bring to light the displayed photographs in what would be an otherwise dark space. Stories of the city are revealed and shared and provide a social and historical account. By placing the gallery between the station entry and the destination of the train platform, everyone gets a glimpse of what the gallery space has to offer on display be it briefly or for more prolonged visits. 


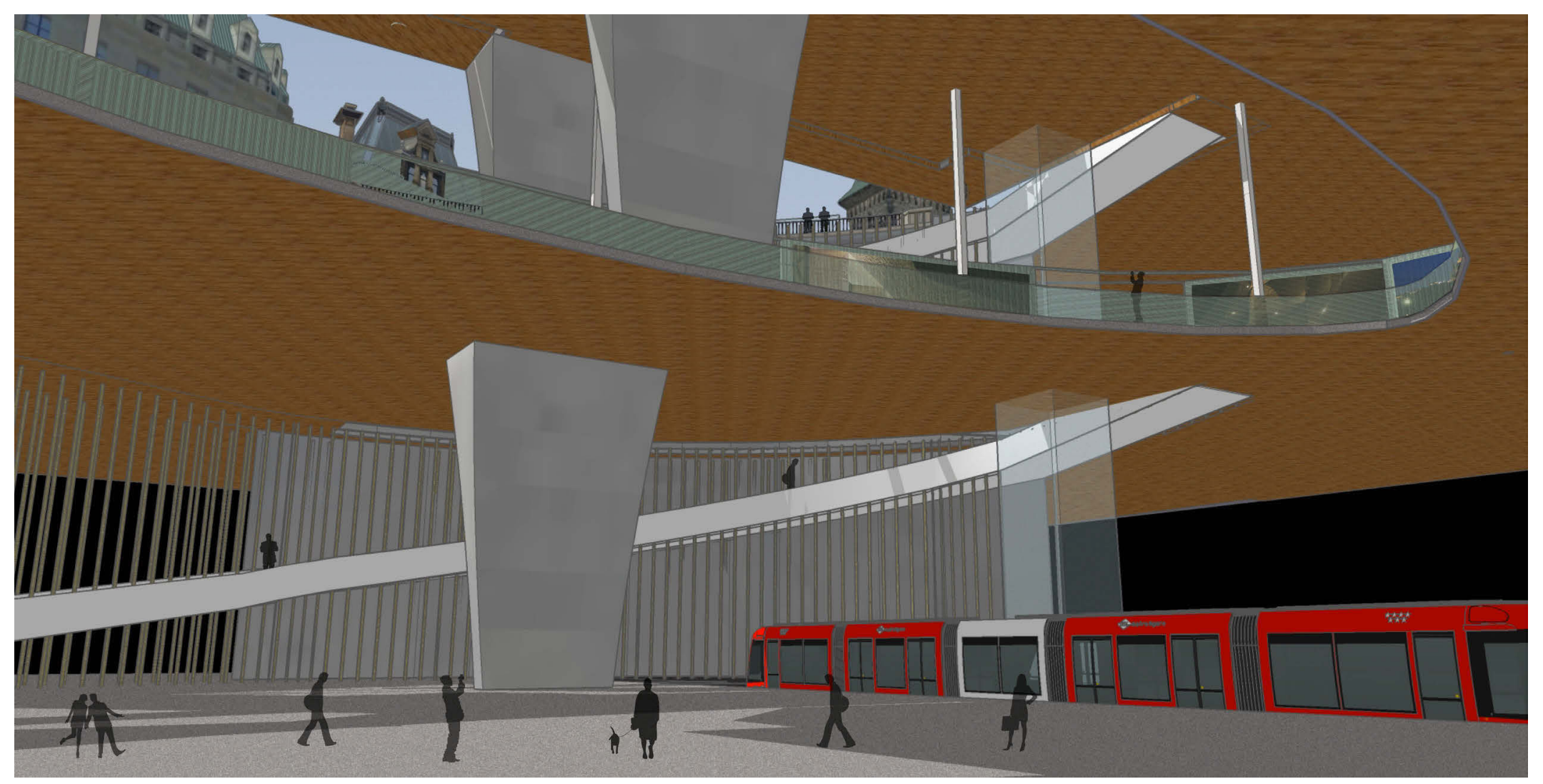

Figure 43: View from Concourse Level showing penetration of daylight and relationship to city

As people make their way down to the station's transit level, they enter the core of the city. In contrast to the open gallery level of the station which reaches out in many directions, the transit level of the station is but a platform carved out of the earth, made to feel bigger through the vertical connections to the levels above through space, views, and light. Whether people enter the station and descend immediately to the transit level to await the next train, or whether they remain in the gallery space for extended periods, they have time while in transit to reflect on the stories that they have experienced from the gallery exhibitions. 
Confederation Square is a unique area in the downtown core, as it is a place of intersection of various neighbourhoods whose edges define the edges of the plaza itself without becoming a part of it. In this place, neighbourhoods, streets, characters of place, and people collide and intersect to literally create an island that reaches out into its surroundings, yet is devoid of any characteristics of one in particular. As a neutral, yet loaded, location with various directions and vantage points that stem from it and towards it, it is an ideal place for the compass of the city, and is especially suitable for the location of a prime downtown transit stop. Often when emerging from below ground, passengers are faced with reorienting themselves despite the fact that they may be familiar with the area. As an LRT stop searching to orient a passenger in the darkness of an underground station, before emerging from below ground, this project questions how light can act as a gateway, suggesting and bringing characteristics and elements of place into the subterranean gateways that connect to places above ground.

\section{A. Gateway towards parliament hill: Ephemeral firelight}

Parliament Hill is a place of significance that many identify as a national symbol due to its historically significant buildings and natural elements. Despite its historic heritage values, traditions, and heavy stone architecture — all things that seem robust and unchangingthere is a part of Parliament Hill as a place that is constantly in flux. Changes occurring outside that accompany protests, celebrations, commemorations, festive lights, and light shows, all contribute to the ephemeral qualities that the front lawn and the façades of the stately buildings take on. Examining a quality of light that speaks to the feeling of place associated with Parliament Hill, firelight, or a flame-similar to the Eternal Flame burning on the front lawn—seems as appropriate as any. The name of the light source itself, as the Centennial or Eternal Flame, is somewhat of a paradox to that of the idea of ephemerality. It does, however, reflect the 


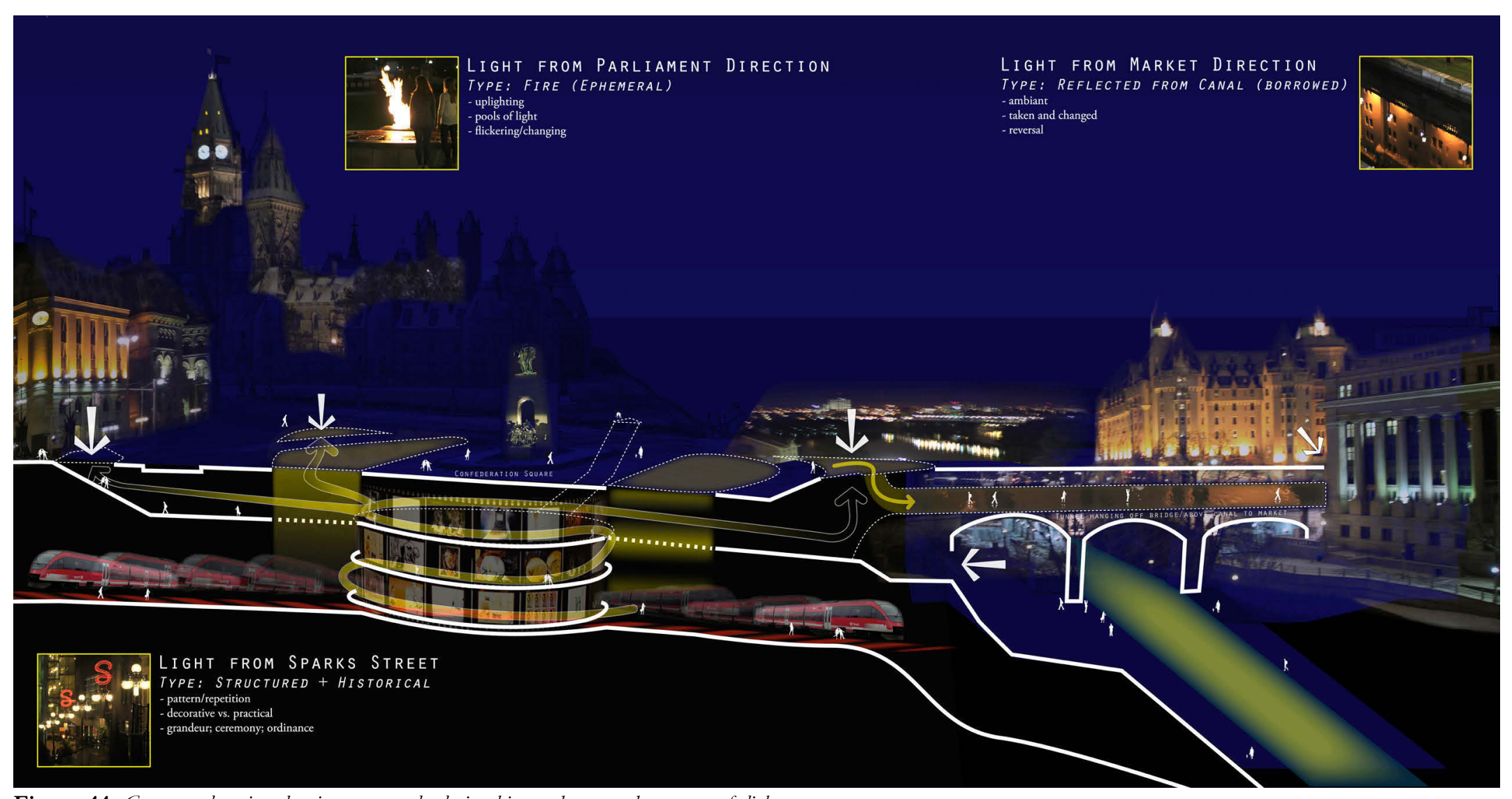

Figure 44: Conceptual section showing nocturnal relationships and proposed gateways of light

character and duality that is present on Parliament Hill. Despite the ephemerality of Parliament Hill—and, equally, the ephemeral and changing qualities associated with the cycle of a fire: wood, fire, coals, and ashes-there remains an element of steadfastness both in Parliament Hill and within an eternally burning flame. Despite the constant flickering of Parliament Hill, be it by who is in power or by what event is happening on the Hill, the location remains constant as a place of democracy and openness for Canadians, welcoming everyone equally. Firelight, also, as a source of light and metaphor, is reminiscent of a campfire and the outdoors, ideals 
often associated with Canadian identity and landscape. Lighting qualities indicative of pools of light, up-lighting, and a sense of changing or flickering, are reminiscent to that of the qualities of light on peoples' faces as they sit gathered around a camp fire in silence, discussion, or song. This not only alludes to the outdoors and a large part of Canadian identity, but also to a sense of gathering and community. As a concept for the entry to the station located closest to Parliament Hill, the notion of flame best reflects the characteristics of this sense of place.

\section{B. Gateway towards the Byward Market and Rideau: Borrowed Reflected Light from the CANAL}

The Eastern portion of downtown that stems from Confederation Square is comprised primarily of the Byward Market and of the Rideau Centre after crossing the Rideau Canal and locks. Both are largely populated by food and shopping areas, and can be

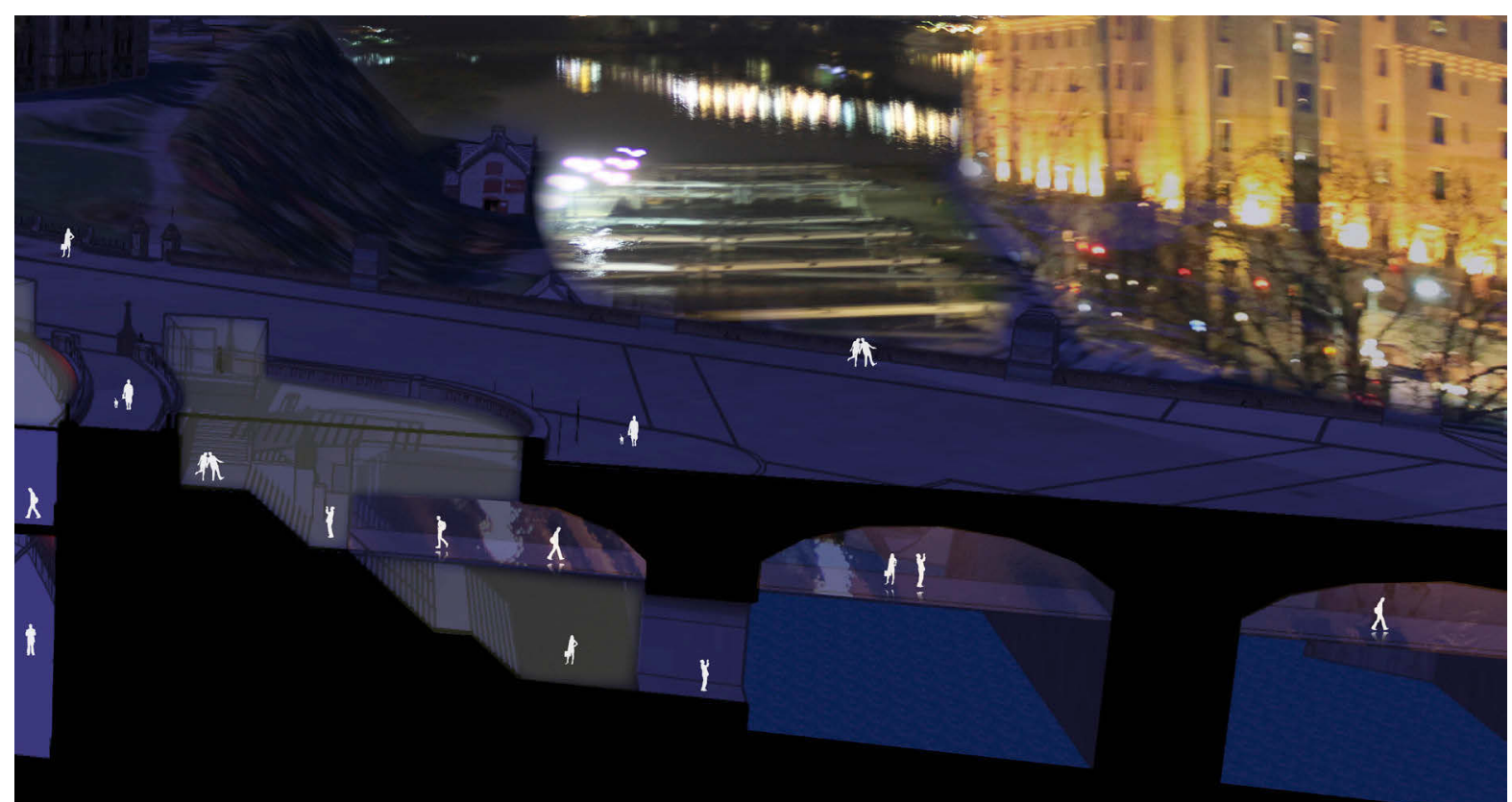

Figure 45: Canal/Rideau gateway lighting concept vedute seen as clusters of businesses, that, as a whole, create a vibrant commercial area. In order to connect to this portion of the city from the station, a glass tunnel hanging from the structure of the existing bridge and over the Rideau Canal is proposed in order to cross the Canal without having to go 
above ground to go around it, or below ground to go under it. This tunnel will continue underground in the direction towards the market, and will emerge at the current location of the underpass between the Government Conference Centre and the Rideau Centre. Taking into account the Canal's importance in orienting people in the city, it seems appropriate to draw inspiration from it in order to inform a lighting concept for the threshold between the station and the East portion of Downtown. Inspired by light reflecting from the surface of the water of the Canal, the idea of borrowed light that is reflected and inverted-essentially taken and changed—will inform lighting conditions within this threshold and transition towards the Market and Rideau. A combination of reflective surfaces and materials such as glass, will be used in combination with lighting that creates an ambient effect of light

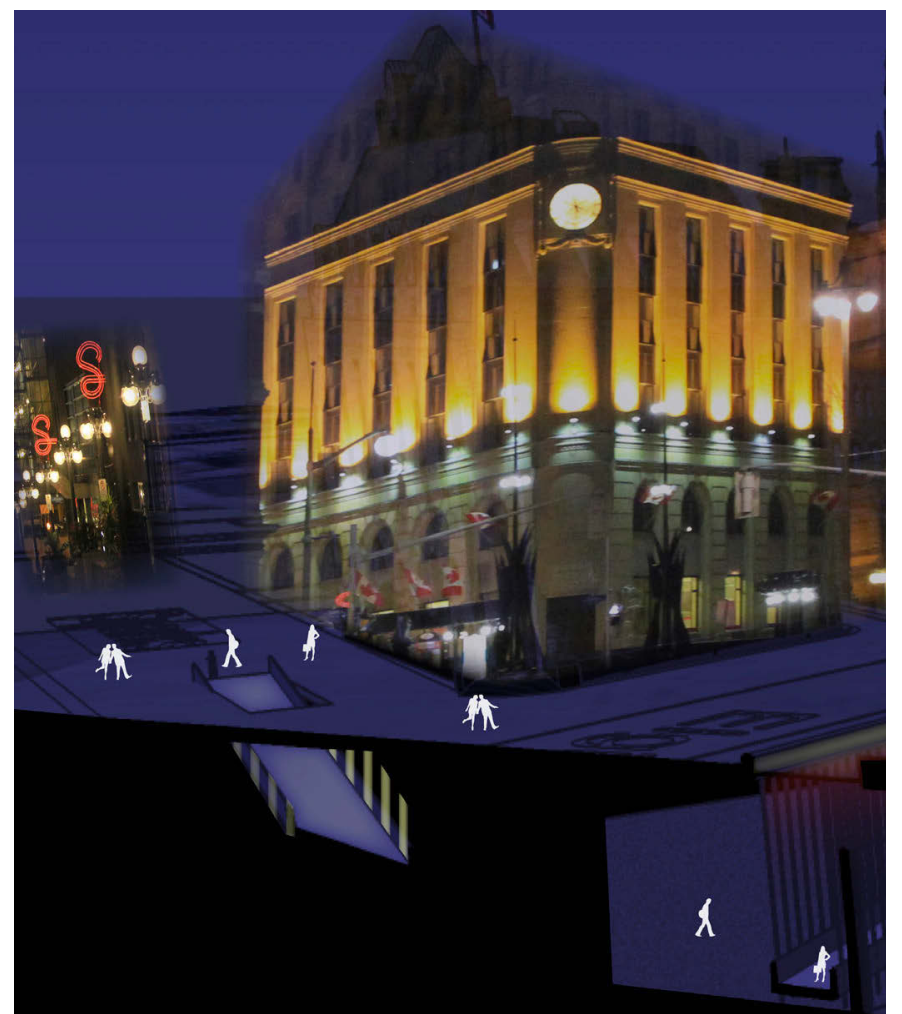

Figure 46: Sparks/Elgin Streets gateway lighting concept vedute reflecting off water. These qualities not only reflect qualities associated with the canal, but also with water as a whole and its importance to the Canadian narrative. Similar to the element of fire, and the flame of Parliament, the element of water reflected through light ties into qualities associated with both Canadian history and identity.

\section{Gateway TOWARdS SPARKS ANd Elgin StREet: ORDERED AND STRUCTURED LIGHT}

Sparks Street and Elgin Street are both significant streets in Ottawa for their individual characteristics and senses of place. Common to both is a sense of grandeur, of history, of ceremony, and of ordinance. Both stem from Confederation Square and provide important views of the city both towards and away from the plaza. When considering a lighting concept 
for the threshold between the station and the ramp that descends into the station from the Eastern end of Sparks Street, history, pattern, repetition, and order, are common traits derived from the character of these two streets. Although varied, the efforts made to preserve heritage architecture in both of these areas, speaks to their inherent importance. As a concept for the threshold between Sparks Street and the gallery, light that gives a sense of a structured and patterned ordinance with a historic character would be best suited in order to reflect the formal qualities of Sparks and Elgin Streets.

The aforementioned qualities that support and indicate a sense of place of the three surrounding gateways, reinforce identifying qualities relating to Ottawa as a city, as well as the Capital of Canada. As such, these conditions are deemed appropriate in a National LRT stop for Ottawa situated at Confederation Square. The thresholds which will help to guide people to their destination not only provide a sense of physical orientation, but also help to provide social and historical orientation, reminding people of core characteristics that are key to Canadians and Canadian identity: the comfort, community, and ephemerality of fire; the tranquility, reflectance and calmness of water; and history combined with subtle but steadfast ordinance, structure, and ceremony.

\section{Varying Qualities of Light in the Station}

\section{A. SEASONS + TIMES OF DAY}

Confederation Square is the ideal place for an LRT station in downtown Ottawa. As a safe zone amidst the busyness of traffic surrounding it, the plaza is a tranquil island in the busy sea of traffic, and is an ideal place to gather one's bearings upon emerging from underground. Though centrally located in an urban context, as a plaza, Confederation Square benefits from a lack of tall buildings in its immediate presence. Though an urban wall can be felt around its perimeter, in the immediate and interior area of the plaza there is much open space. This benefits the voids cut in the slab, enhancing and strengthening their ability to let light in and out of the 
underground, allowing it to penetrate deeply into the subterranean space. During the changing times of day and seasons, this allows the sun to act as a spotlight and developer of images within the underground space, moving around in different patterns, and resulting in a variety of shadows and enhanced lighting qualities. The movable display panels can use this to their advantage in order to reconfigure the gallery display spaces to adapt to changing sun or lighting conditions.

Additionally, through different filters being applied between the sun and the space where the light falls, or between the light emerging and above ground, different conditions will be created, some controllable, and others not. Colour-changing and deciduous foliage, colourful vegetation and plants such as tulips, as well as climactic conditions such as snow and rain will combine with both natural and artificial lighting conditions to create changing and ephemeral conditions in and around Confederation Square.

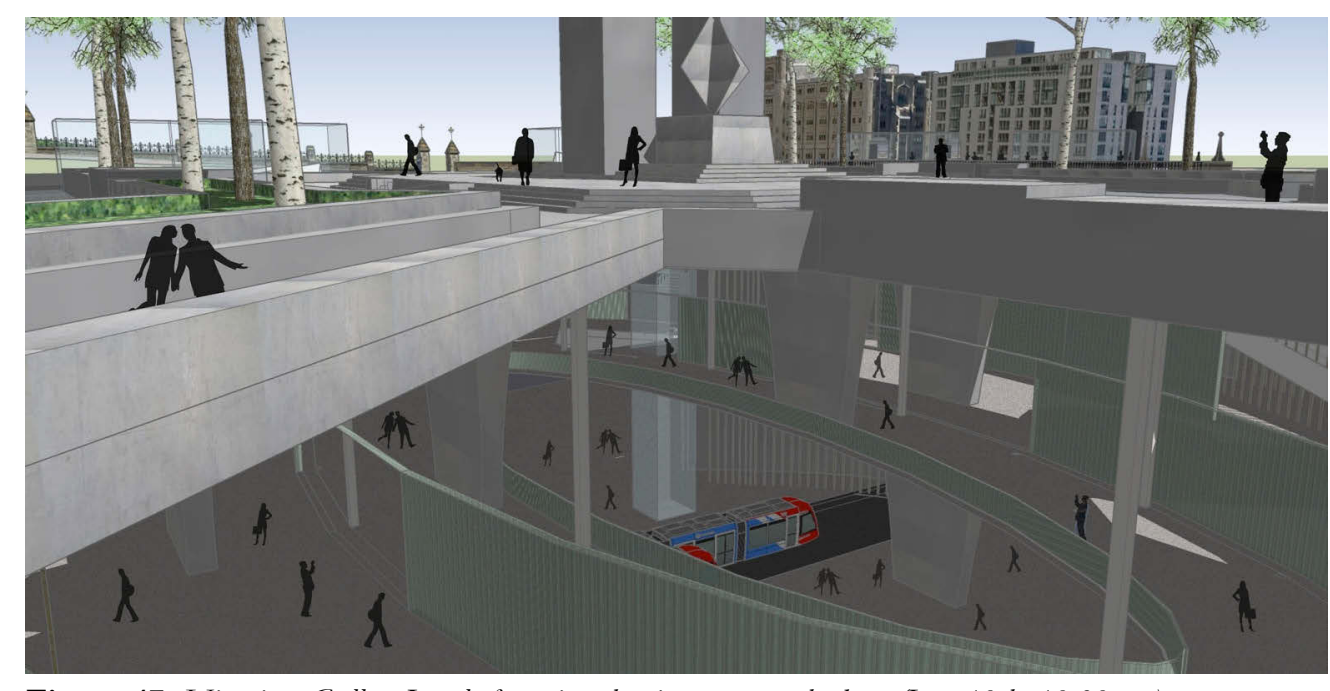

Figure 47: Vien into Gallery Level of station showing summer shadows (June 10th, 10:30 am)

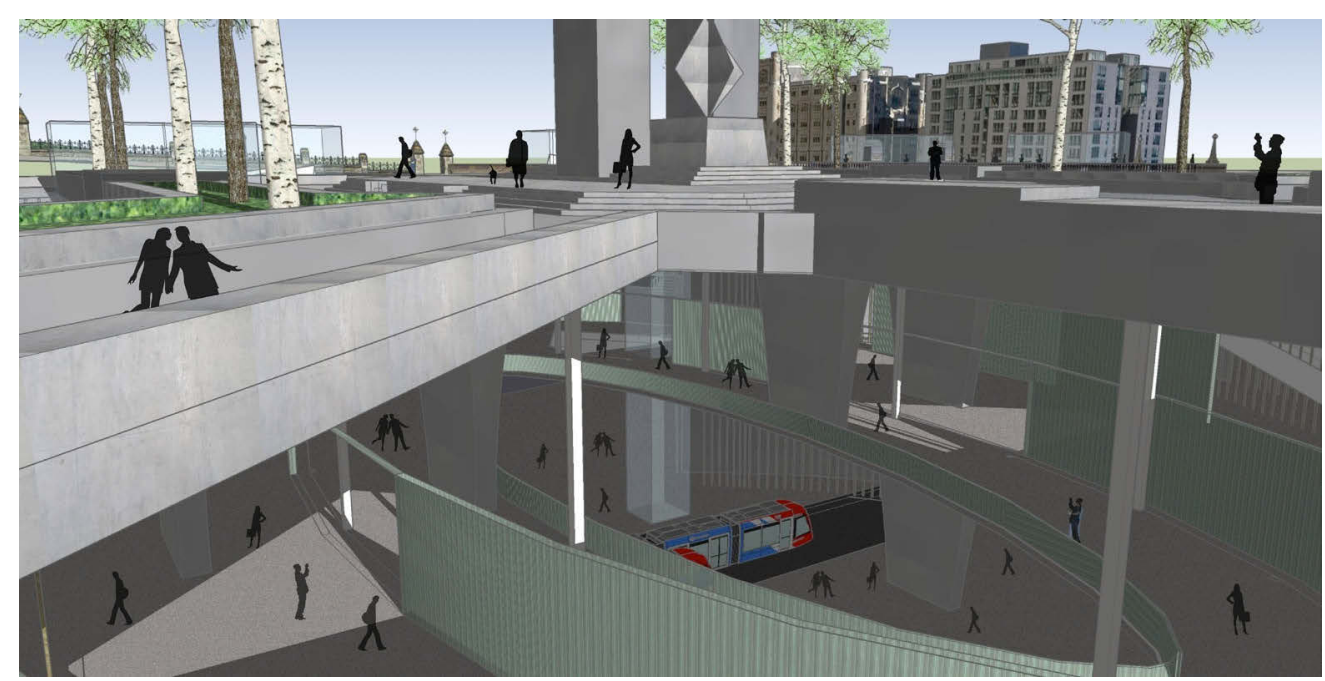

Figure 48: View into Gallery Level of station showing winter shadows (February 10th, 10:30 am) 


\section{iv $\mid$ The Reversal and Duality of the City: Day and night}

\section{The Changing nature of the City from Day to night: Reversal of the City AND BUILDINGS}

Light is of utmost importance to life as a whole_-without it we would see nothing and everything would appear flat without definition. The profound effect that electricity has had on the ability for cities to remain alive and visible at night has changed much about social life from what is possible to do at night to who is comfortable being out at night. Light does not necessarily provide safety or security, but it helps to bring comfort

"Light creates ambiance and feel of a place, as well as the expression of a structure" to areas otherwise left in darkness as well as adding poetic narratives and meanings.

Sunlight and electrical light work in tandem to light cities throughout the day and night, accounting for the daily shifts that occur within cities, public spaces, and buildings. Sunlight changes positions throughout the day, revealing and concealing itself behind clouds at the scale of the atmosphere, and behind buildings and vegetation at the scale of the city. Eventually, the lack of sunlight gives way to electrical light, which, too, then fades to darkness in parts of the city before commencing its daily rhythm once more. Not only does the city change throughout the day as qualities of light present in it change, it undergoes a reversal. Reflective buildings with impenetrable glass façades up during the day act as fortresses lining the street—at night they let down their guard, revealing their insides. At night, the people that inhabited the building during the day spill out into the street, and the building reveals its inside, allowing the city to see through its skin. 


\section{Emerging Connections and Landmarks at night: ORder and Clarity}

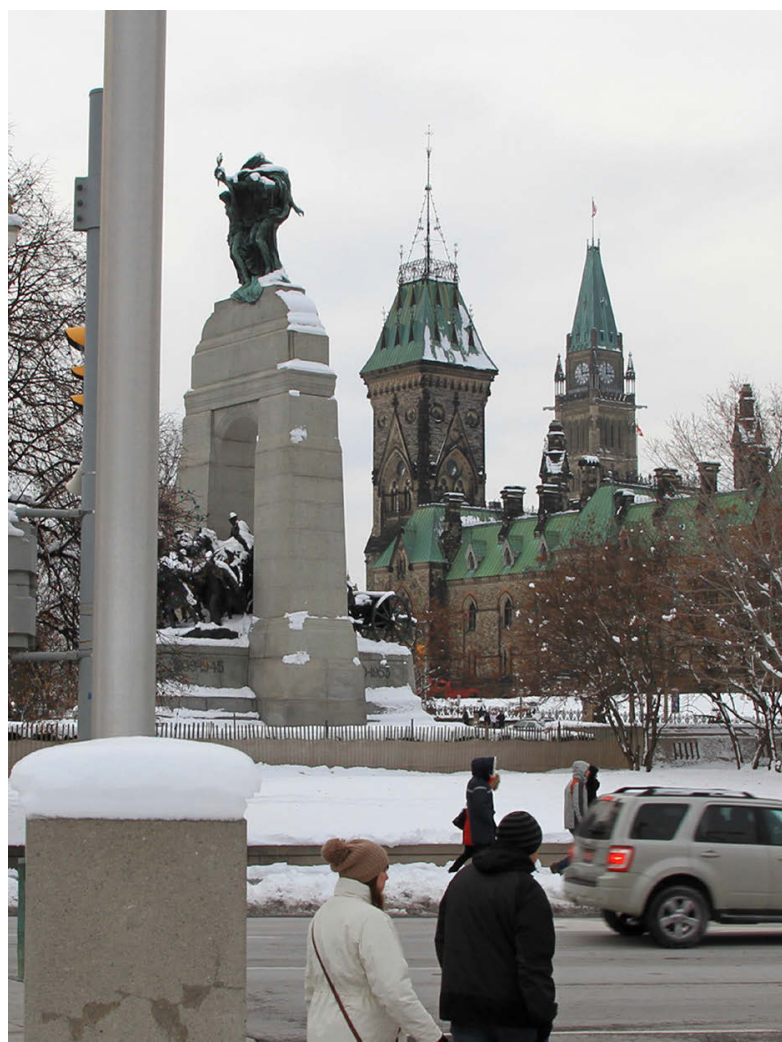

Figure 49: Diurnal layering of Confederation Square and surrounding landmarks be important. At the beginning of his career, Alvar Aalto wrote, "At night the buildings must sleep. He thought that it is the city as a living phenomenon that lights the buildings, and that this sufficed. Later, his clients demanded that his than relying on the visible and volumetric architectural qualities that buildings posses in space during the day, at night buildings must rely on light to remain present in the city and to reinforce the part they play in its composition. A building having a nocturnal presence, however, has not always been believed by all to
Not only do buildings undergo a reversal and change at night, but so do landmarks, public spaces, and streets. Order and clarity at night are different from that which is visible during the day, and hierarchies shift as darkness sets in. Rather

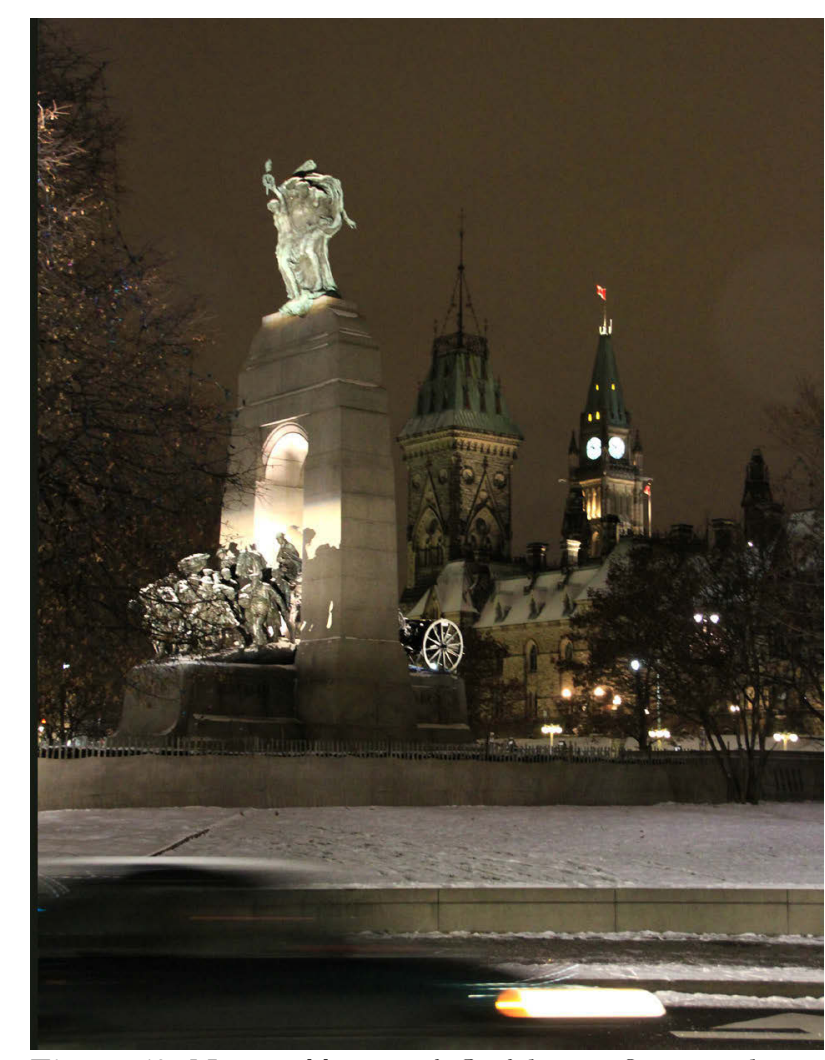

Figure 50: Nocturnal layering of Confederation Square and surrounding landmarks 
buildings be lit, [as] they were remarkable."10 Though night neglects the ability to show buildings in the same light as during the day, perhaps light as a material can allow for the important details of a building to be shown without the unbiased light shed on building by the sun. Although the changing position of the sun and the change of seasons allows for various states of a building to be exposed, they are not necessarily the ones that are preferred to be shown unless they have been carefully calculated and considered by the architect. An architect, in consultation with an architectural lighting designer, can ensure a building's nocturnal side brings to light the important details and language of the building in an expressive and formulated manner. A delicate balance of the use of light is needed in order to let the right parts of the building shine through without over-lighting its composition: it is less a matter of how much light and more an issue of what to
"At the beginning of his career, "Alvar Aalto wrote, "At night the buildings must sleep."

He thought that it is the city as a living phenomenon that lights the buildings, and that this sufficed. Later, his clients demanded that his buildings be lit, and [that] they were remarkable."

- AWP | NightscaPES

light.

\section{Invisible Spaces: The Ephemerality and Magic of Light, Night and BU I LDINGS}

Though one could argue that the darkness of the night hides the city in its shadows, one should think of the night as a blank canvas for the city - a canvas that is not new, but one that allows for hidden stories to be told that aren't possible during the day; one that allows for invisible spaces to come to light; one that allows for the shifting of the hierarchy of the city. Though much work may need 
to be done in order to preserve the same hierarchy of the city that is present during the day, perhaps the night should be different from the day. Perhaps, just as people get tired and sleep, the city should get tired and sleep too, revealing a different and masqued side of their personality during nocturnal hours. Attempting to carry the same feeling that exists in city spaces during the day through to the night is perhaps a falsity and a false representation of the city. Is it right to show buildings as though they are occupied, when in fact there is no one inside? Would preserving the reflective guard that some buildings put up during the day during the night not, too, be deceptive? Would this not essentially be untrue in the same way that façadism creates an inside that does not relate to its façade?

The notion of invisibility at the scale of a building is an event in which architecture acting as a background can make way for human acts and interactions to come to the forefront. The Copenhagen Concert Hall by French architect Jean Nouvel is an example of this type of interaction occurring, where the building as a whole becomes an invisible space. When speaking about his Copenhagen Concert Hall, Jean Nouvel refers to it as "a mystery that changes under the light of day and night, whose interior can only be guessed at." ${ }^{11}$ The building as a whole acts invisible, sitting behind and hiding within a dark-blue mesh and fibreglass façade. When talking about the building and its layers, Nouvel says "the centre is just that - a labyrinth, an interior urban landscape. On one side, the world of musicians with courtyards, terraces, and vegetation [and] on the other, Piranesian public spaces link together the performance halls, the restaurant, the street. The abstract is invaded by the figurative; the permanent is complemented by the ephemeral." ${ }^{\prime 2}$ The walls of the façade act as a mechanism for projection and disguise, adding a complexity to the building through its different invisible layers, and the acts that lie between them. The building hides behind this curtain of a façade, revealing itself only through illumination at night. The exterior dark-blue façade, the "true" exterior wall of the building, and all the spaces within the building, all act as curtains to reveal other spaces, changing transparency at different times to reveal the various spaces within the building. Nouvel refers to the

11 Merrick, Jay. "Rhapsody in Blue: Is Jean Nouvel's New Concert Hall the Best in the World?" The Independent. Independent Digital News and Media, 22 Jan. 2009. Web. 20 Mar. 2014.

12 Ibid (Merrick., Rhapsody) 


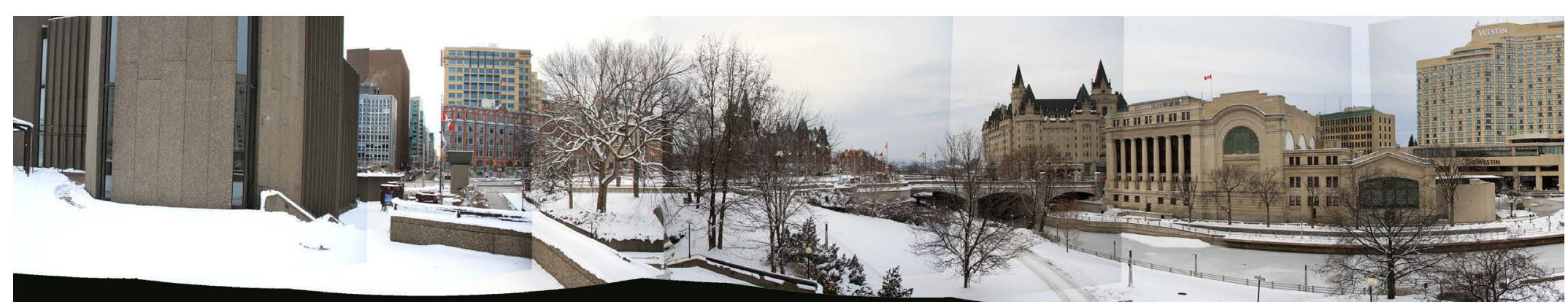

Figure 51: Diurnal view looking towards Confederation Square

façades as "diaphanous filters permitting views of the city, the canal, and neighbouring architecture. At night these façades become screens for projecting images. Each room becomes a discovery, each detail an invention." ${ }^{13}$ As Nouvel states, even the details of the building bear an invisible quality, invisibly aiding to enhance acoustics, drainage and ventilation. ${ }^{14}$

People change from day to night— they wake up, live through the day, and then get tired and sleep. Should cities and buildings not do this too? Some level of consistency must remain at night in cities, but perhaps buildings, spaces, and places—like people—should

13 Ibid (Merrick., Rhapsody)

14 "Of Hidden Helpers - Danish Radio Concert Hall by Jean Nouvel | Architecture at Stylepark." Of Hidden Helpers - Danish Radio Concert Hall by Jean Nouvel. N.p., 13 Oct. 2011. Web. 20 Mar. 2014.

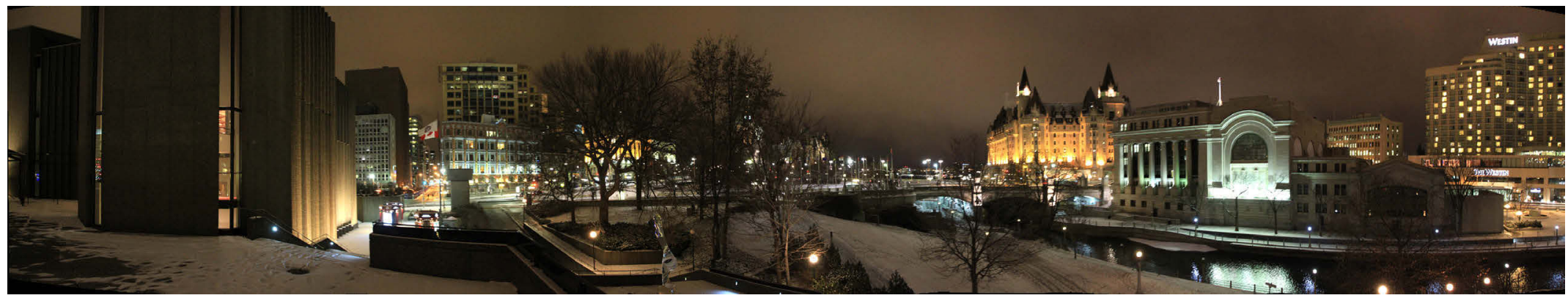

Figure 52: Nocturnal View looking towards Confederation Square 
take on their own nocturnal presence. Some sleep at night, while others work the night shift or stay up all night. Night is a time of unknown, of mystery, of darkness, of magic. According the Stanley McCandless, "light is the means of all seeing, yet the rays themselves are invisible. Only under special conditions as with a search light is it possible to see the density, colour, and direction of the rays and even here no indication of the movement of the speed of light from the source to a distant point is given. This makes the design and control of light a kind of magic which must be mastered as well as any other technique of expression." ${ }^{\text {15 }}$ Just as light has the ability to take on a magical state, it must be an invisible material, remaining hidden and revealing only what is necessary.

Confederation Square is an anchor in the city of Ottawa, and the prime location for a national LRT stop. Not only is it a central location in the downtown core, it is the ideal place to provide social, historical and physical orientation for the people of the city as well as for visitors and tourists. The Plaza, and many of its surrounding areas, however, suffer from a lack of activity at night. Making the plaza a destination that will inevitably be used at all times of the day will help to enliven the plaza and allow nocturnal uses and activities to be generated and stemmed from it. The magic of Confederation Square is waiting to cast its spell and to reveal what it has to offer as a major transit station. Give people a reason to go somewhere and they will go —ignite the beacon and the people will follow, travelling in a nocturnal vedute in search of a light.

$\overline{15}$ McCandless, Stanley. Foreword. A Syllabus of Stage Lighting. New Haven, CT: Drama Book Specialists, 1964. N. page. Print. 


\section{B I B L I OGRAPHY}

“About Trajectum Lumen.” Trajectum Lumen. 2014. 20 Mar. 2014 <http://www.trajectumlumen.com/en/about>.

Armengaud, Marc and Mathias Armengaud, Alessandra Cianchetta. Nightscapes: Nocturnal Landscapes. Barcelona: Gustavo Gili. 2010. Print.

Bowers, Brian. Lengthening the Day: a History of Ligbting Technology Oxford: Oxford Univeristy Press. 1998. Print.

City of Ottawa, Downtown Moves: Transforming Ottawa's Streets. 2013.

Cuff, Dana and Roger Sherman. Fast-forward urbanism: retbinking architecture's engagement with the city. New York: Princeton Architectural Press, 2011. Print.

"Definition of beacon in English:." Beacon: Definition of beacon in Oxford dictionary (British \& World English). 20 Mar. $2014<$ http:// www.oxforddictionaries.com/definition/english/beacon?q=beacon>.

Fierro, Annette. The Glass State: The Technology of the Spectacle, Paris, 1981-1998. Cambridge, Mass: MIT Press, 2003. Print.

Fleming, Ronald Lee. The Art of Placemaking: Interpreting Community Through Public Art and Urban Design. London: Merrell Pub. Ltd., 2007. Print.

Gastil, Raymond, and Zoèe Alderfer Ryan. Open: New Designs for Public Space. New York: Van Alen Institute; distributed by Princeton Architectural Press, 2004. Print.

Goldberger, Paul, and Debra Waters. Theatres. Mulgrave: Images Publishing, 2000. Print.

Government of Canada. Building on a Solid Foundation: A New Approach to Implementing the Long Term Vision \& Plan. Ottawa: Government of Canada - Parliamentary Precinct, 2007. Print.

Graham, Stephen, and Simon Marvin. Splintering Urbanism: Networked Infrastructures, Tecbnological Mobilities and the Urban Condition. London: Routledge, 2001. Print. 
Jennings, Sarah. Art and Politics: the History of the National Arts Centre. Toronto: Dundurn, c2009. Print.

McCandless, Stanley. A Syllabus of Stage Ligbting. New Haven, CT: Drama Book Specialists, 1964. N. page. Print.

Merrick, Jay. "Rhapsody in Blue: Is Jean Nouvel's New Concert Hall the Best in the World?” The Independent. Independent Digital News and Media, 22 Jan. 2009. Web. 20 Mar. 2014. < http://www .independent.co.uk/arts-entertainment/music/features/rhapsody-in-blue-isjean-nouvels-new-concert-hall-the-best-in-the-world-1488546.html>.

Miguelez, Alain. A Theatre Near You: 150 years of going to the show in Ottawa-Gatineau. Manotick, Ont.: Penumbra Press, 2004. Print.

Moyer, Janet Lennox. The Landscape Lighting Book. New York: J. Wiley. 1992. Print.

Mulryne, J. R., and Margaret Shewring. Making Space for Theatre: British Architecture and Theatre since 1958. Stratford-upon-Avon: Mulryne and Shewring, 1995. Print.

"Of Hidden Helpers - Danish Radio Concert Hall by Jean Nouvel | Architecture at Stylepark." Of Hidden Helpers - Danish Radio Concert Hall by Jean Nouvel. N.p., 13 Oct. 2011. Web. 20 Mar. 2014. <http://www.stylepark.com/en/architecture/of-hidden-helpers-danish-radioconcert-hall-by-jean-nouvel/326196>.

“Quartier des spectacles.” Quartier des spectacles. 2006-2014. Quartier des spectacles. 20 Mar. 2014 <http://www.quartierdesspectacles. com/en/about/>.

Rossi, Aldo, and Peter Eisenman. The Architecture of the City. Cambridge, MA: MIT, 1982. Print.

Salter, Chris. Entangled: Technology and the Transformation of Performance. Cambridge, MA: MIT, 2010. Print.

The Editors of Encyclopædia Britannica. "Veduta (visual arts)." Encyclopedia Britannica Online. Encyclopedia Britannica. 24 Mar. 2014 $<$ http://www.britannica.com/EBchecked/topic/624498/veduta>.

“Vedute.” Wikipedia. 22 Feb. 2013. Wikimedia Foundation. 25 Mar. 2014 <http://en.wikipedia.org/wiki/Vedute>.

Watson, Sophie, and Gary Bridge. The Blackwell City Reader. Malden, MA; Chichester, West Sussex, U.K: Wiley-Blackwell, 2010. 